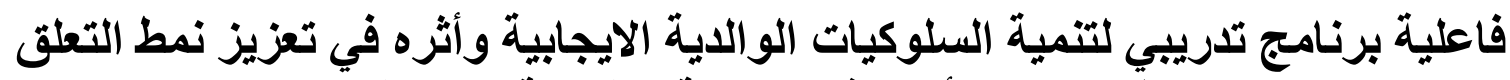

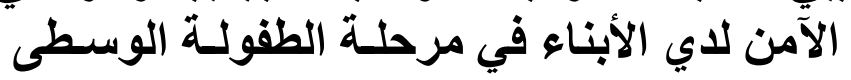

\author{
نيللي كرم الله رمضان خليل القلسي

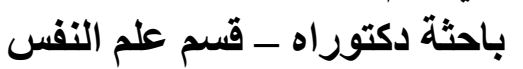 \\ كلية البنات، جامعة عين شمس، مصراه \\ Nellykaram50@yahoo.com
}

د. شاهيناز إسماعيل عبد الهادي

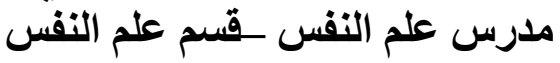

كلية البنات، جامعة عين شمس، مصر علفر

\author{
أ. أد اسماء عبد المنعم إبراهيم

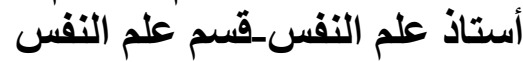 \\ كلية البنات، جامعة عين شمس، مصر علفر
}

المستخلص: - 20 - 20

هدفت الدراسة إلي اختبار أثر برنـامج تدريبي لتنميـة السلوكيات الو الديـة الايجابيـة للدى الأمهات

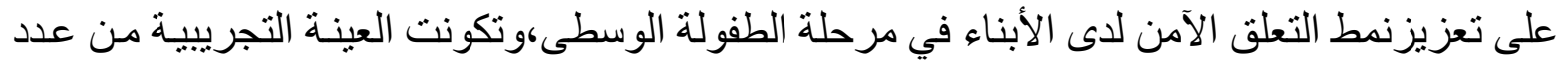

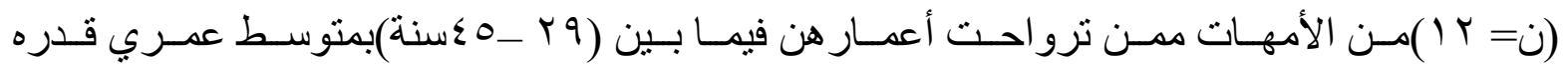

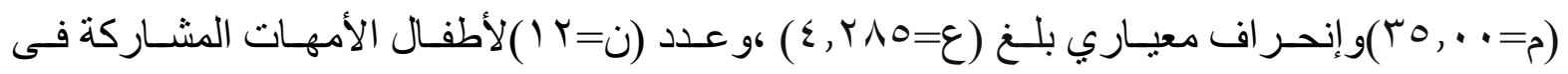

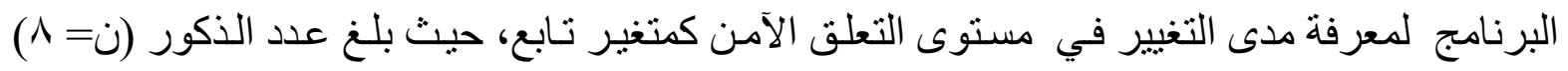

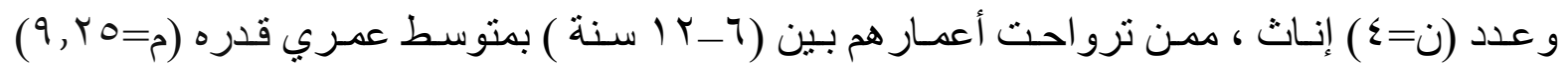

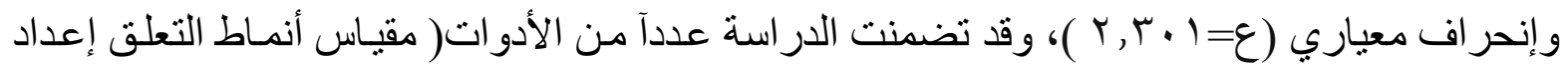

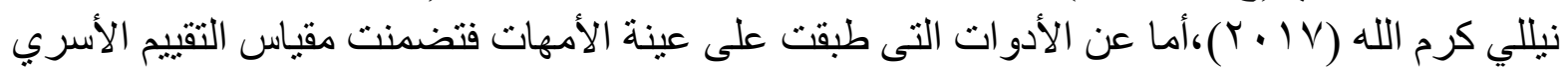

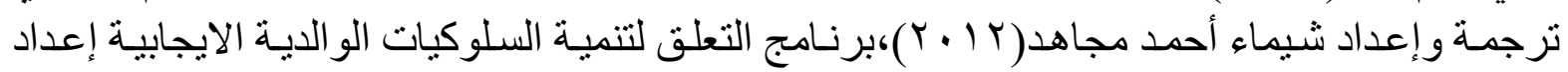

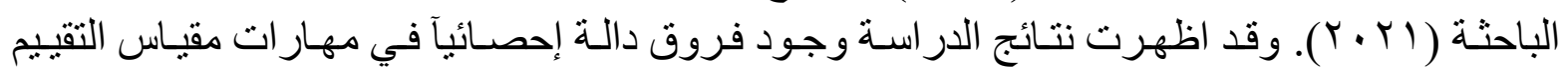

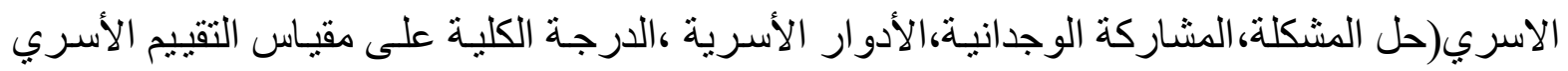

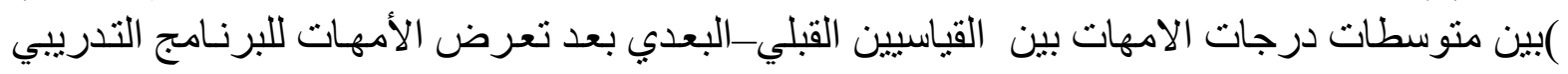

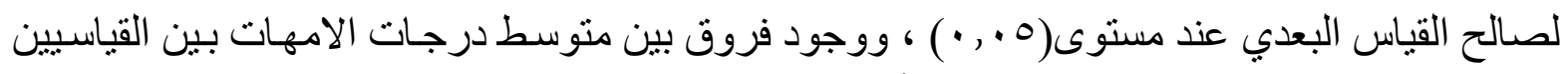

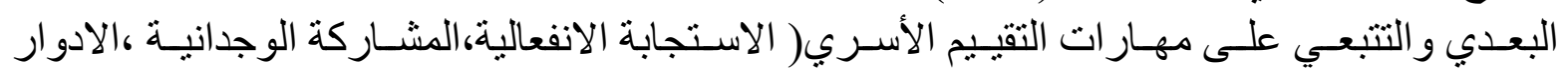

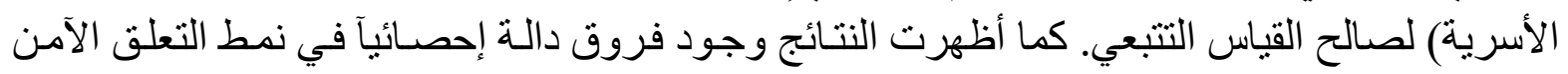

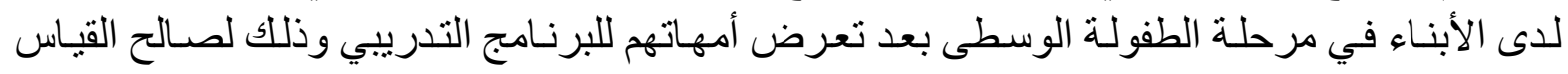

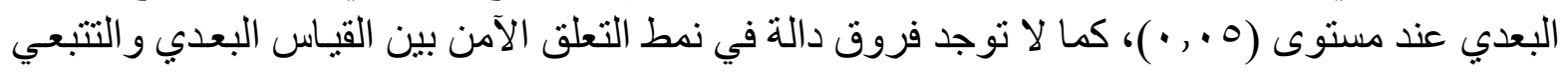

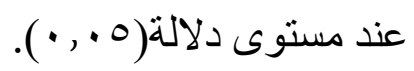

الكلمات الدالة: السلوكيات الو الدية الايجابية، نمط التعلق الآمن ،البرنامج التدريبي. 


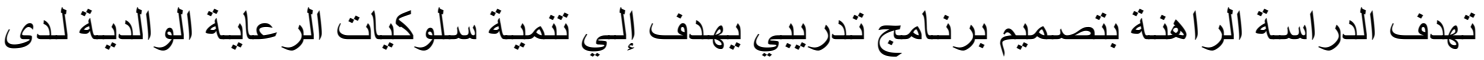

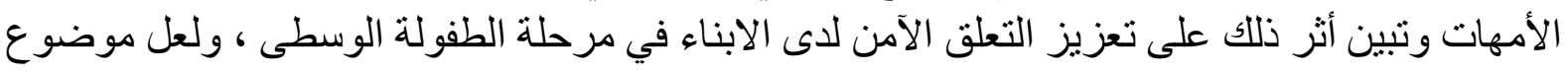

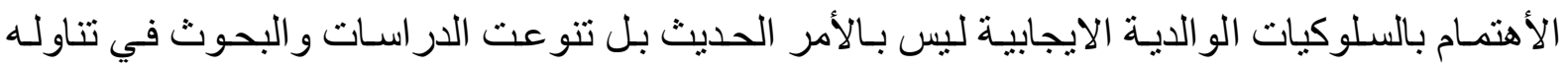

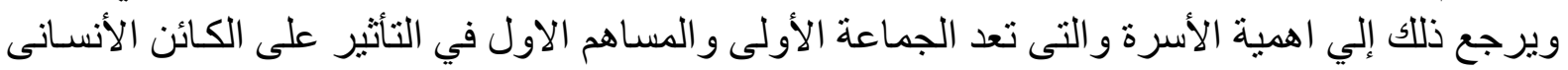

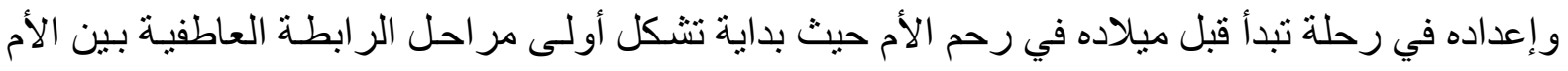

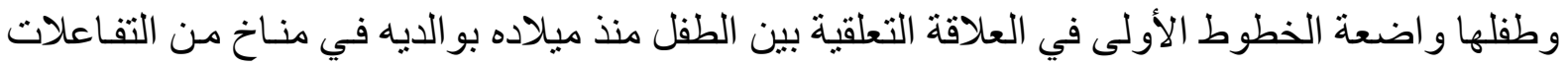

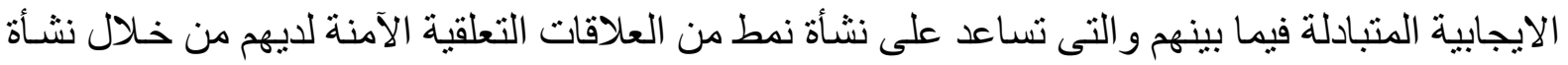
نماذج عاملة داخلية في اللاشعور.

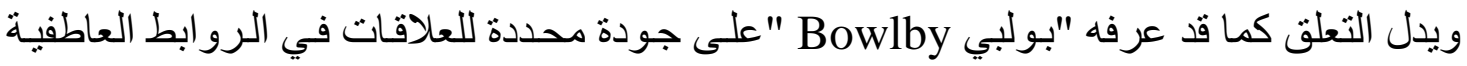

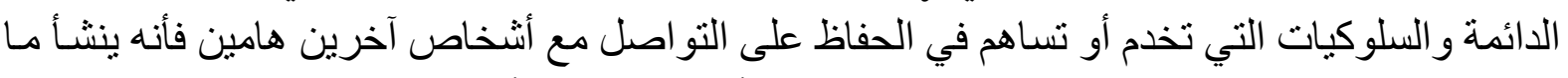

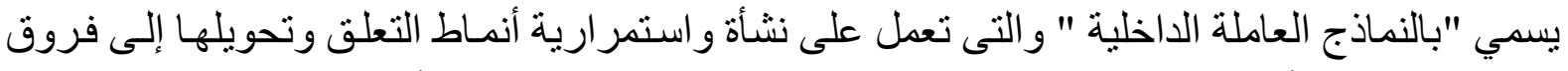

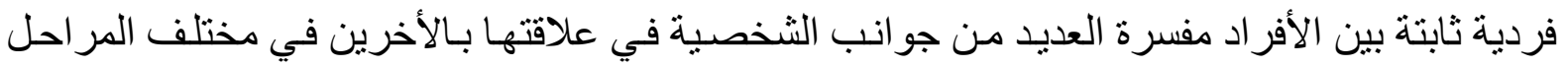

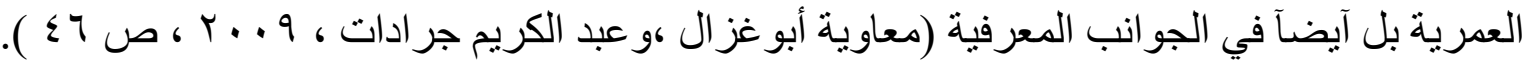

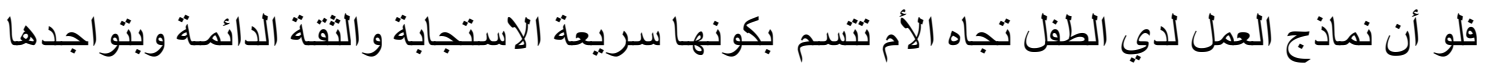

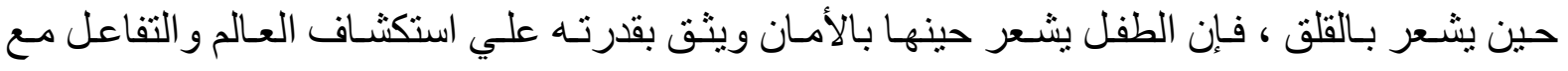

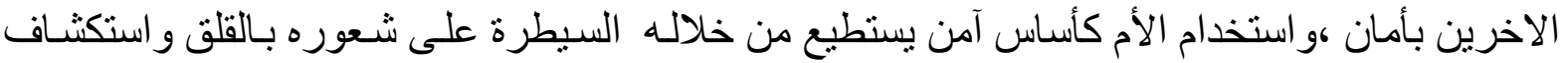

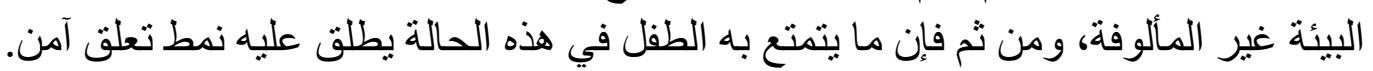
.(Wagner, Patricia Ellen 1992, p.g 12:13)

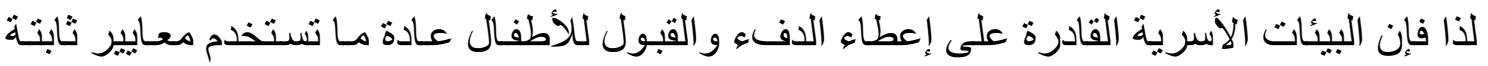

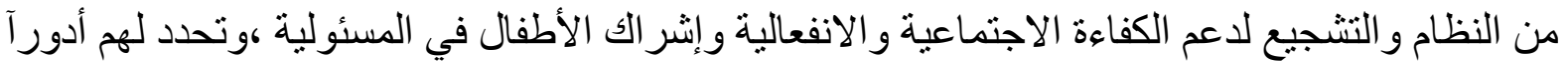

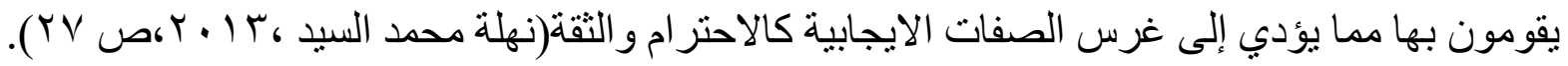

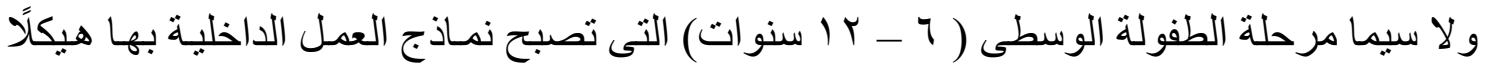

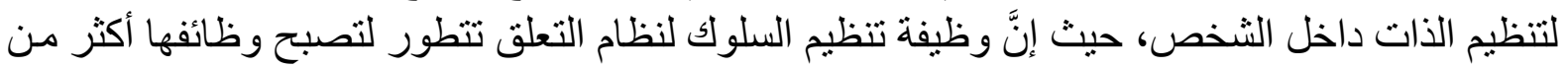

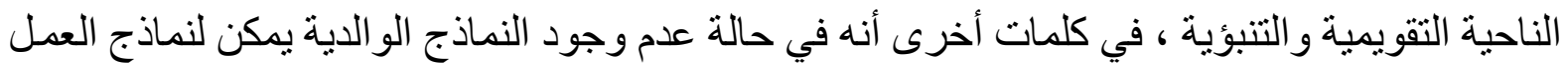

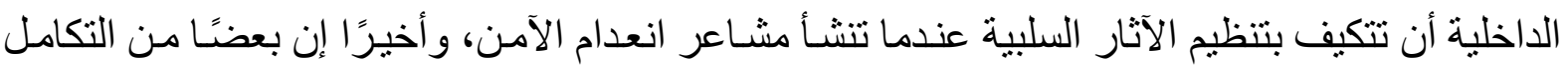

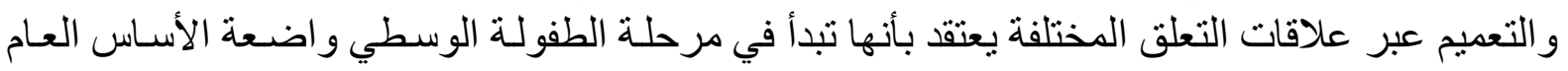

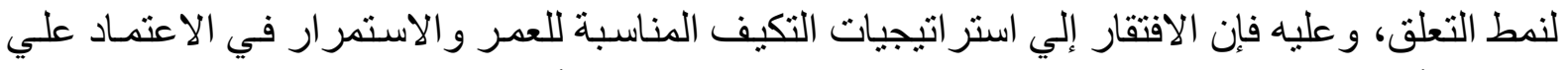

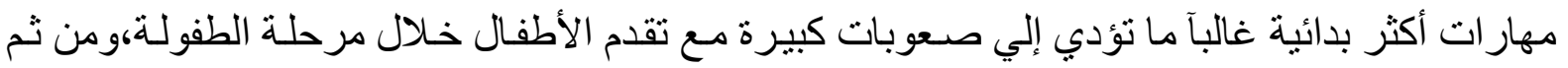

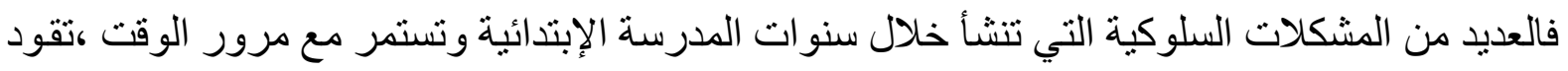
نظام التكيف إلي التوقف، وكلها ترجع إلي الإضطر ابات المبكرة التبكرة في تقديم الر عاية. (Blaustein,MargaretE\&Kinniburgh,Kristine M.,2007, p.g 48;

Moss.,François.,Julie .,Zdebik \& Lépine,2009.p.g415)

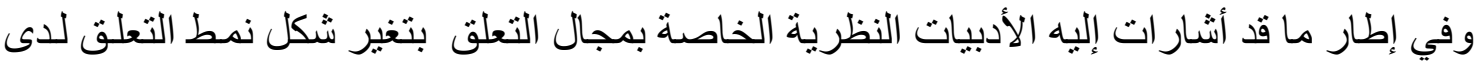

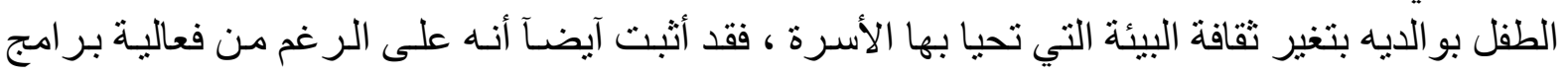

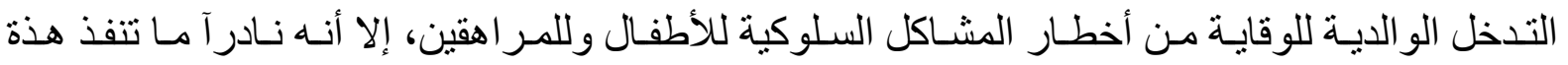

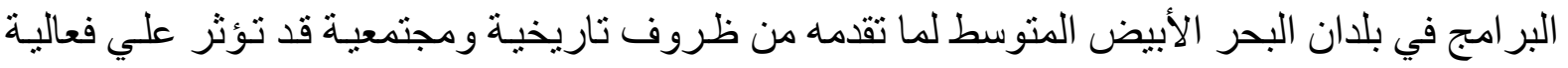

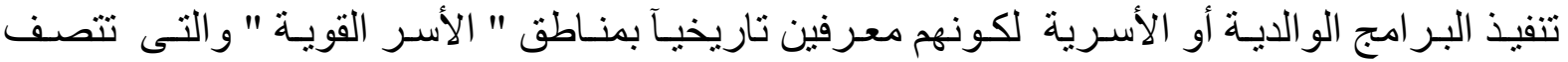


بالعلاقات الأسرية الوثيقة و الروابط العاطفية القوية و العميقة ،لذا فمن المرجح أن للمارسات الو الدية تأثير

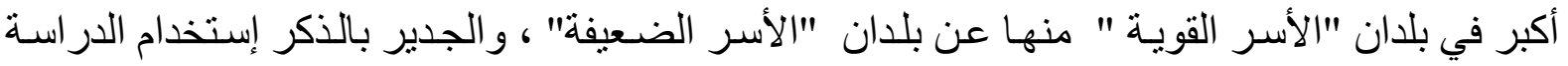

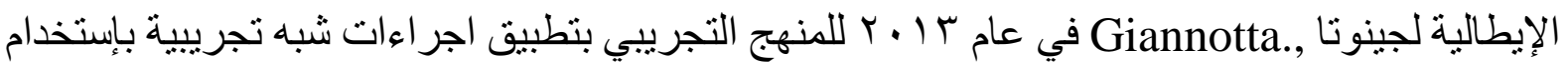

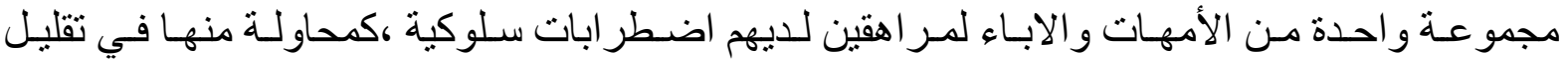

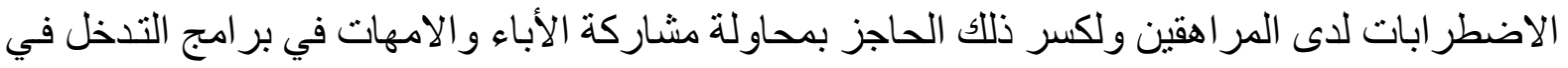

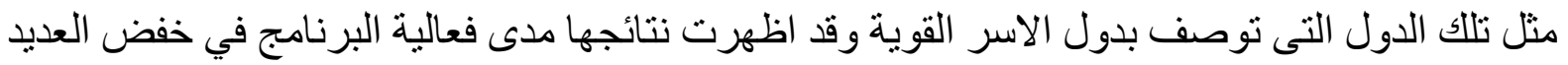
من المشاكل و الاضطر ابات لدي المر اهقين (Giannotta., Ortega\& Statin, 2013, p.g 72:73).

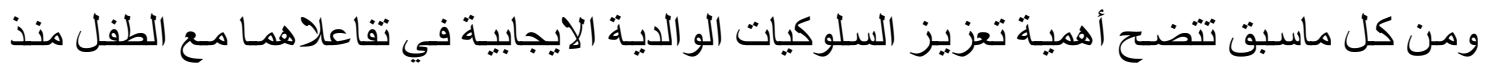

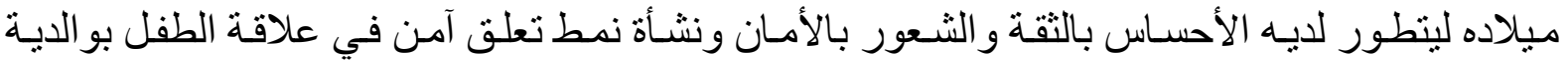

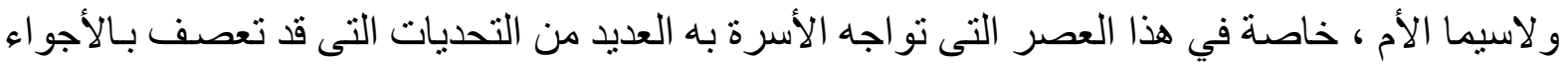

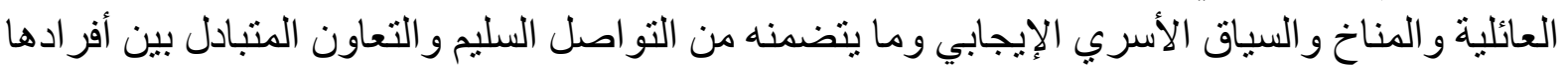

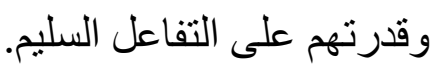

\section{مشكلة البحث}

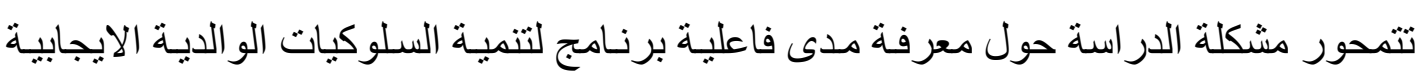

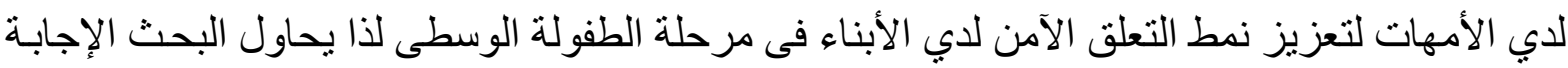

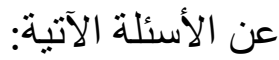

( ) هل توجد فروق بين متوسطى درجات القياس القبلي و البعدي على مقياس التقييم الأسري للدى عينـة

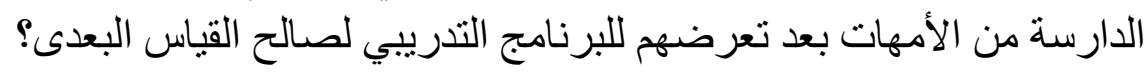

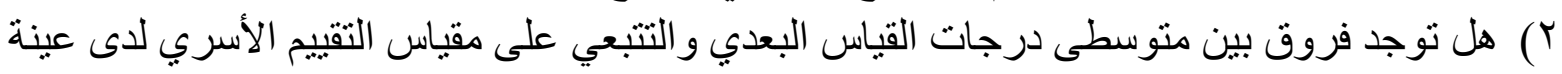

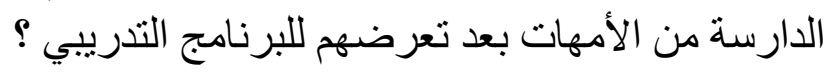

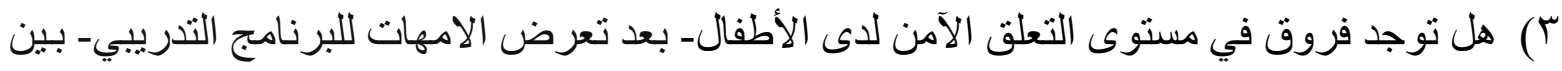

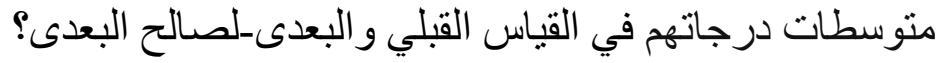

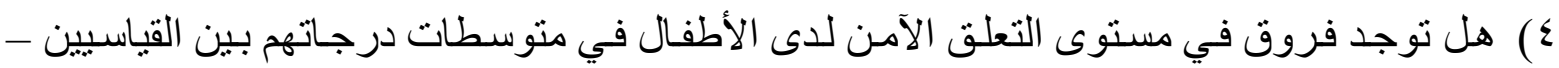

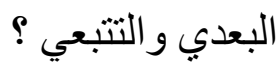

\section{أهداف البحث}

ا ـ التحقق من فاعلية البرنـامج التدريبي ومستوى التحسن في السلوكيات الو الديـة الايجابية لدى

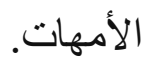

r- التحقق من التغير في مستوى نمط التعلق الآمن لدى الأطفال في مرحلة الطفولة الوسطى أثر تعرض الأمهات للبرنامج التدريبي.

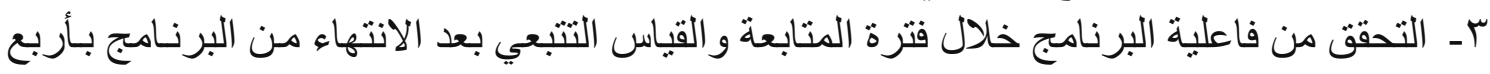

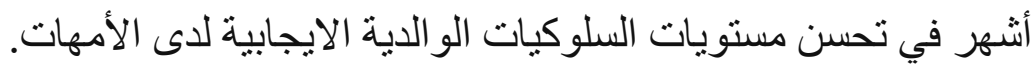

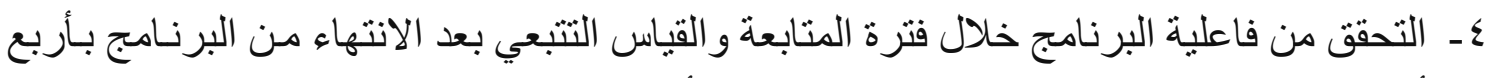
أشهر في تحسن مستوي نمط التعلق الآمن لاعى الأطفال.

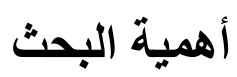




\section{أولاً: الأهمية النظرية}

ا اتتحدد أهمية الدر اسة الحالية من أهمية متغير اتها ، فالعلاقة التعلقية الآمنـة بين الو الدين و الطفل هي بداية لخلق وتشكيل تمثيلات عقلية لدى الأطفال عن ذاتهم و عن الأخرين تتسم بـالتو افق و التنظيم العاطفي و الذي لله من تأثثير كبير وطويل المدي على شخصية الطفل. ب - تسهم هذة الدر اسة في إلقاء الضوء علي العلاقة بين السلوكيات الو الدية الايجابية في تربية الأبناء وبين نو عية التعلق لدي الطفل بو الديه.

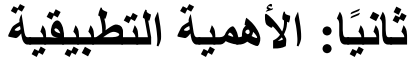

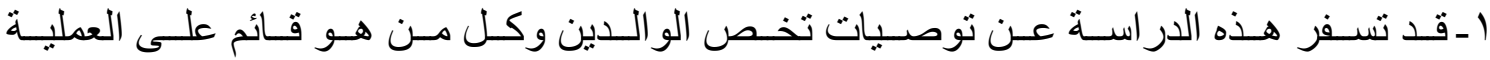

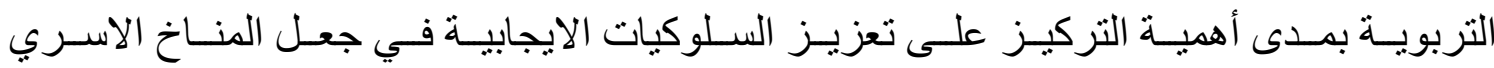

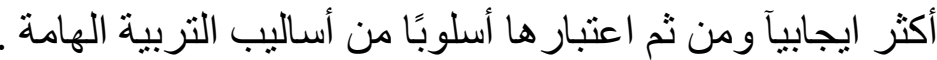

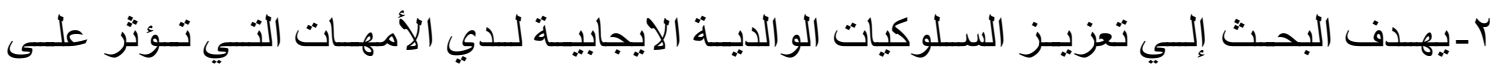

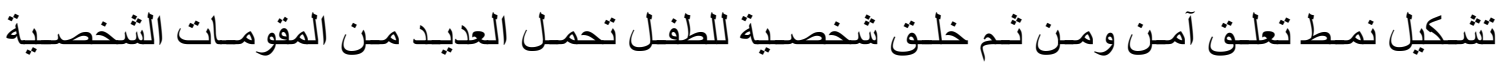

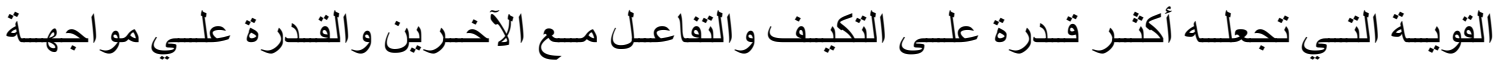
الأزمات التي قد تقابله.

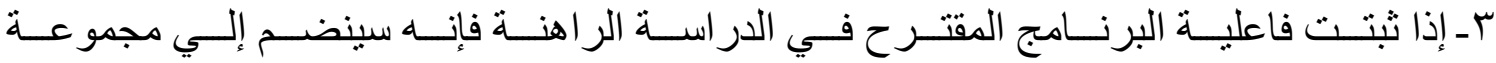

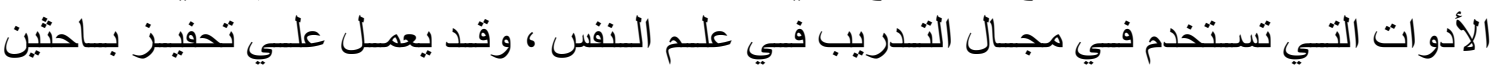
آخرين لتطويره.

\section{تعريف مفاهيم مصطلحات البحث}

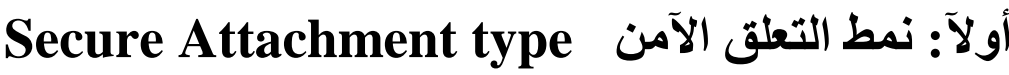

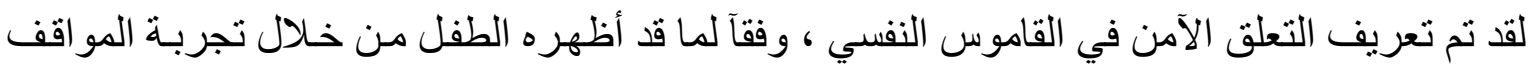

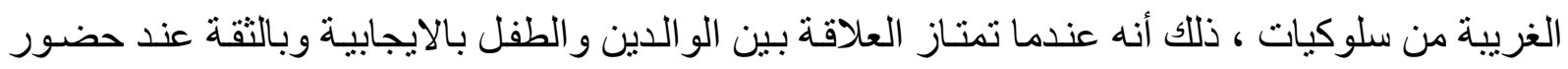

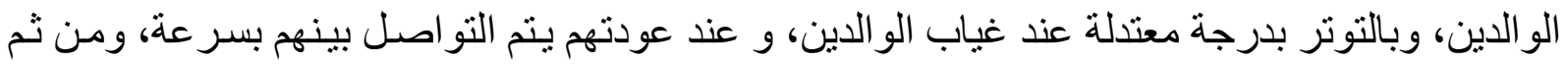
يتصف نمط التعلق عندئذ لدى الطفل بالتعلق الآمن. (American Psychological Association (2020) Dictionary of psychology (Th Ed.), Washington, DC 20002-4242)

ويمكن تعريف نمط التعلق الآمن إجرائياً كما يلي :

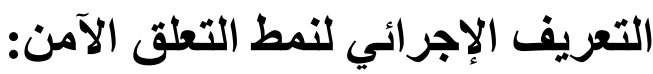

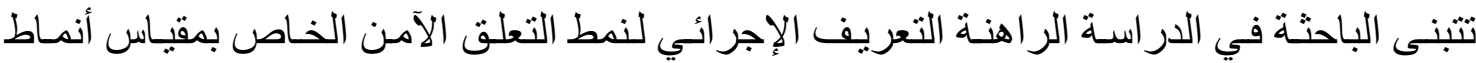

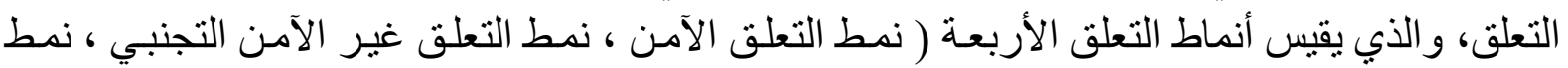

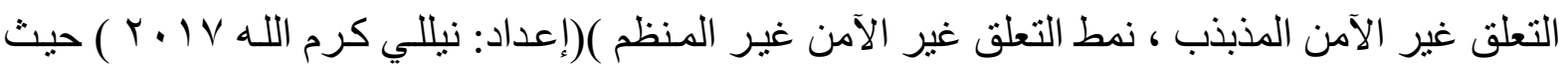

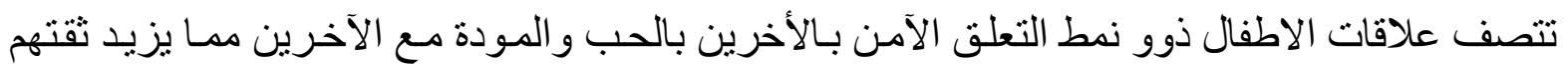

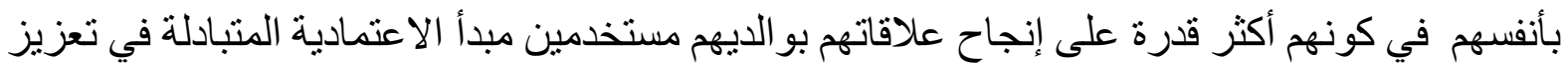
الألفة النفسية بين بعضهم البعضهو ان الدرجة المرتفعة علي هذا النمط تثير إلي امتلاك الطفل لنمط تعلق

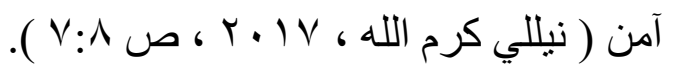




\section{ثانياً : برامج تنمية السلوكيات الوالدية الايجابية}

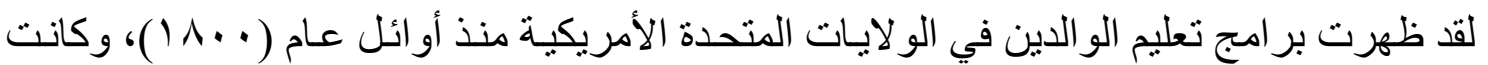

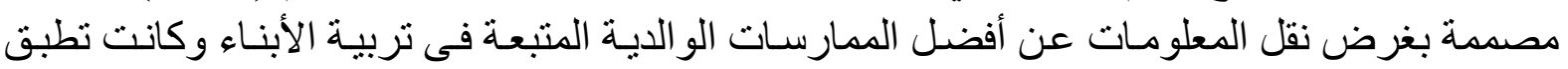

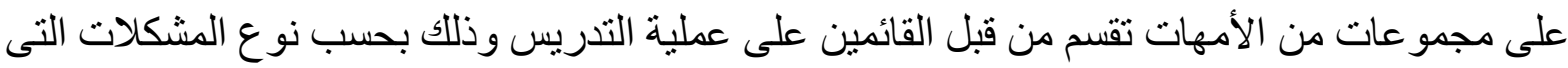

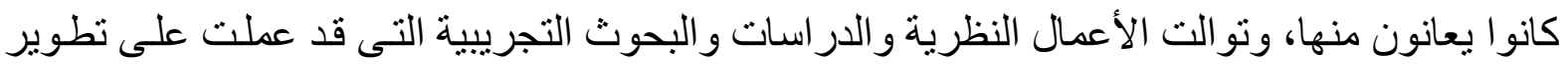

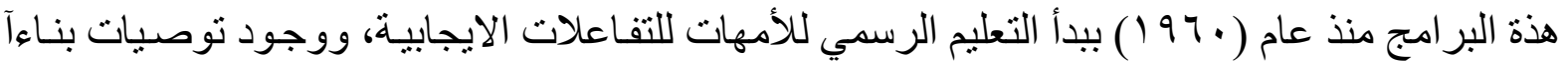

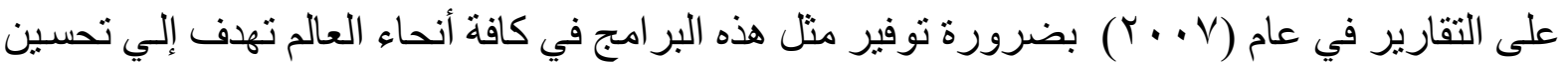

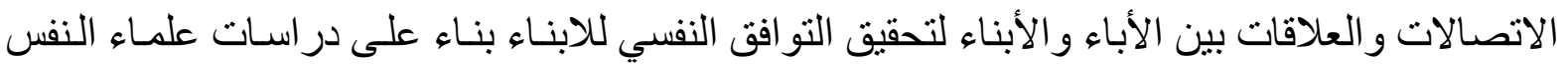

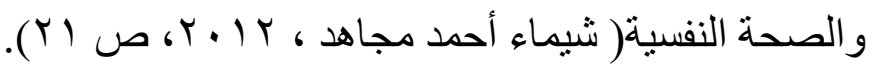

\section{وتعرف الباحثة السلوكيات الوالدية الايجابية إجرائياً :}

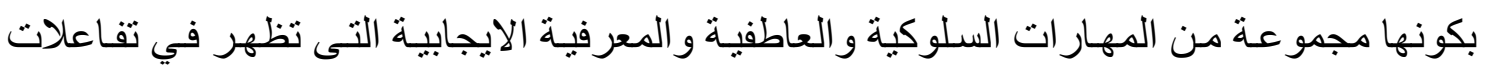

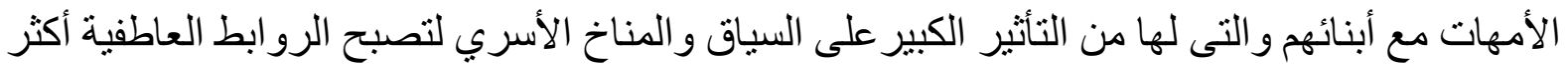

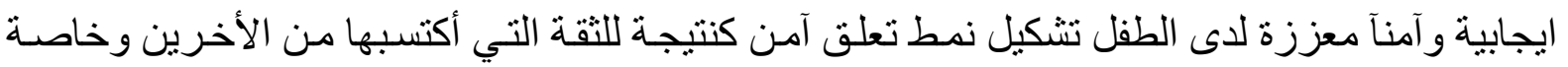

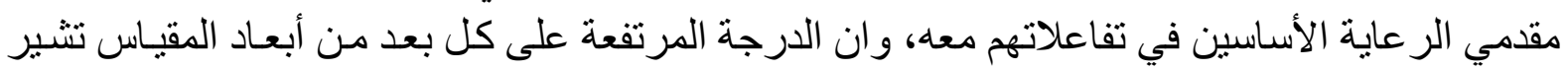

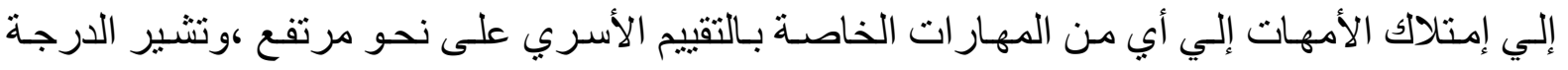
المرتفعة على المقياس ككل على إمتلاك الامهات لسلوكيات و الدية ايجابية.

\section{الأطار النظري

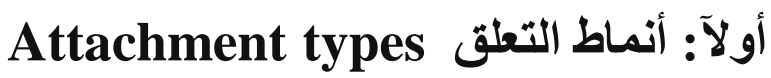 (ا) الخلفية النظرية لمفهوم أنماط التعلق التقاط}

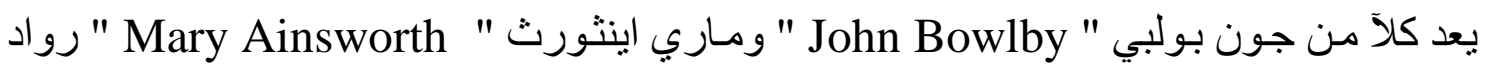

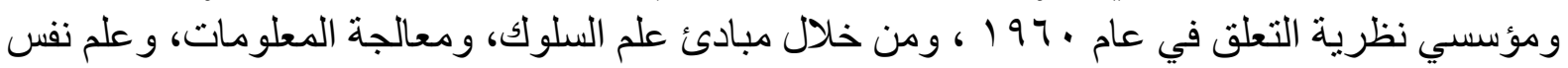

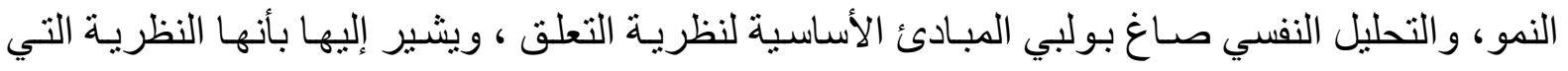

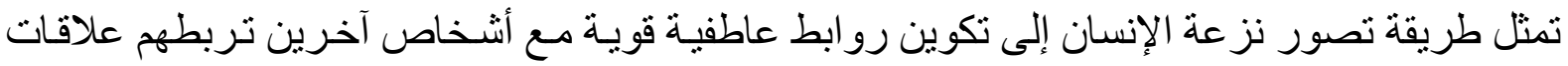

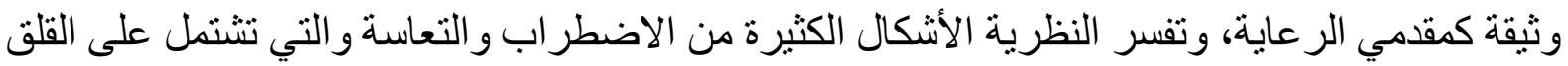

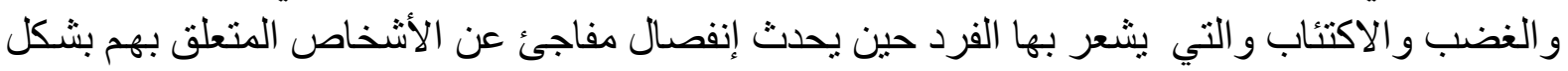

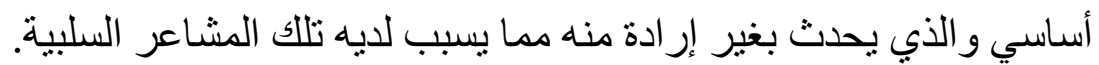

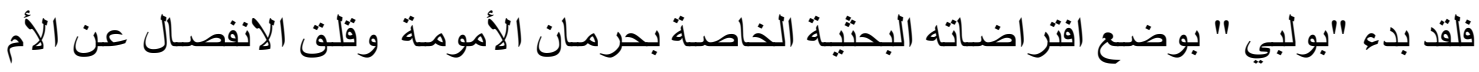

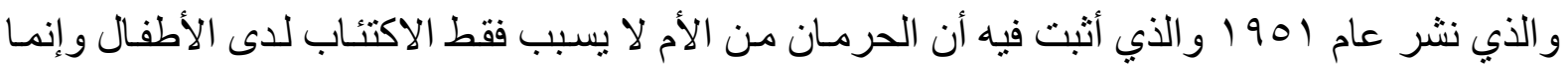

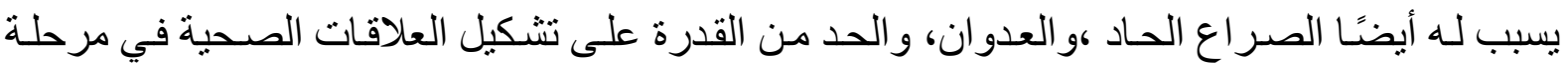
البلوغ. وقد تميزت در اسات "جون بولبي" بأنها دراسـات تتتـاول كيفية معالجة الأطفال لسلوكيات القلق

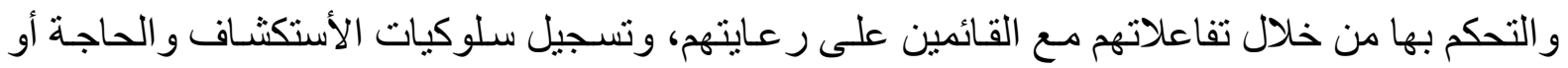

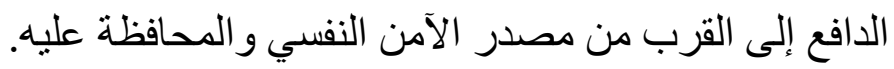




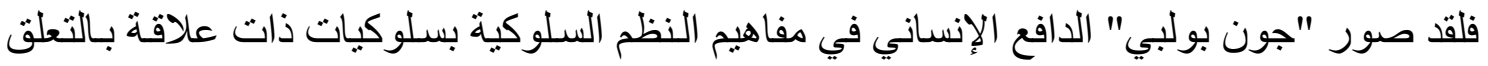

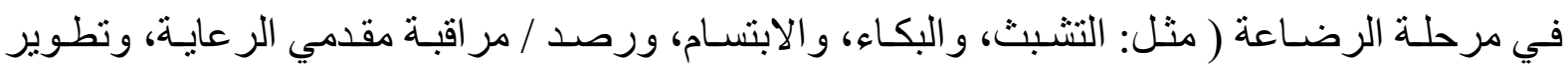

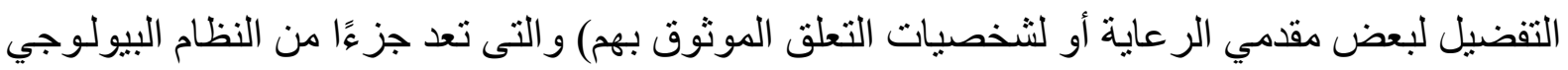

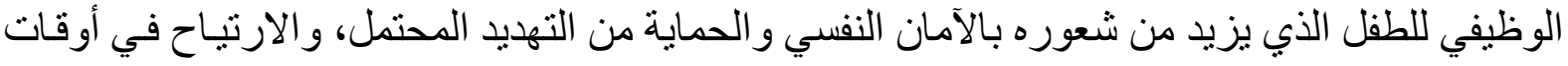

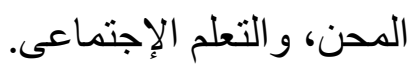

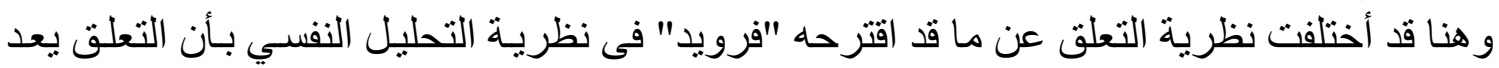

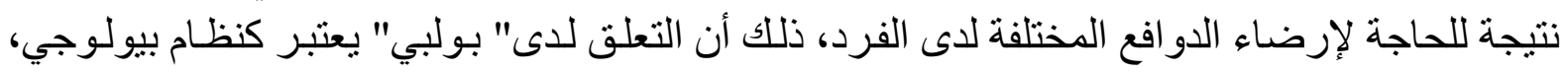

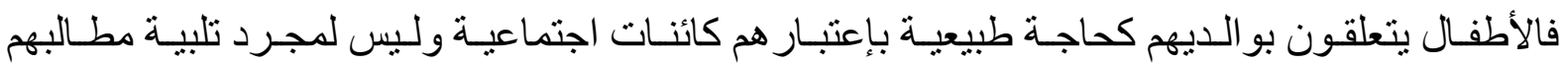

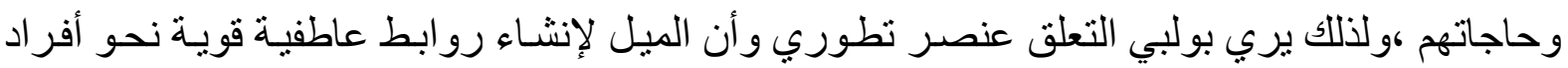

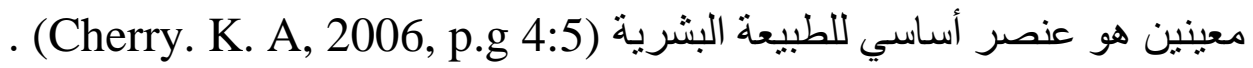

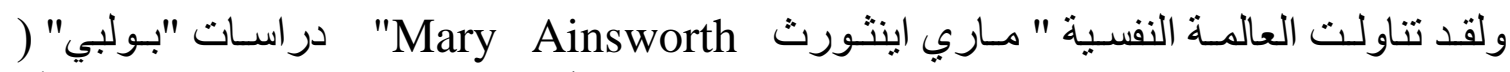

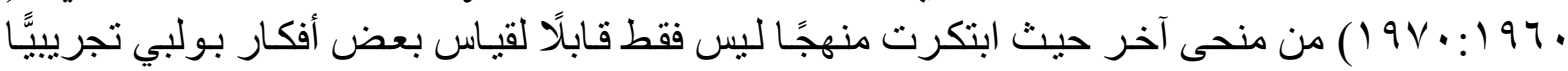

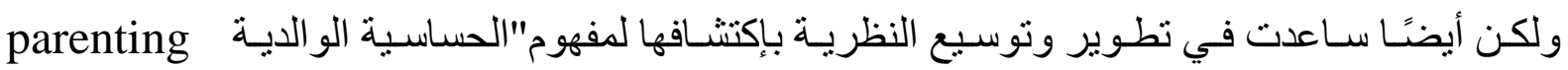
"sensitivity

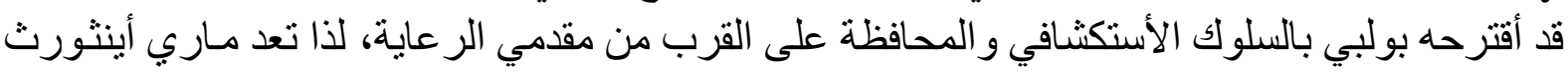

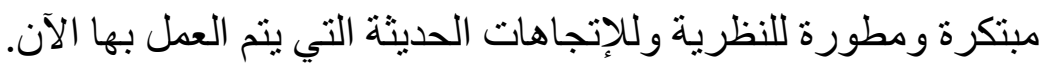

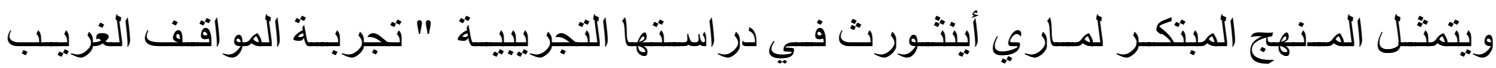
The Strange Situation

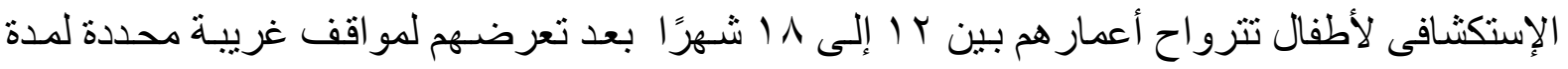

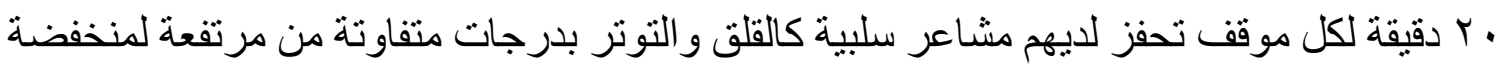

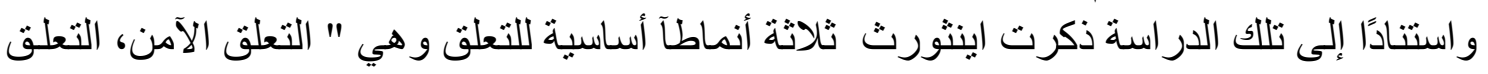

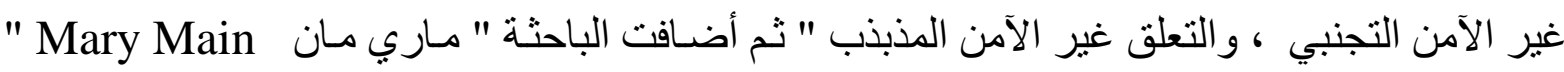

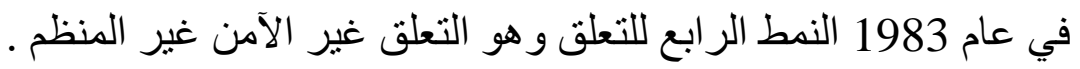
(Bretherton. Inge, 1992, P.G759:775; cherry.k, 2006, p.g5)

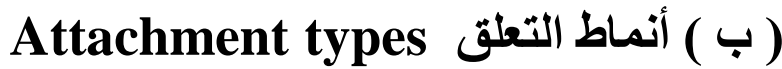

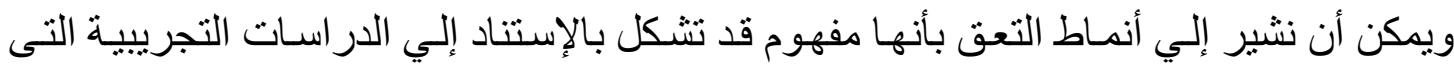

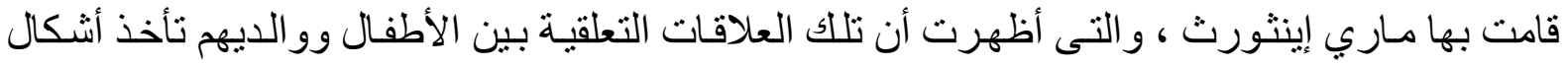

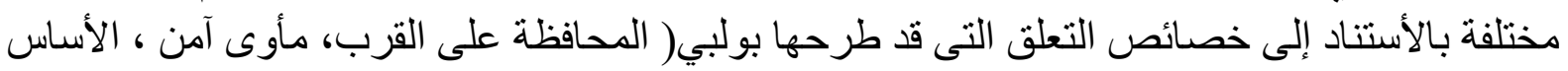

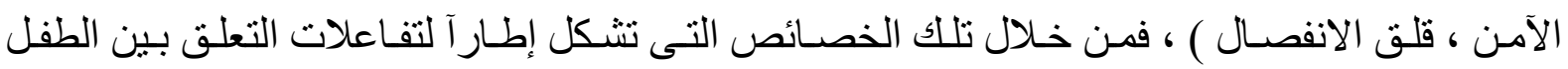

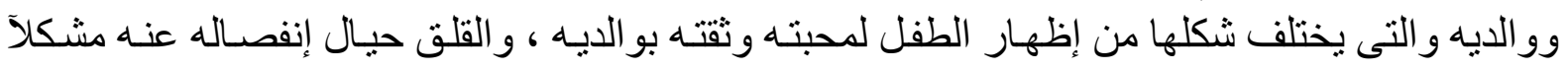

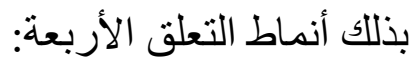

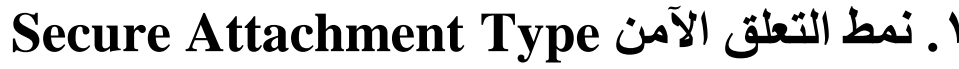

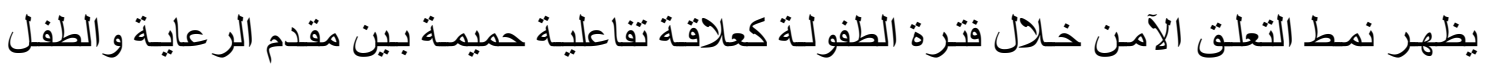

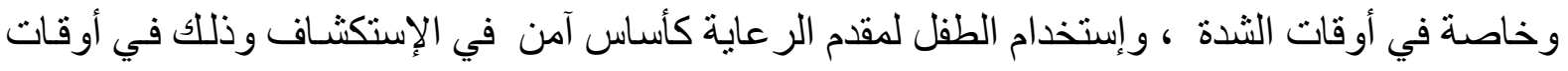

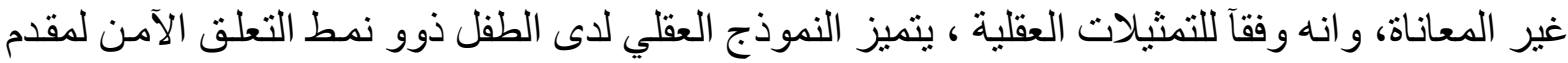


الرعاية بإعتباره متجاوباً ودائم القرب منه ومن ثم يبني صورة منو افقه عن ذاته بكونـه جدير بالر عاية

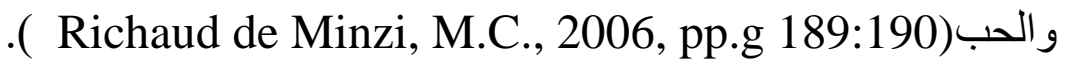
ويعد التعلق الآمن أقوى أنماط التعلق و الذي ينشأ عندما توجد علاقة تبادلية صحية بين الطفل ومن

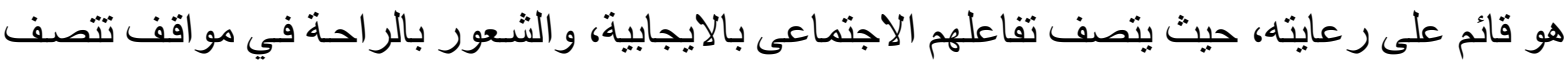

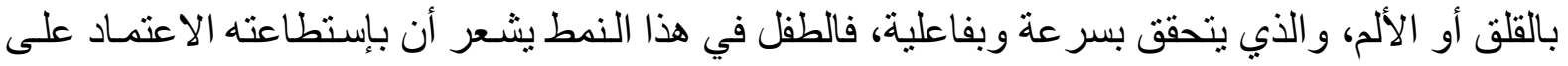

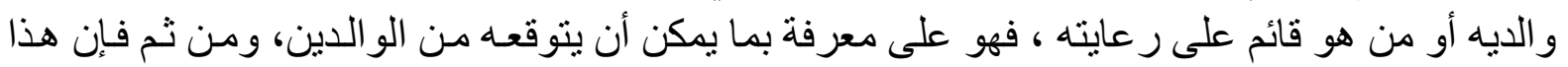

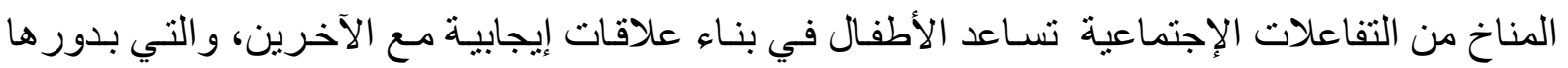

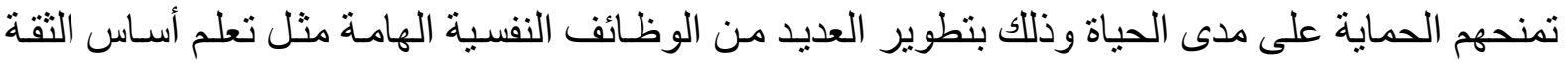

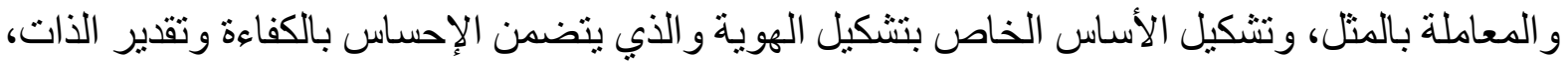

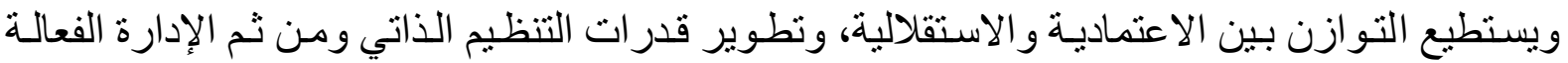

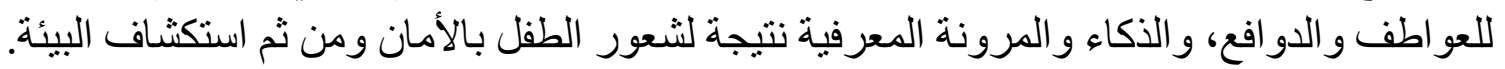

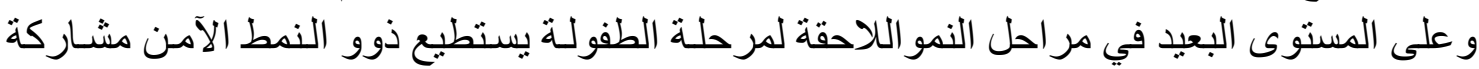

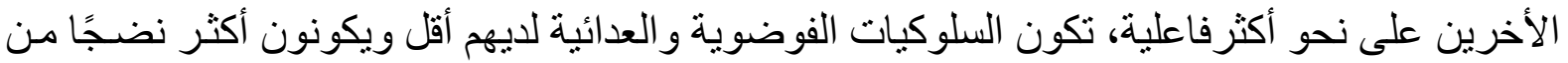

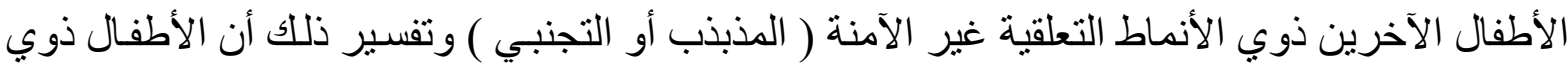

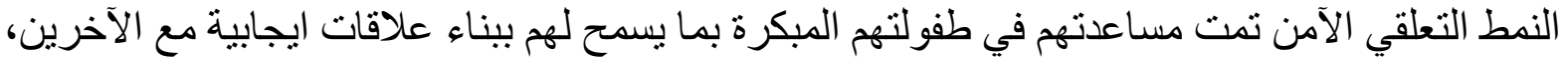

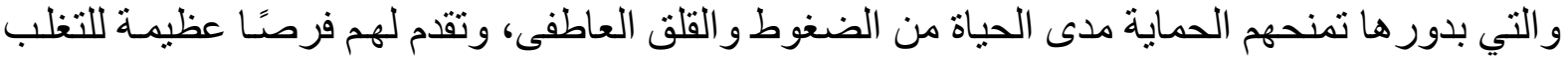
على أحداث الحياة الصنادمة ومواجهتها.

(Cherry, K., 2006, p .g 4-5; Neil, julit. Hall, 2007,”para.3)

و الجدير بالذكر أن التعلق ليس بشيء يقوم به الآباء لأبنائهم بل هو شئ يخلقه الأطفال و الآبـاء معًا

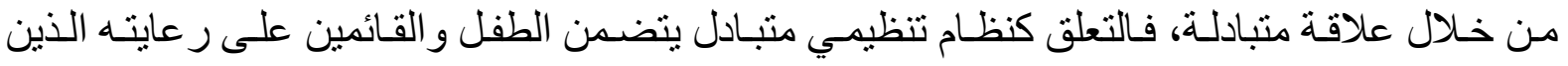

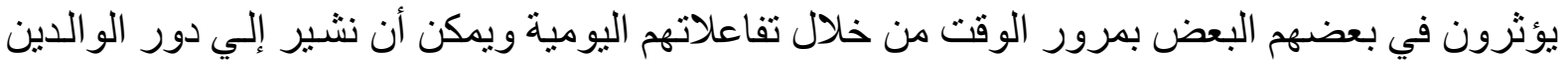
ومدى حساسية إستجابتهم في خلق نمط نعلق البهن آمن كما يلي:

\section{دور الوالدين فى نشأة نمط التعلق الآمن :}

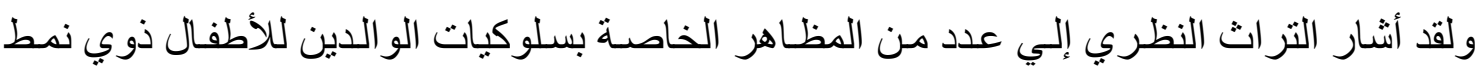

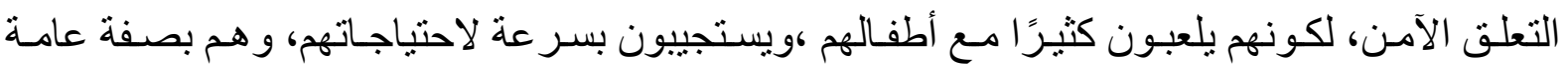
متجاوبون مع أبنائهم بالقياس لآباء الأطفال ذوي الأونا الأنماط التعلقية غير الآمنة.

.(Cherry, K., 2006, p.g 5)

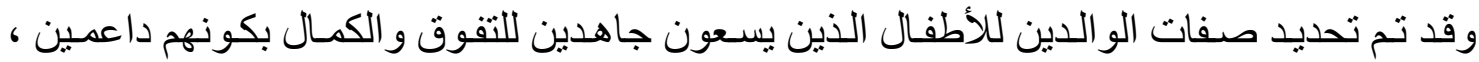

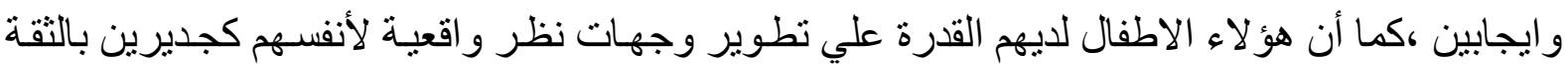

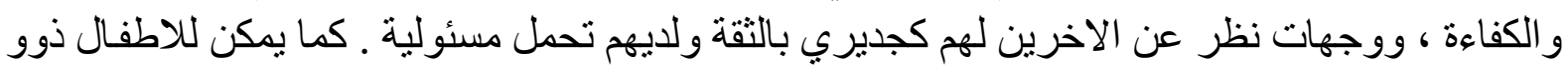

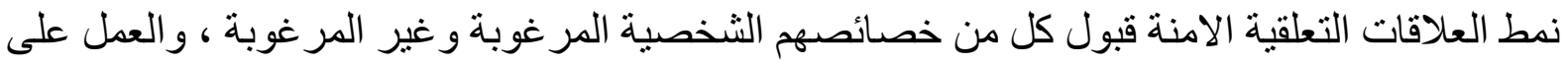
تعديلها فلديهم القدرة علي وصف الفسهم من حيث الايجابية و الاعتر اف ايضاً بكونهم أقل من الكمال. (Rice, Mizadeh , 2000, p .g 239)

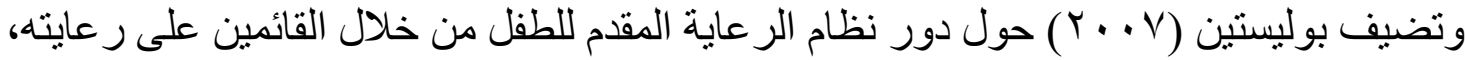

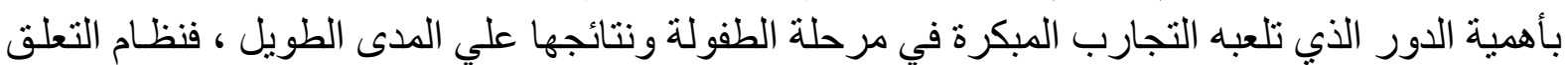

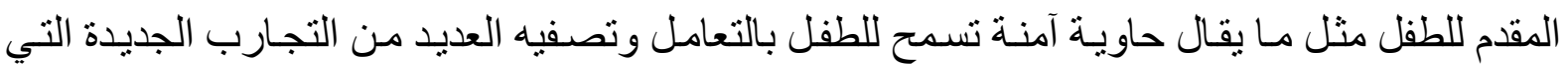




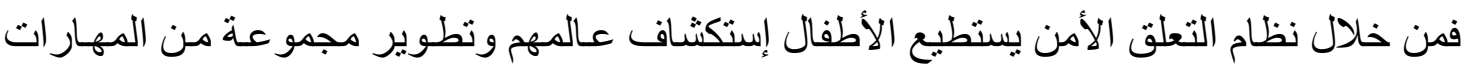

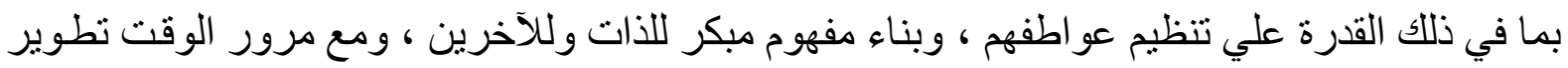

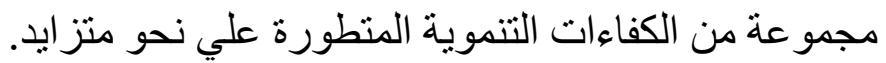

(Blaustein , Kinniburgh, 2007,p.g 48)

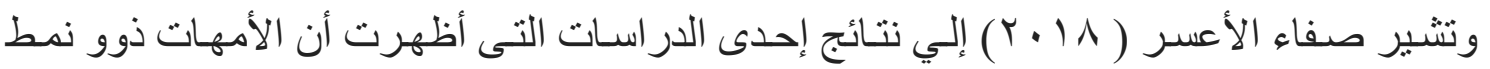

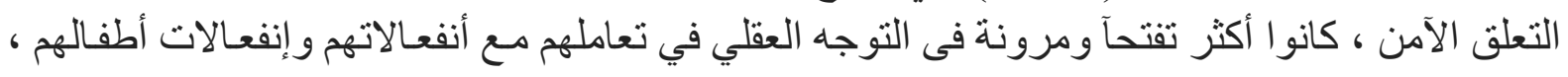

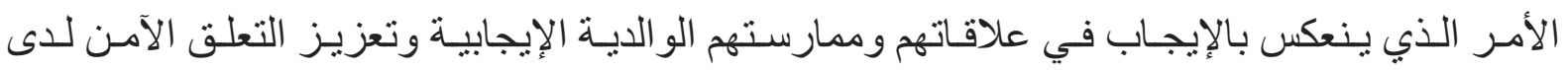

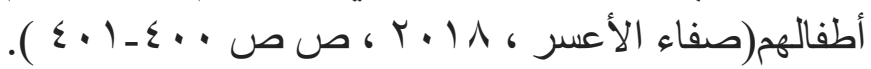

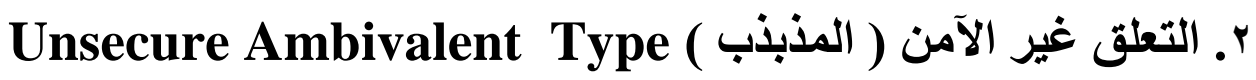

\section{Attachment}

إن الأطفال ذوي ذللك النمط يعيشون خبرة التعلق المتناقض أو المذبذب، ويقصد بمصطلح التذبذب التبان Ambivalence

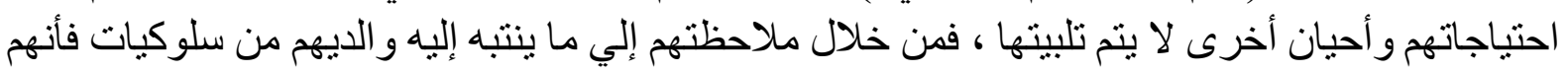

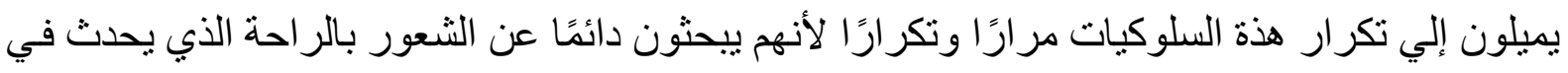

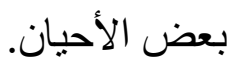

ويميل الأطفال ذوو نمط التعلق غير الآمن المذبذب إلى أن يكونو المرتبكين بشدة تجـاه الغرباء فهم

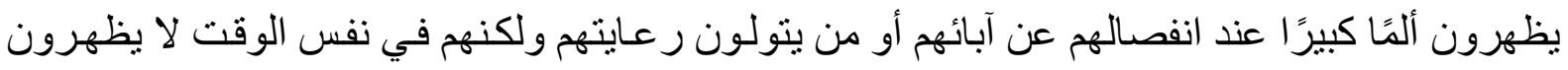

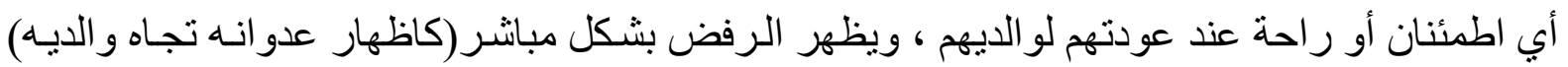

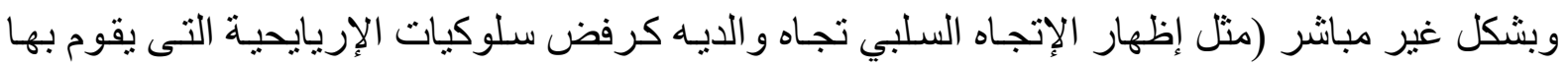
و الايه تجاهله).

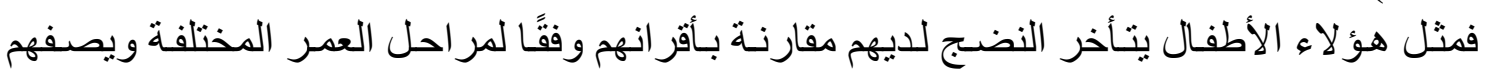

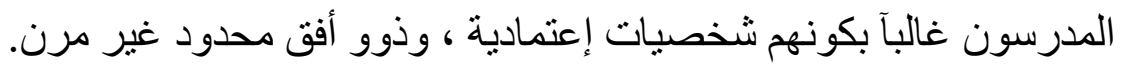

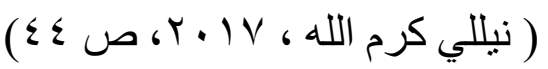

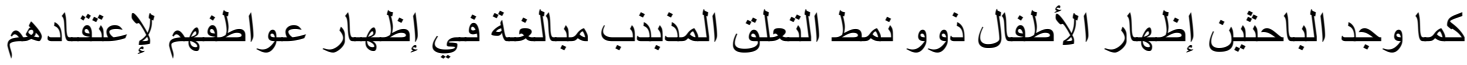

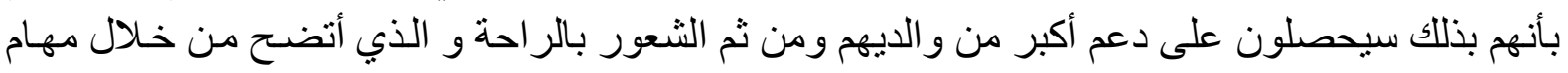

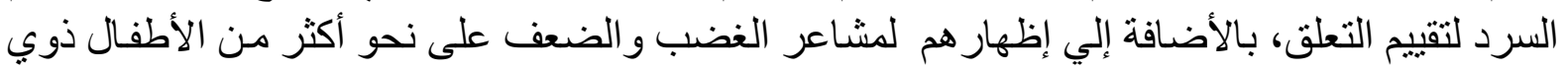

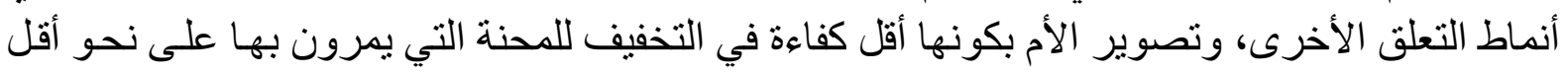

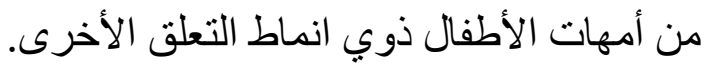

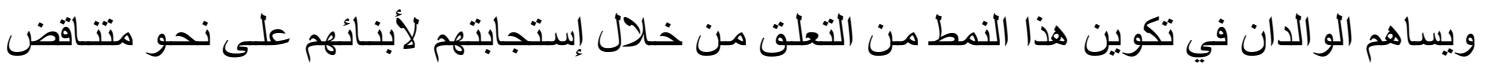

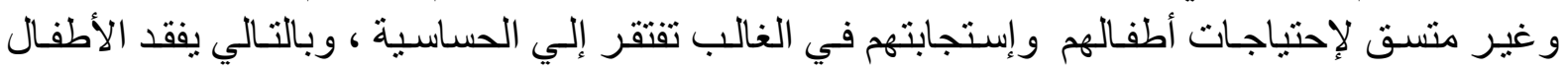
القدرة على توقع إستجابتهم (Williams , Kennedy 2012, p.g 20).

\section{r. التعلق غير الآمن( التجنبي)}

\section{Avoidant Attachment Unsecure Type}

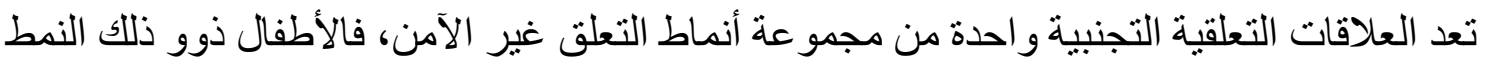

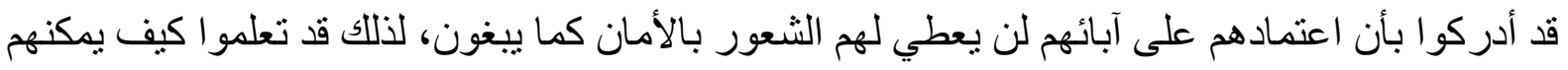

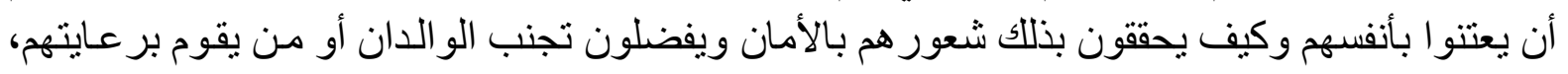




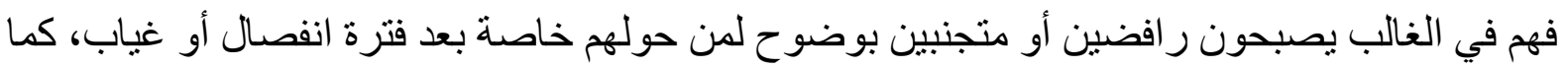

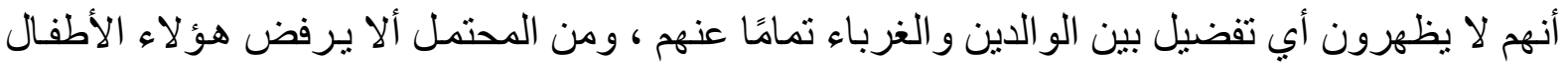

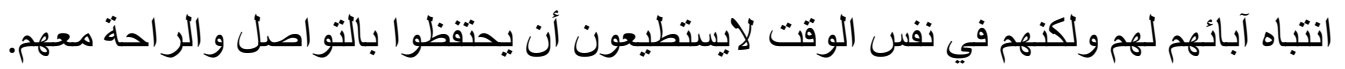

( Williams , Kennedy2012, p.g 20)

كما أن الأطفال ذوو ذلك الندط للتعلق سيطورون من الميكانيزمات الدفاعية البديلة مـا يساعدهم

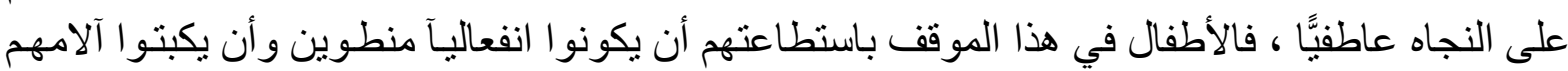

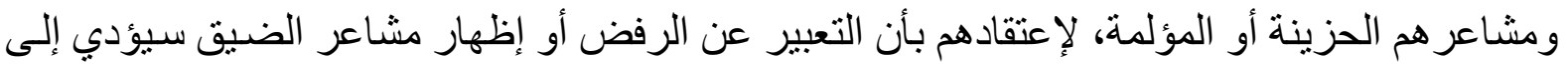

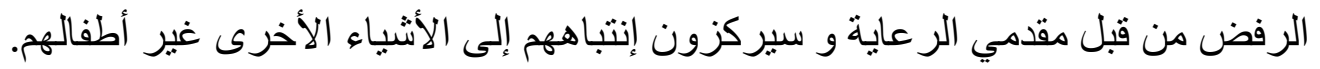

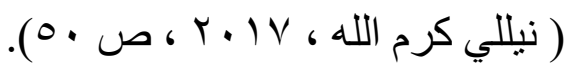

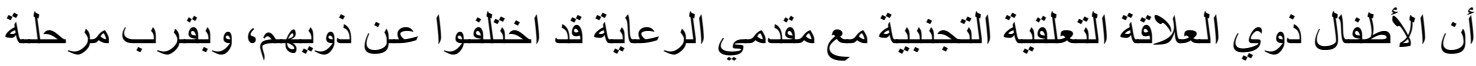

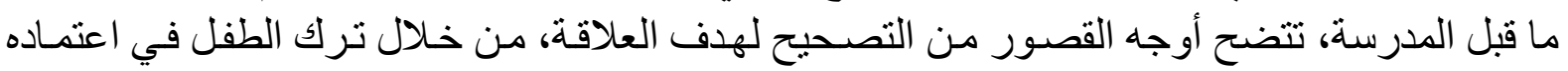

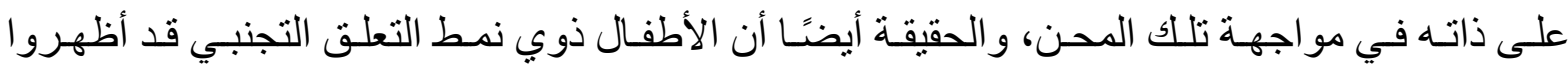

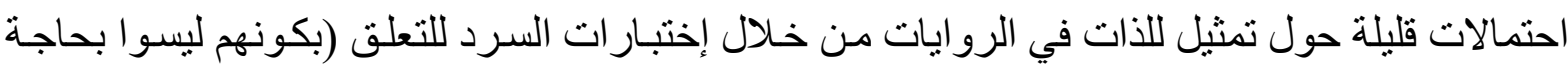

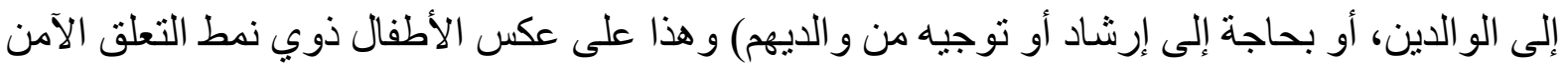

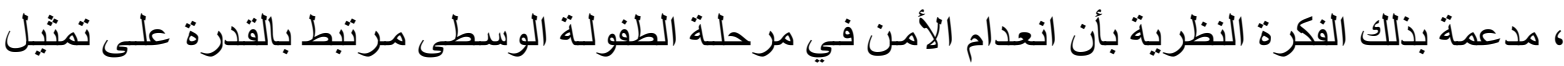

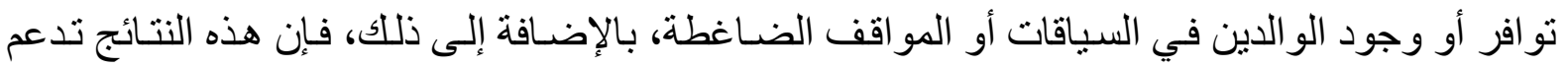

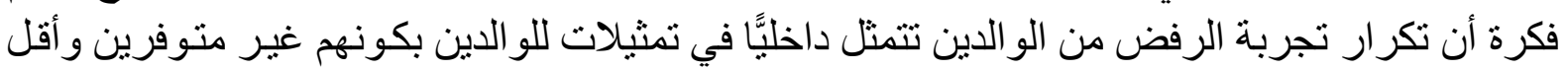
مشاركة في التنظيم العاطفي.

(Moss, Ellen ., François,Jean Bureau., Julie Béliveau, Marie .,Zdebik

,Magdalena\& Lépine .Suzanne.,2009, “para 7”).

\section{Disorganized Unsecure Attachment Type}

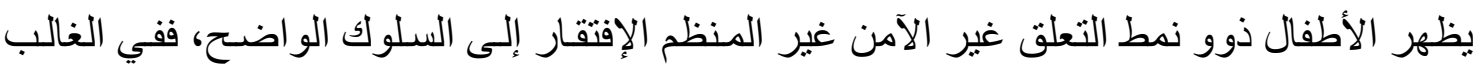

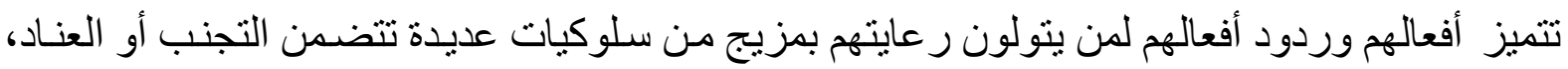

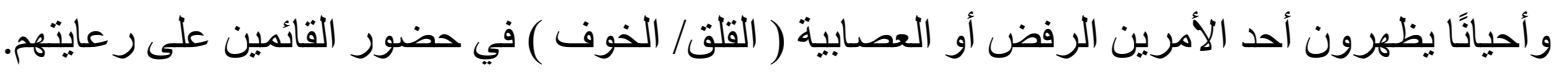

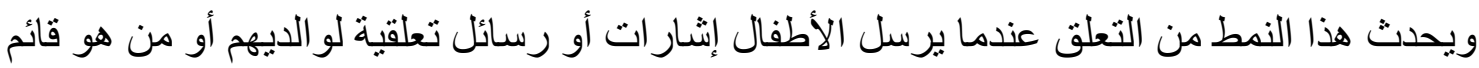

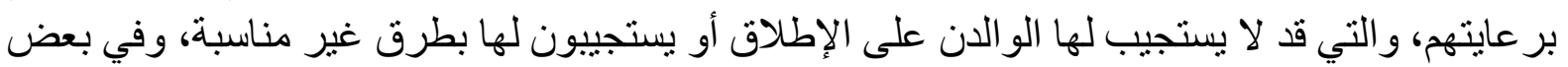

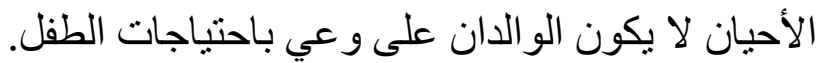

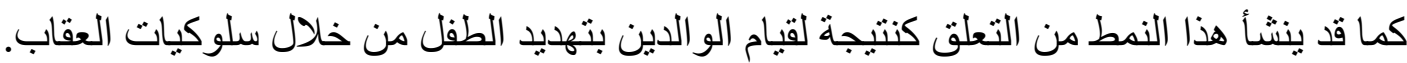

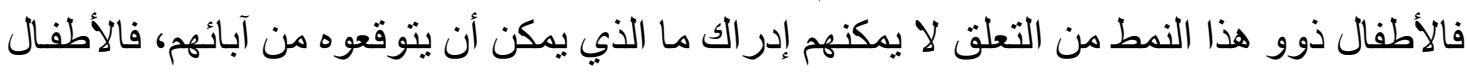

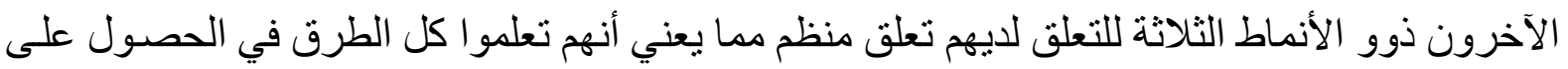

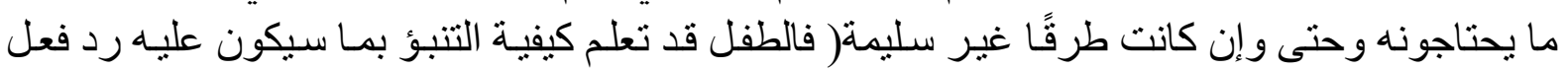

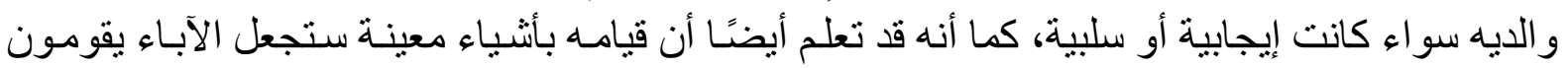

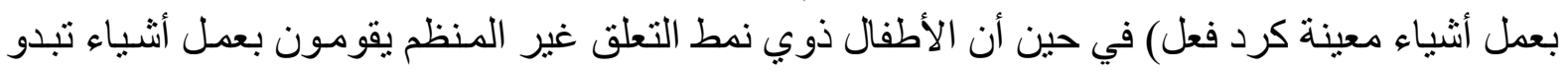

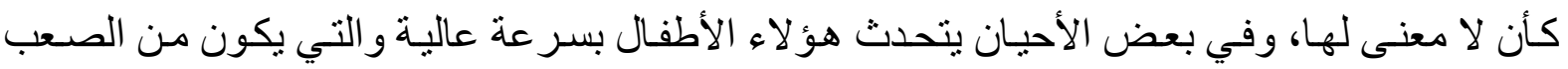


فمعظم الأطفال ذوي ذلك النمط من التعلق يجدون صعوبة في فهم مشـاعر الأطفال الآخرين كما

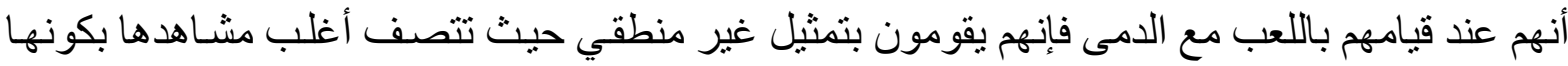

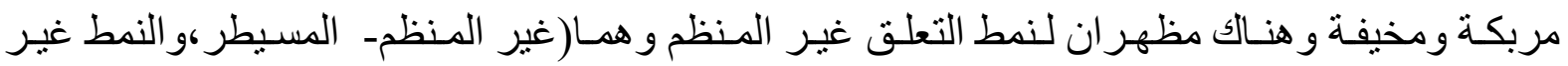

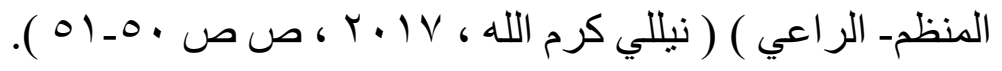

\section{ثانيآ: برامج التدخل في مجال التعلق والسلوكيات الوالدية الايجابية}

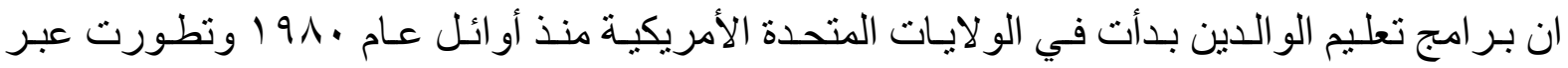

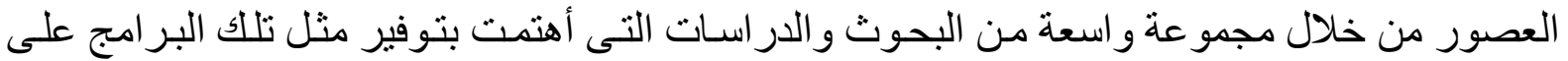

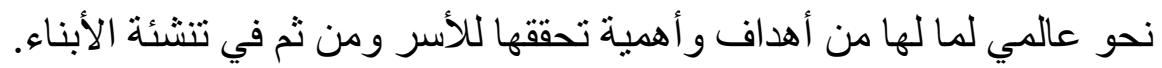

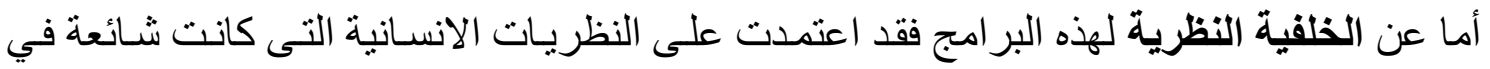

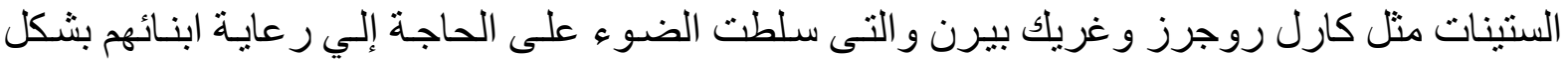

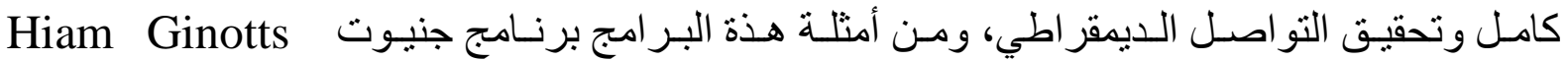

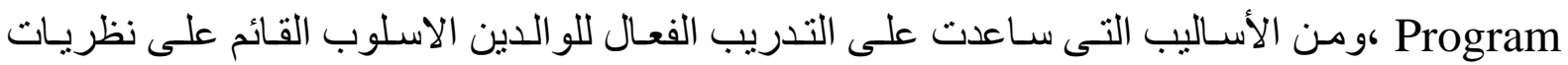

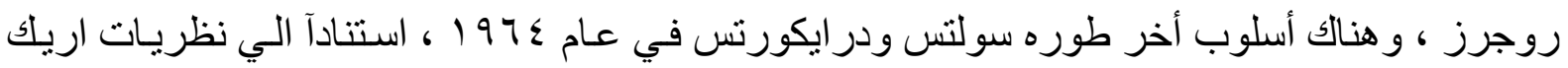

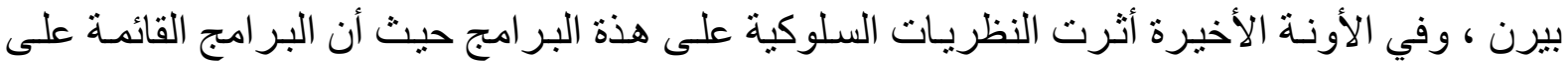

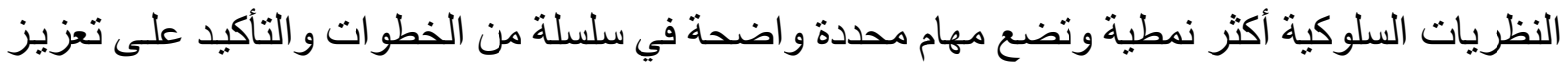

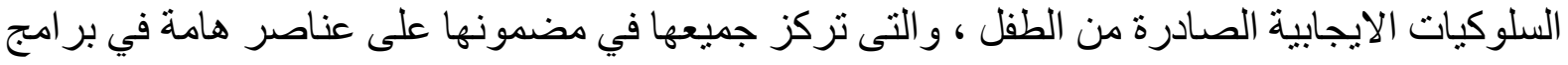

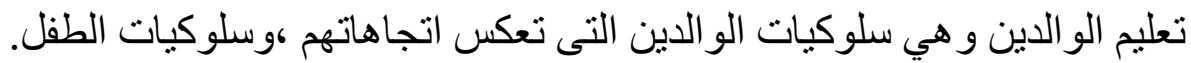

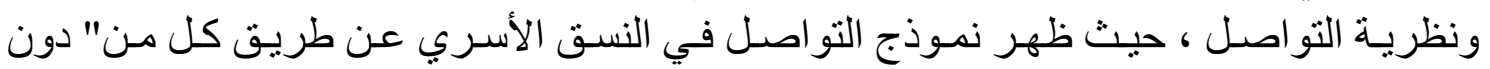

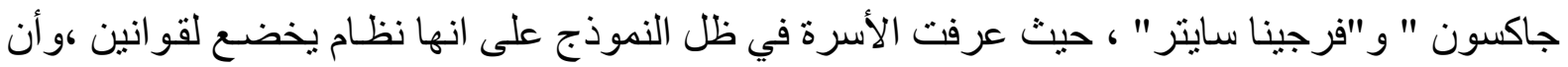

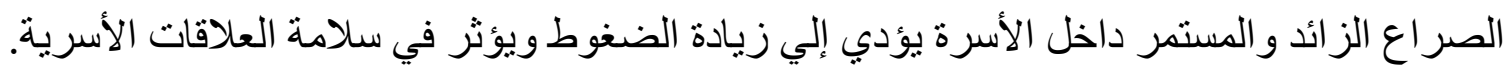

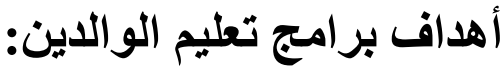

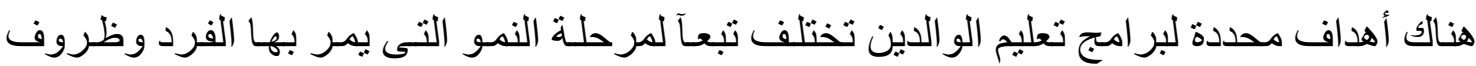

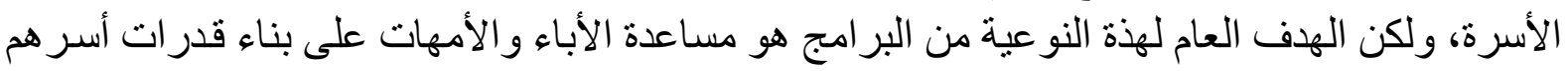

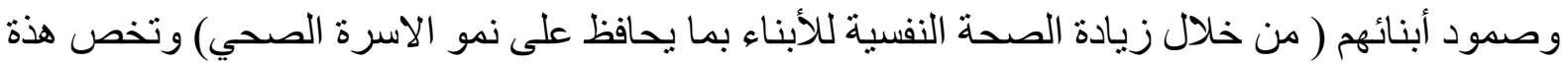

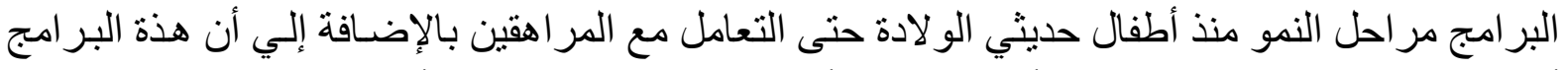

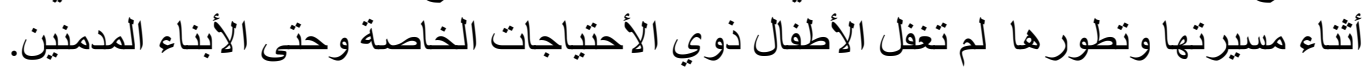

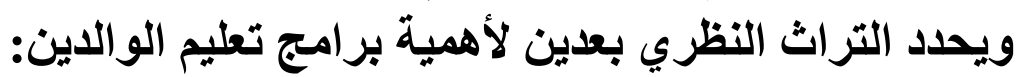

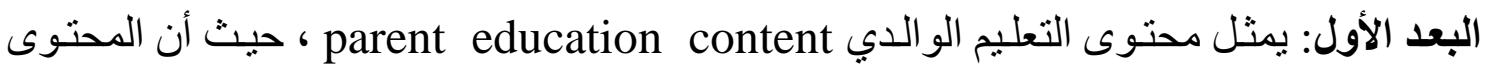

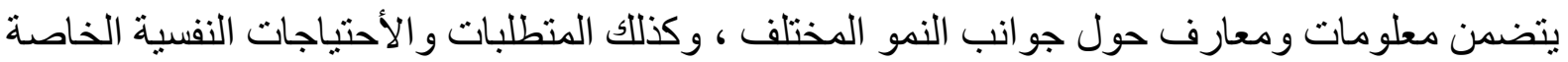

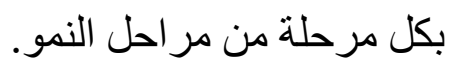

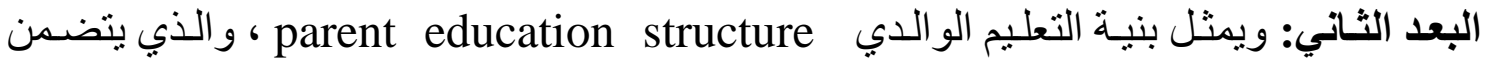

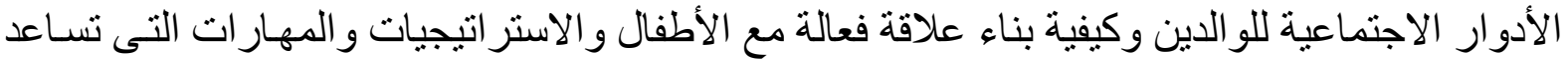

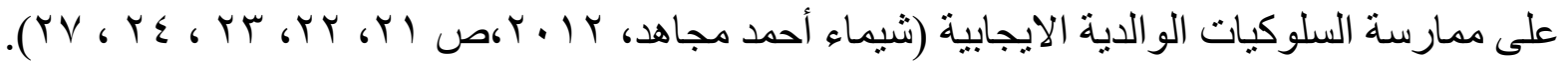


ولقد أثري مجال التدخل الخـاص بنظريـة التعلق بر امج تعليم الو الدين في مجـال الصحة النفسية

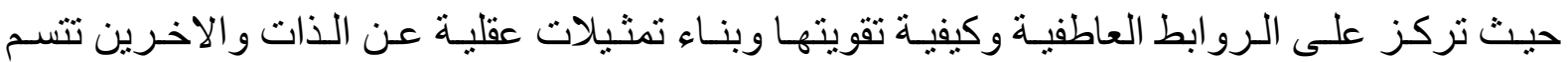

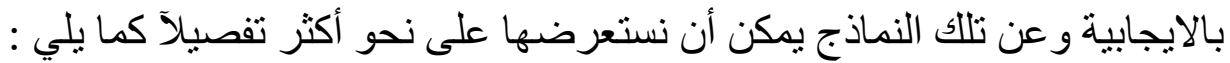
فقد أعتمدت در اسـة Giannotta, Fabrizia; Ortega, Enrique\& Stattin, Hakan, 2013

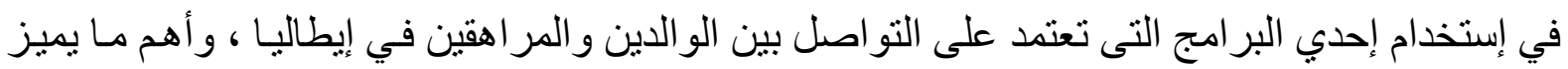

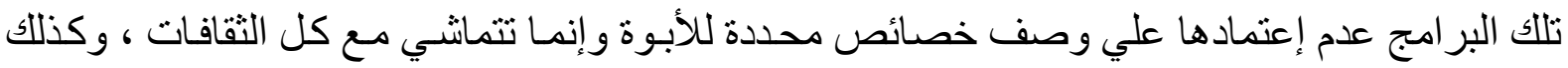

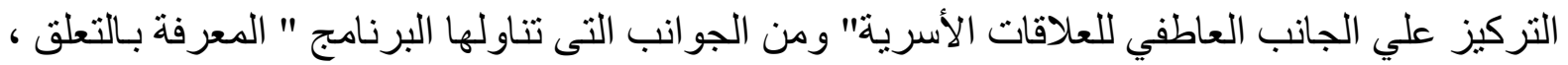

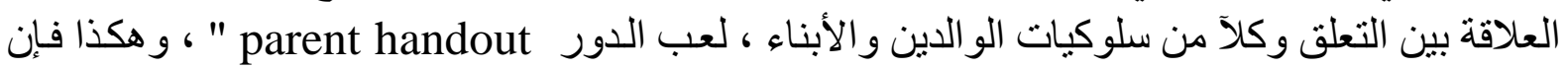

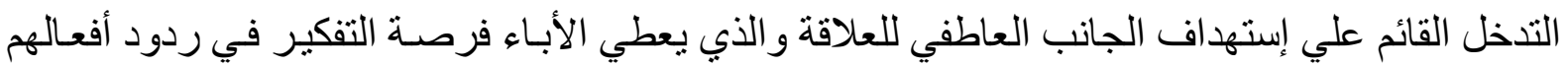

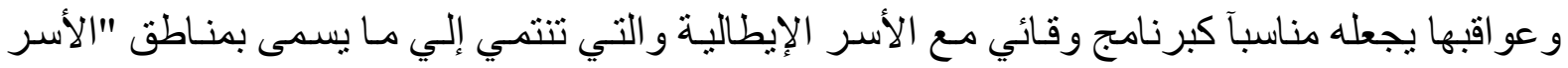

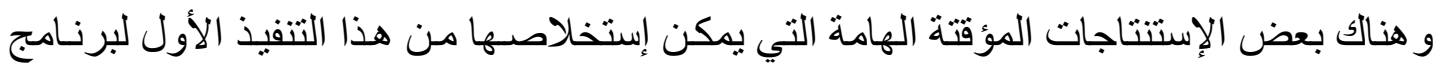

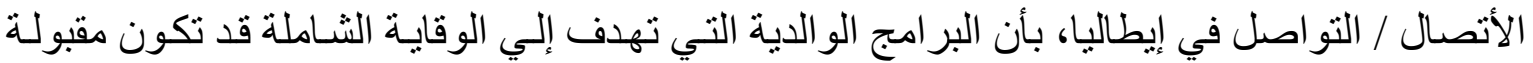

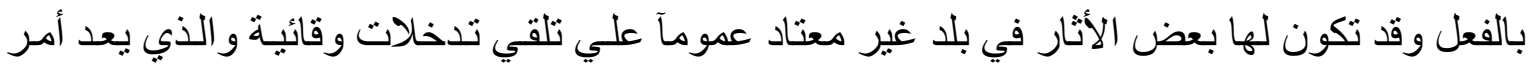

هام (Giannotta et.al, 2013, p.g75:77)

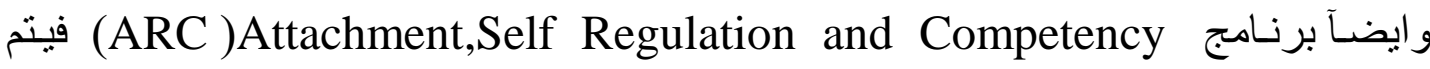

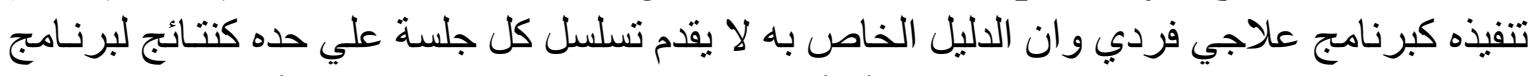

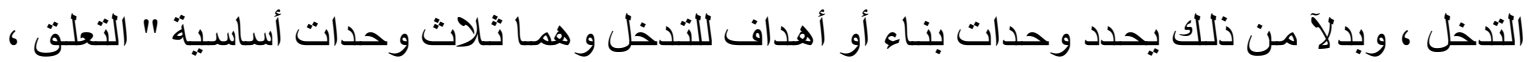

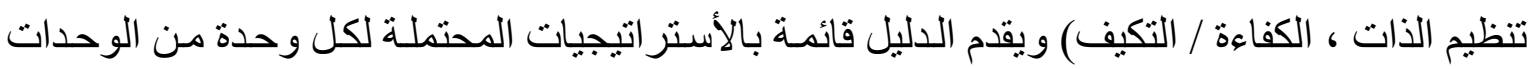

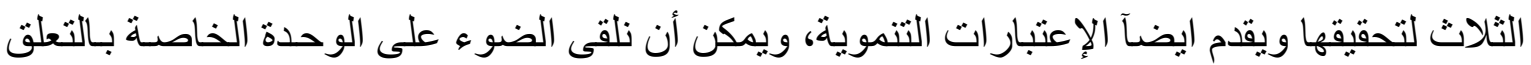
كما يلي:

حيث يستهدف نظام التعلق نظام الرعاية المقدم للطفل ،ويتضمن ذللك المجال أربعة وحدات بنـاء

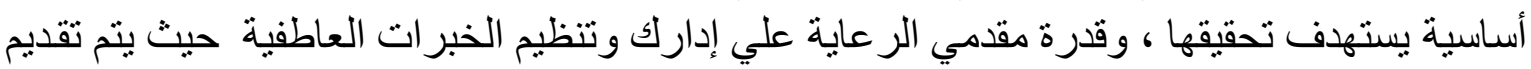

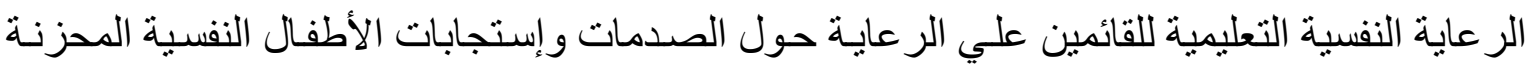

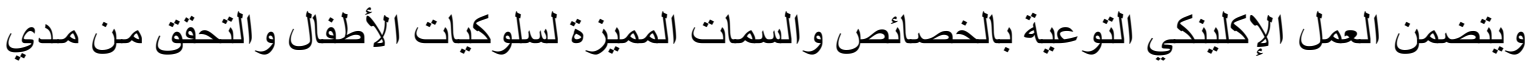

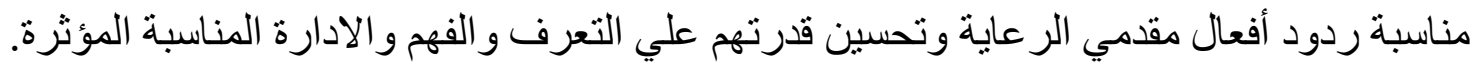

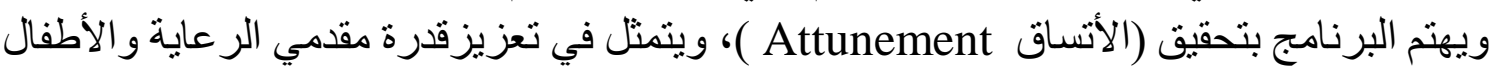

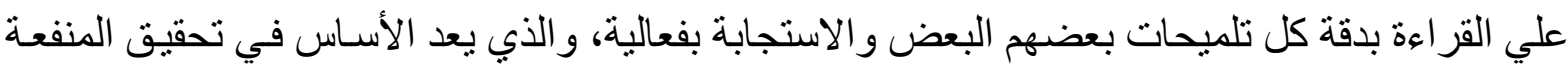

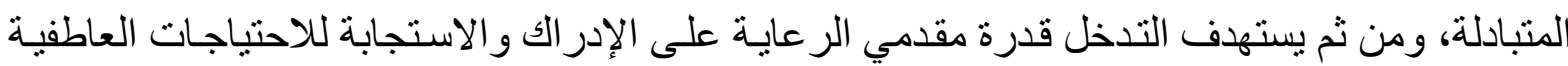

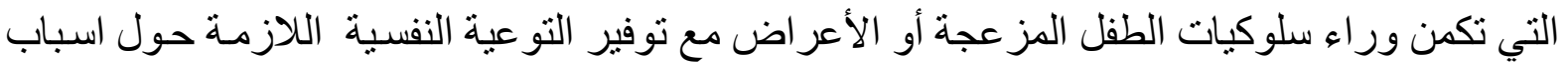

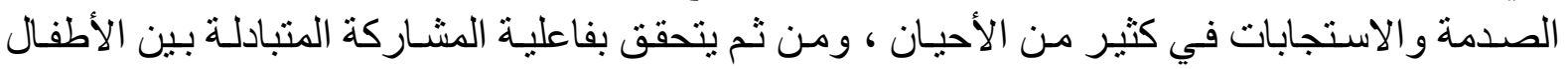

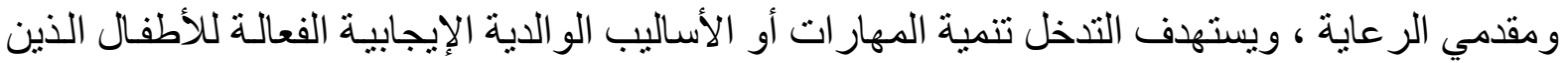

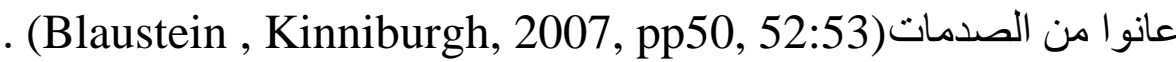

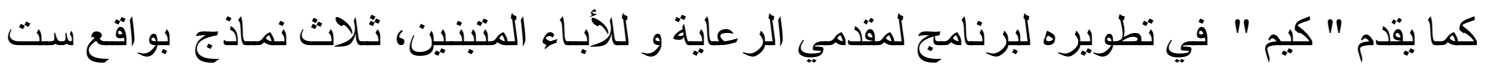

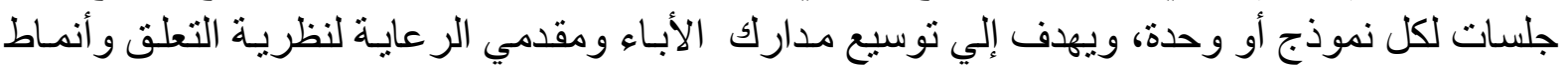

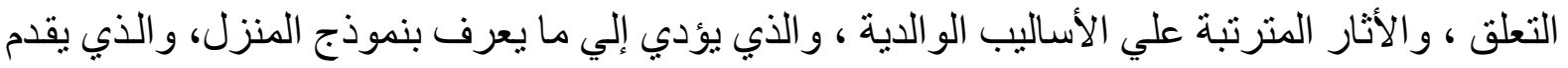




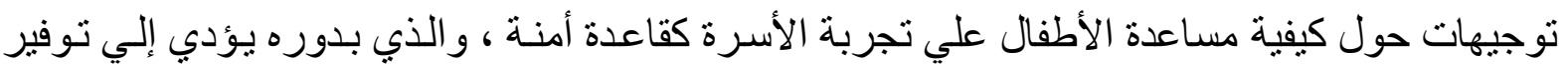

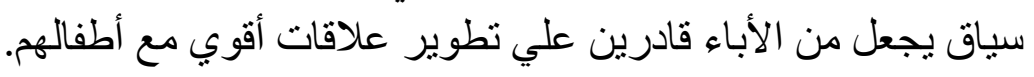

(Kim, Angel; Rubin, Kenneth; Burgess, Kim; Oh, Wonjung;Rose-Krasnor, Linda; Booth-Laforce, Cathryn,2006,p.g 75 :76)

\section{الار اسات السابقة :}

حيث نهتم بعرض عدد من الدراسات التى تناولت علاقات التعلق بين الو الدين و الطفل في علاقتهها

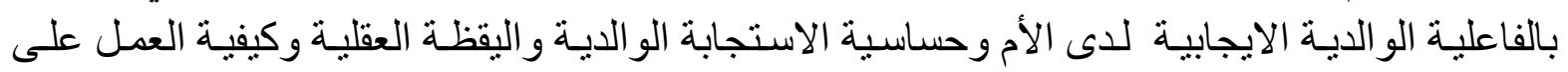
تنميتها،ضضلاً عن التأثيرات طويلة الأمد على التعلق الآمن:

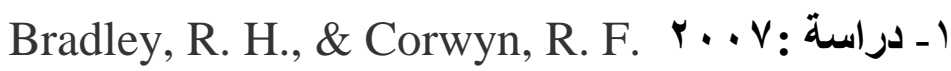

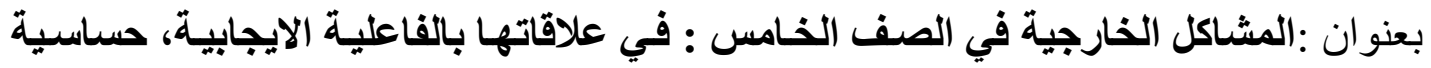

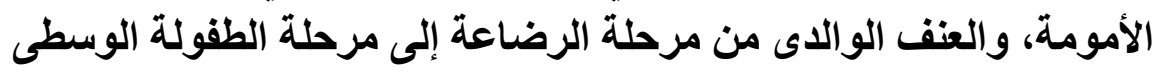

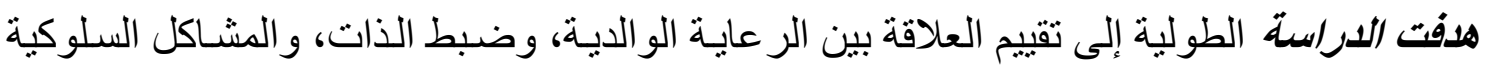

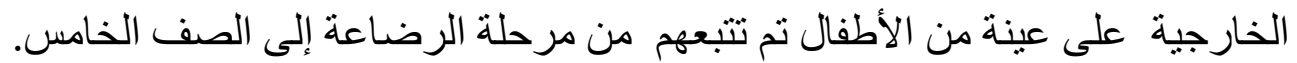

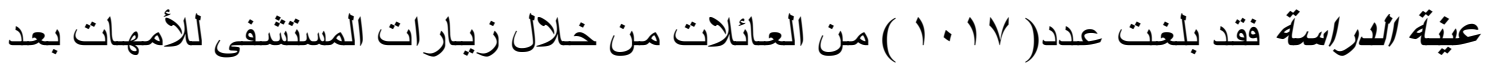

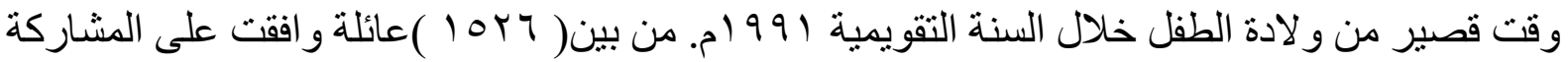

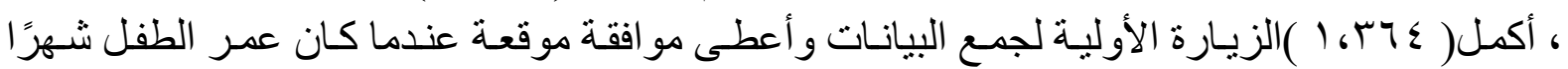

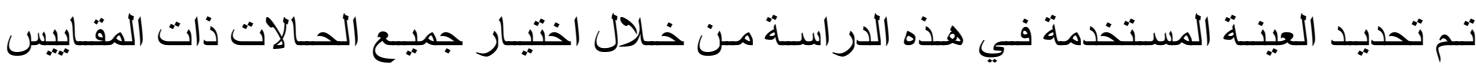

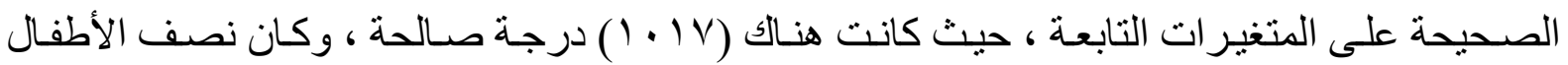

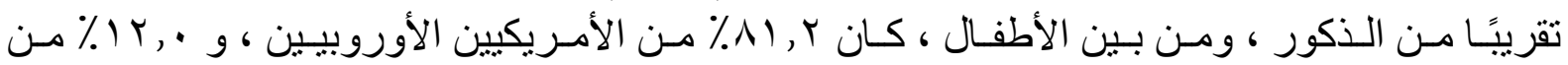

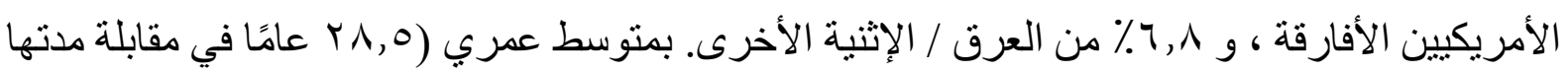

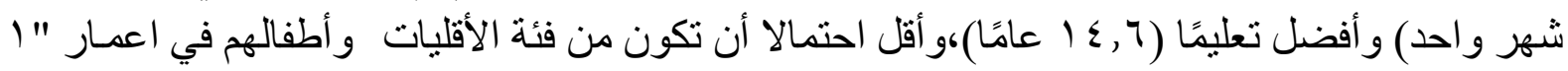

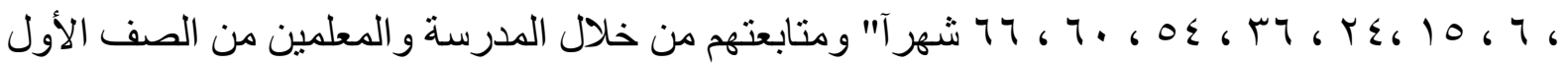

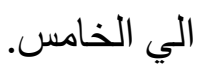

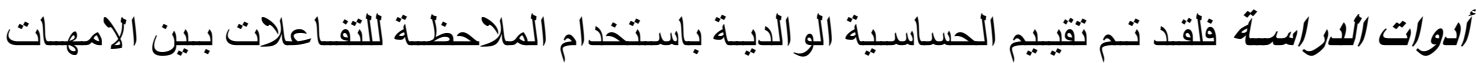

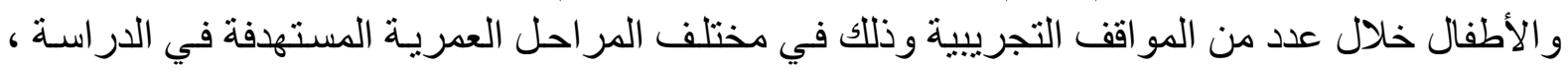

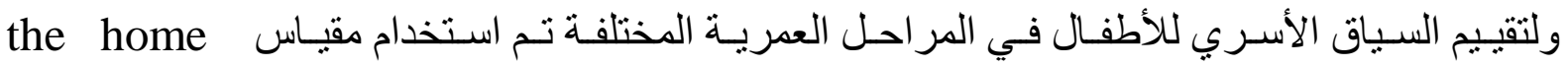
. inventory "Coldwell\&bradely,1984"

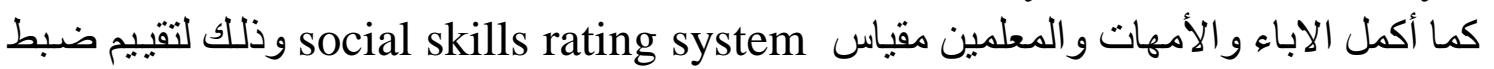

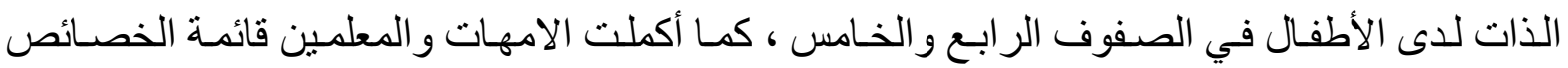

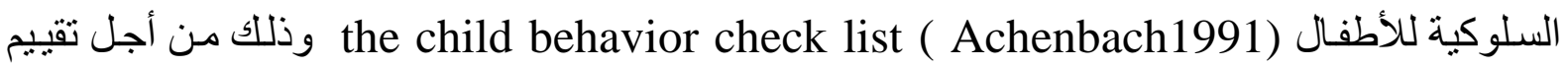

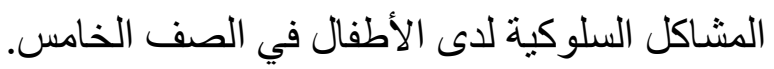

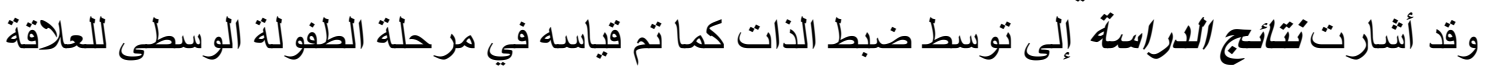

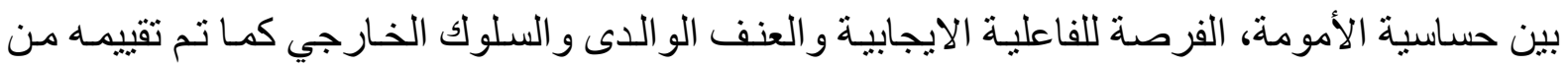
خلال تقارير كلٍ من الأم - و المدرسين. 


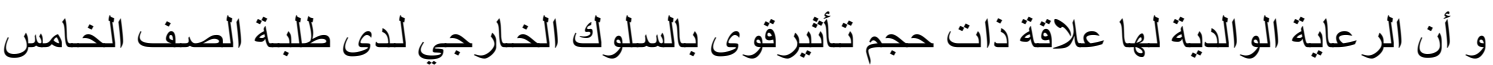

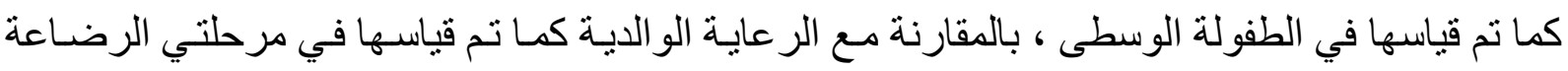

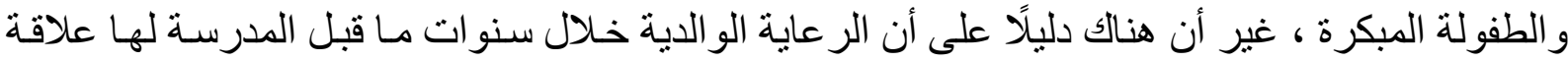
بالسلوك الخارجي لدى طلبة الصف الخامس من خلال الرعاية الو الدية الدية اللاحقة وضبط الذاتل الذات

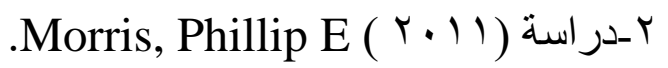

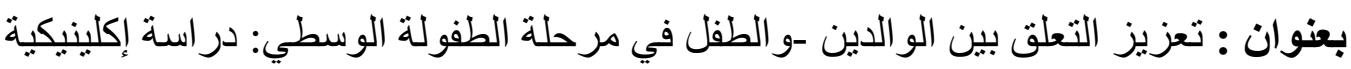

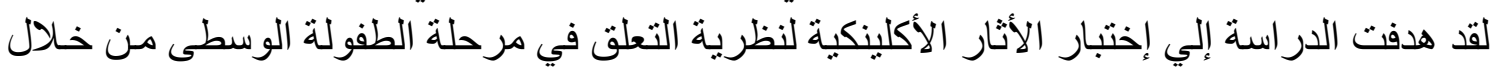

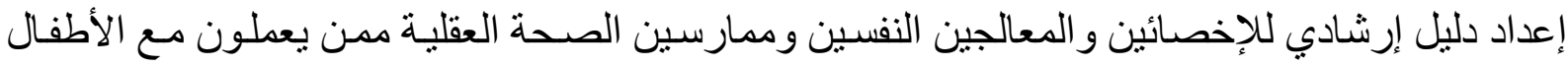

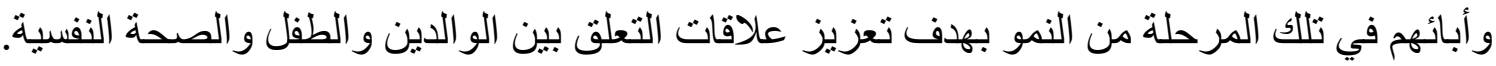

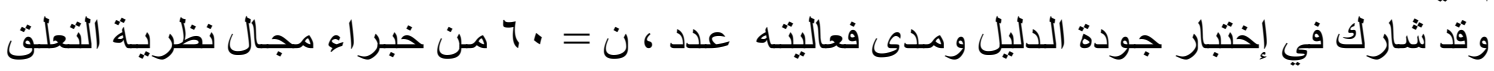

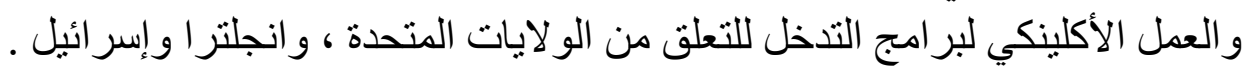

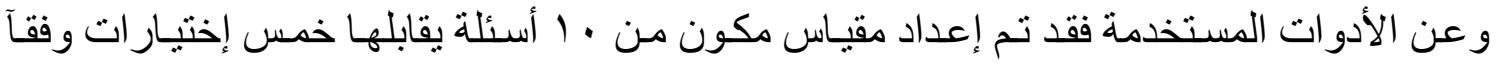

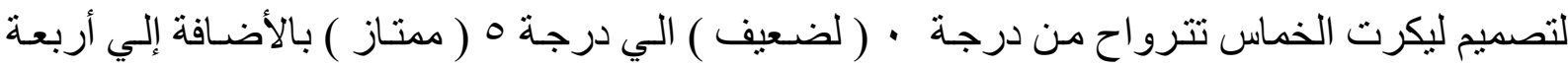

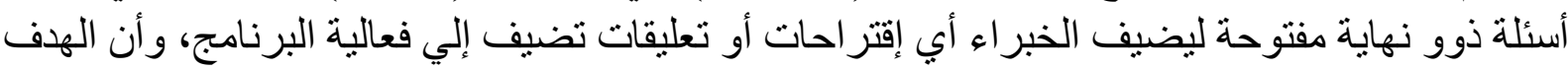

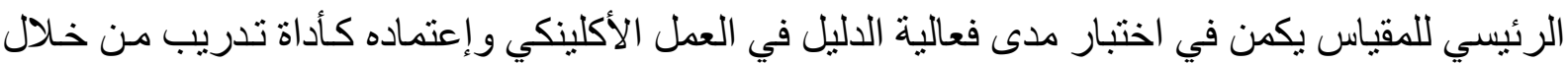

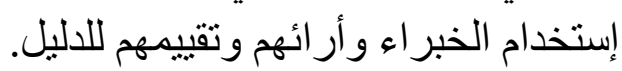

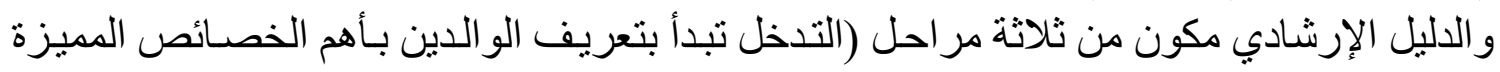

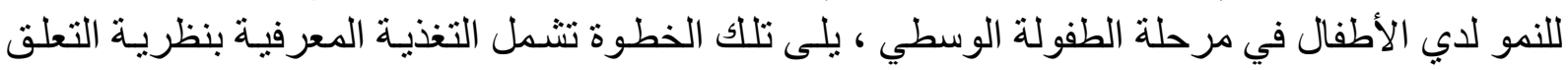

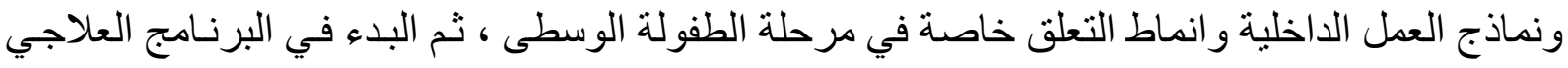

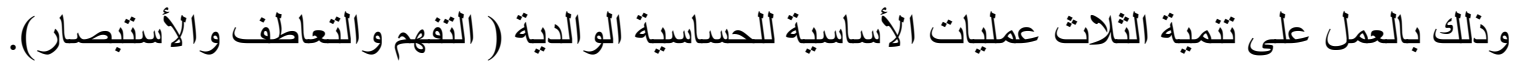

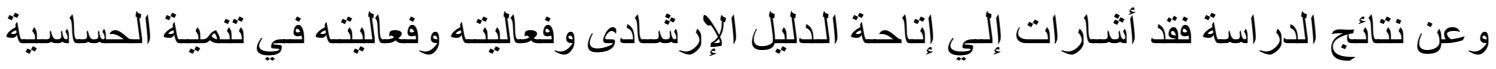

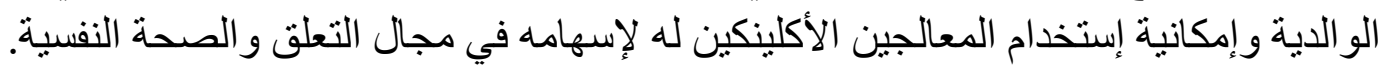

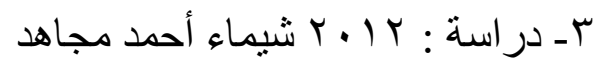

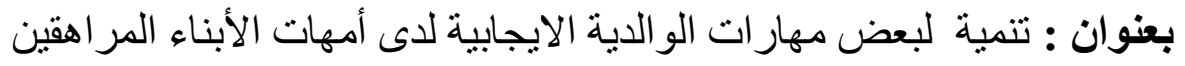

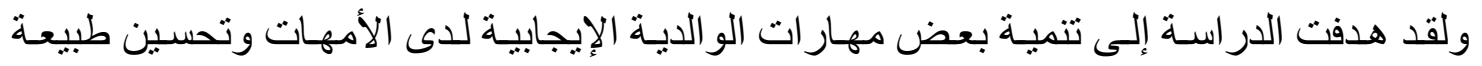
التفاعلات بين الأم و أبنائها في مرحلة المي تلنة المر اهقة المتوسطة.

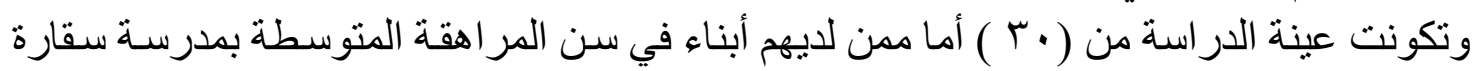

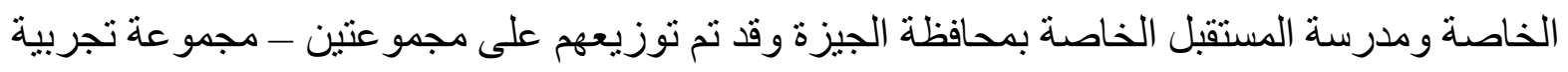

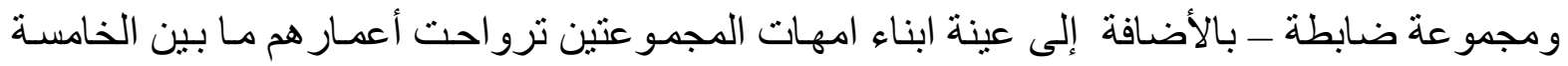

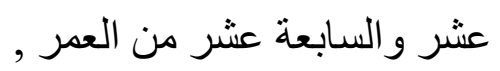

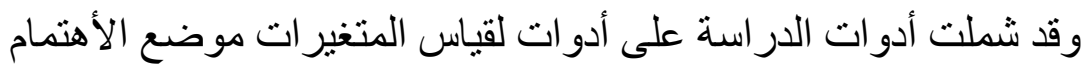

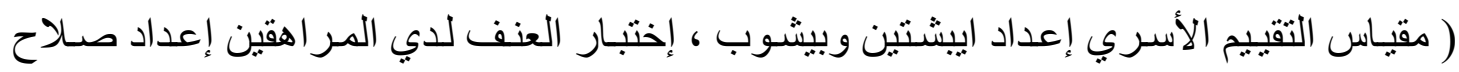

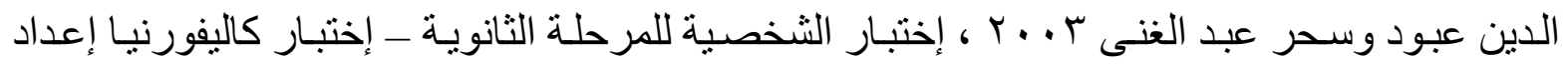

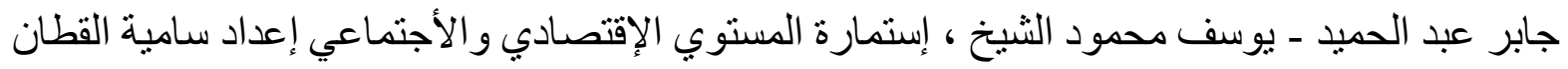

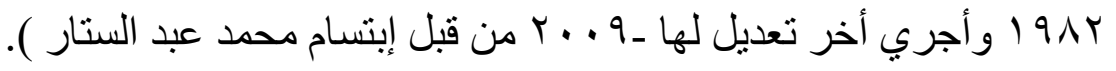




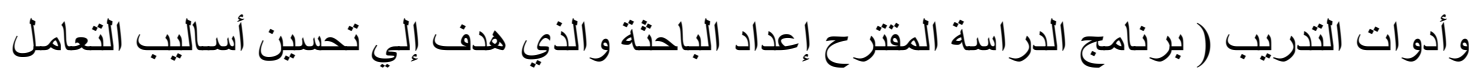

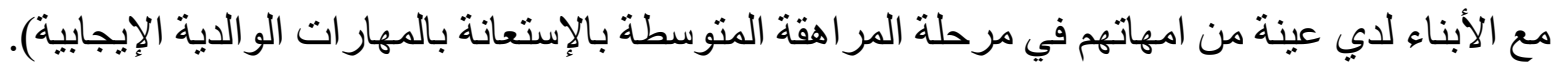

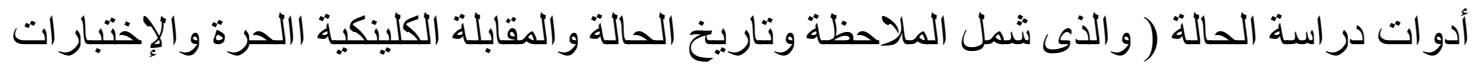

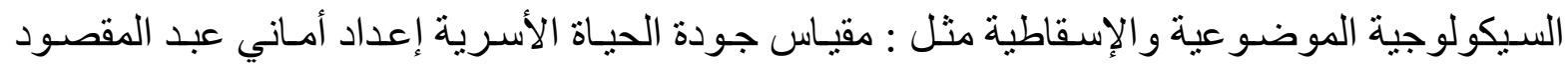

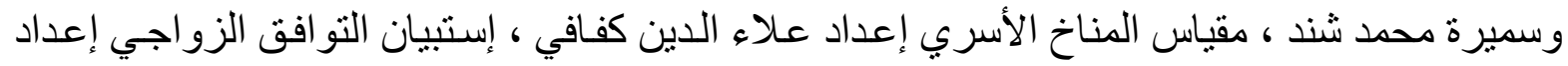

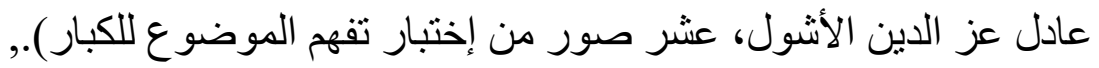

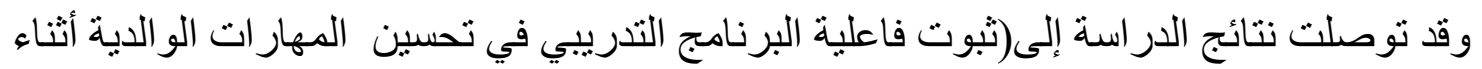

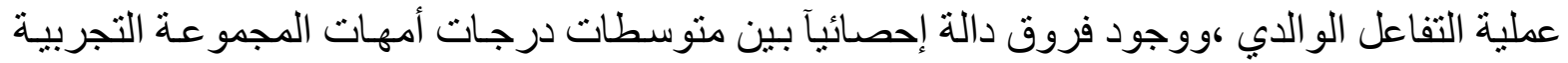

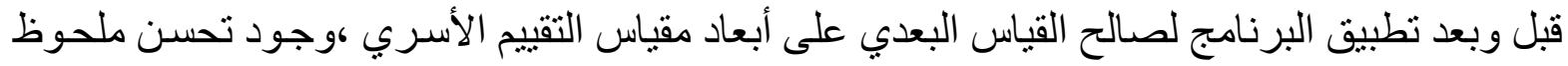

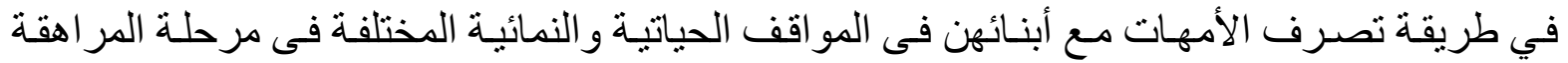

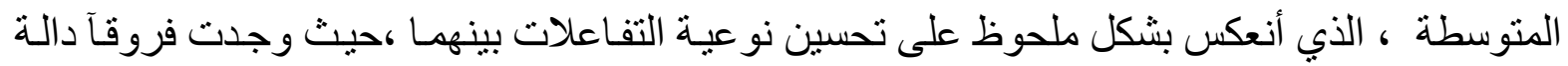

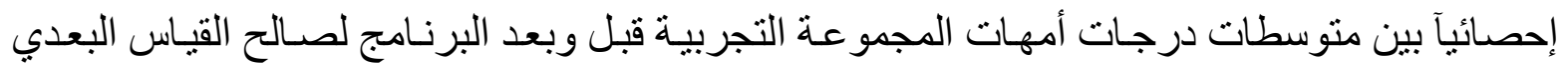

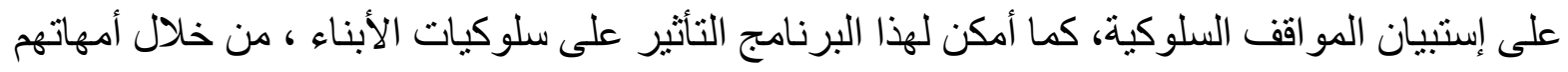

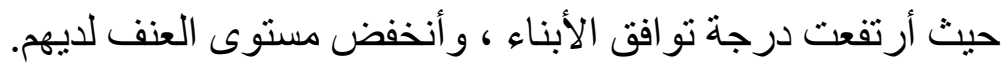

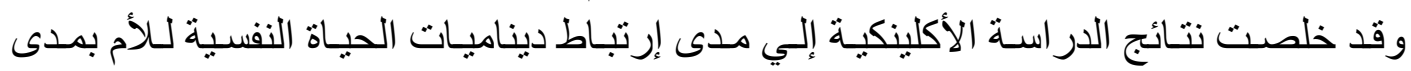
إستفاداتها من تدريبات البرنامج لأن سلوك الإنسان محصلة لما هو شعوري ولان شعوري.

$$
\text { ع ـ دراسة (ع ا ب r) ) ريما أحمد عواد البر اهيمي }
$$

بعنوان : تنمية الرعاية الو الدية لأمهات الطفل كفيف البصر ولائية الديه مدخل لخفض الأعر اض الكلينكية

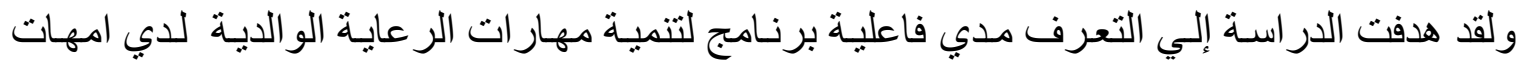

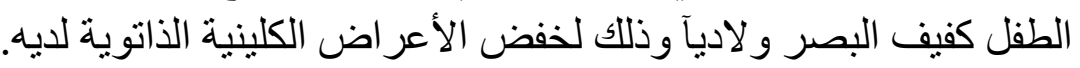

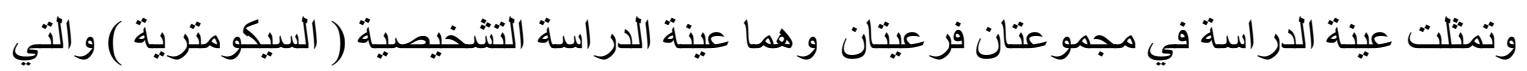

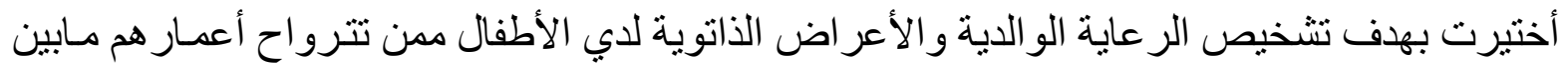

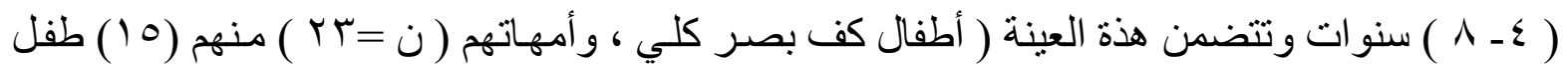

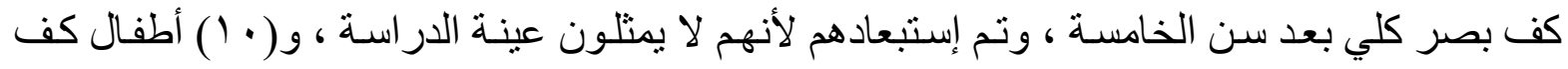

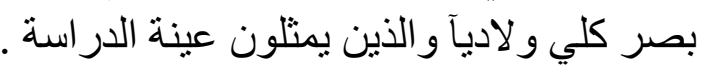

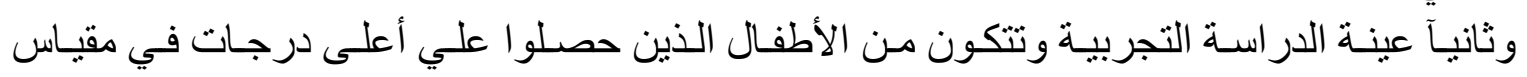

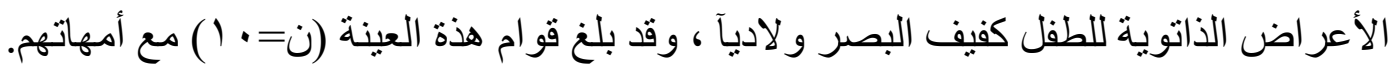

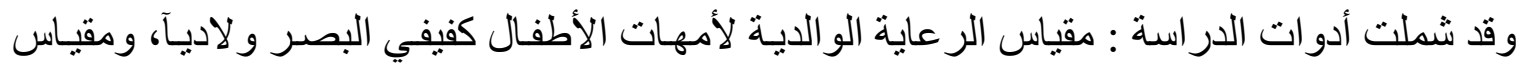

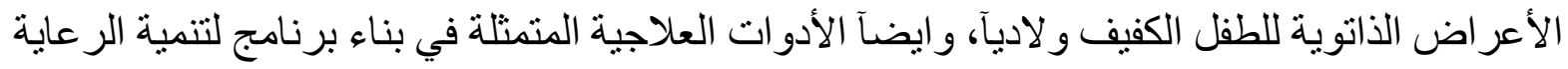

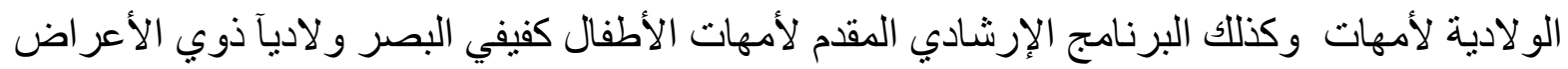

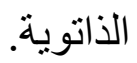

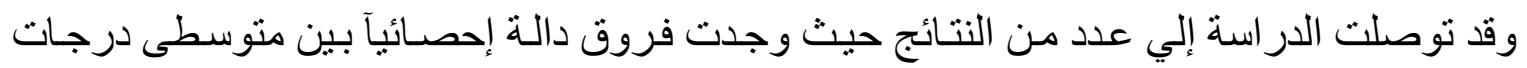

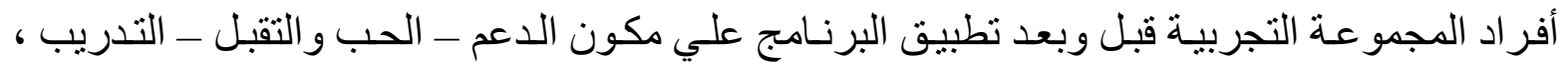

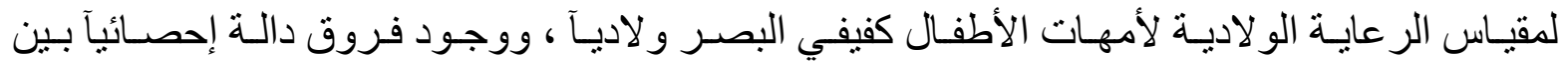

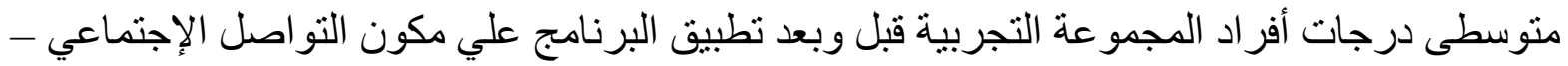


التو اصل اللغوي ـ السلوكيات النمطية ـ الإنفعالات و المشاعر ، بصدد مقياس الأعر اض الذاتوية للطفل

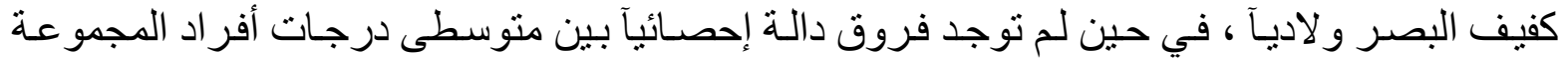

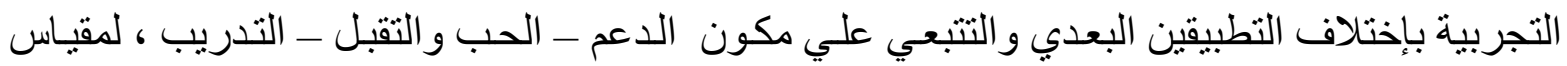

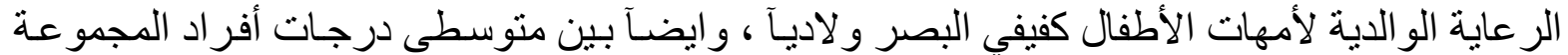

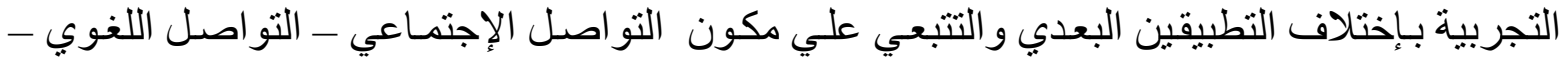

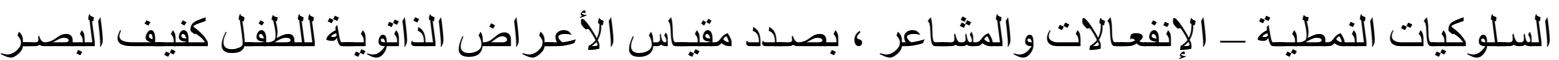
و لادياً.

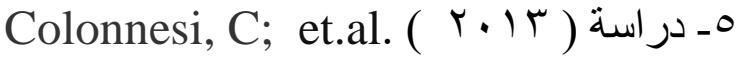

بعنوان :الأساس الآمن للتنذل القائم على التعلق و المعتمد على اليقظة العقلية لاى العائلات المتبناه.

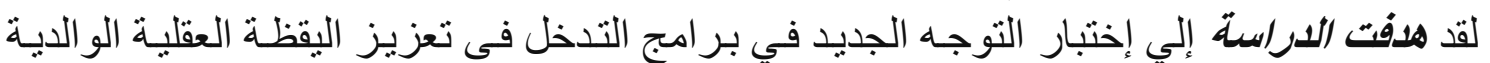

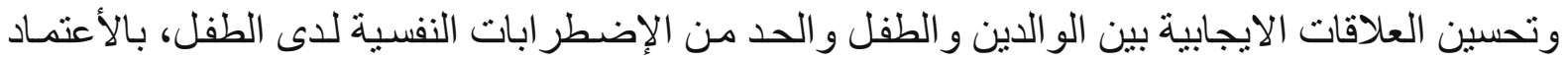

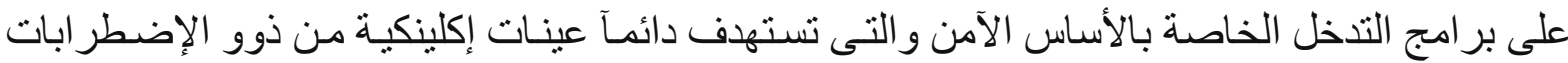

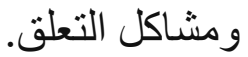

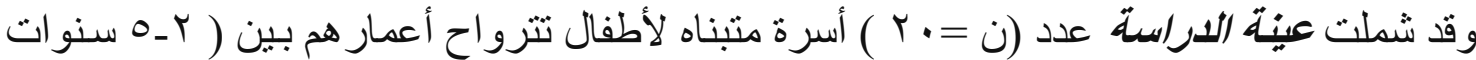

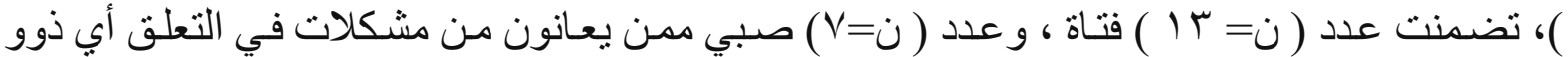

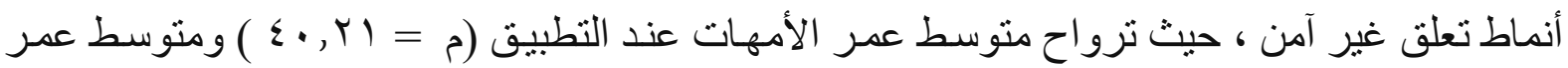

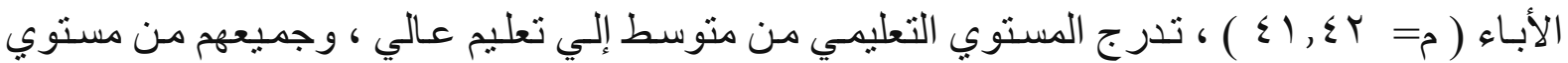
اجتماعي و اقتصادي متوسط. أدوات اللاراسة حيث انقسمت الي استخدام ادوات تشخيصية و التي قام بتطبيقها الأبـاء و الأمهات

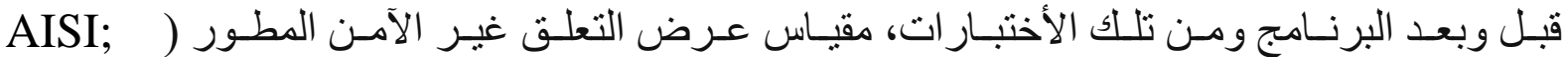
( Polderman et al., 2008; Wissink et al., 2012)

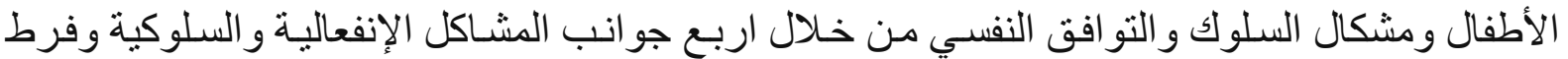

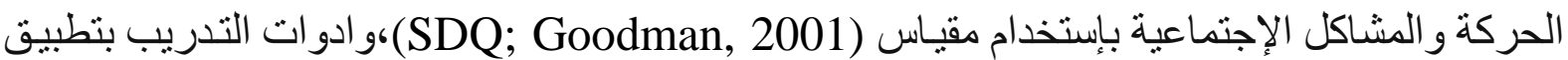

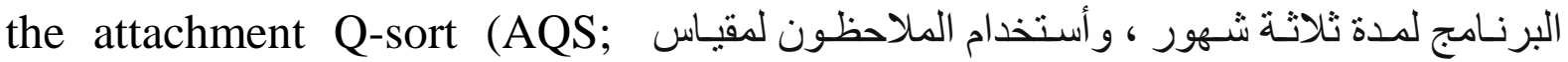
MBQS (Pederson, وذللك لتقييم التعلق لدى الأطفال ، ومقياس Waters \& Deane, 1985)

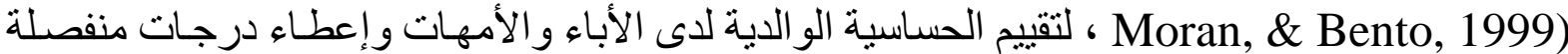

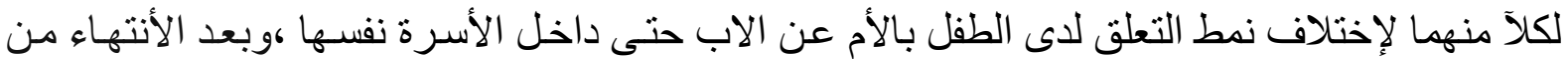

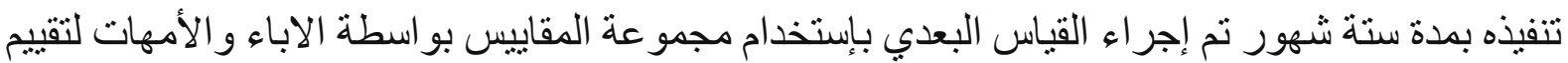
نمط التعلق لدى الطفل ومشاكل السلوك لد لديها.

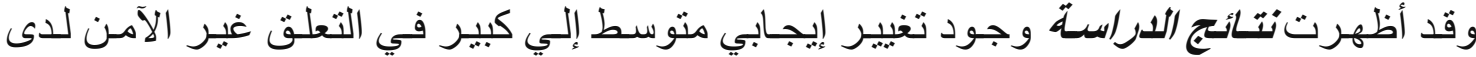

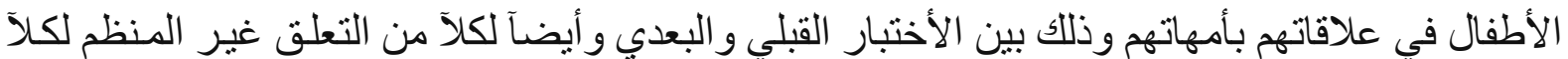

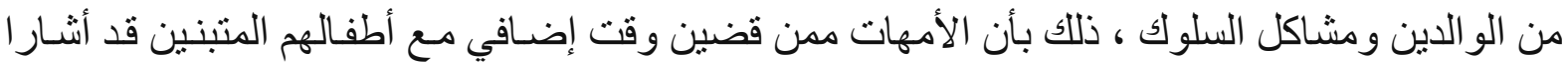

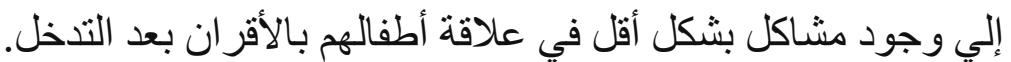

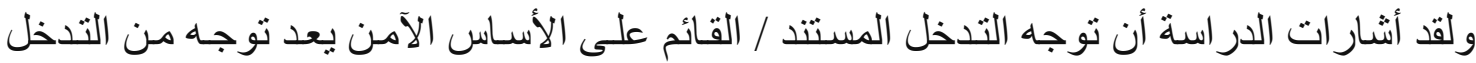
الو اعد في تحسين العلاقات بين الو الدين و الطفل في الأسر بالتبني وتقليل مشاكل التعلق و السلوك. 


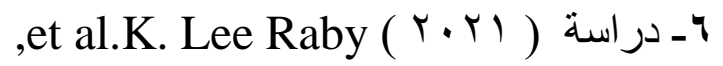
بعنوان : التأثثير ات طويلة الأمد على التعلق الآمن : نتائج الدر اسـات التجربيـة لبرنامج التدخل القائم

على التعلق و السلوك الحيوي البيولوجي (ABC)

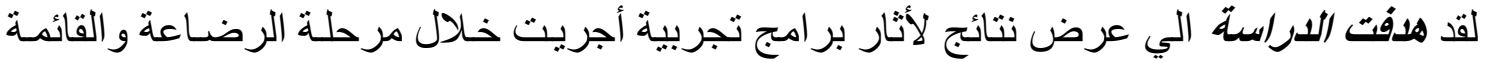

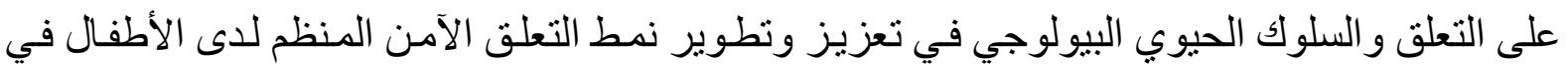

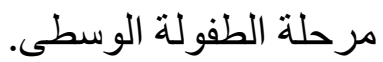

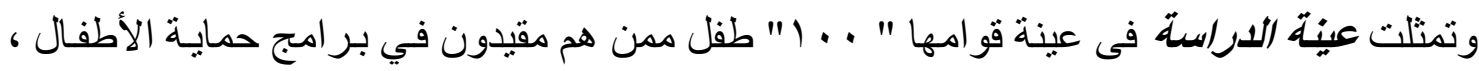

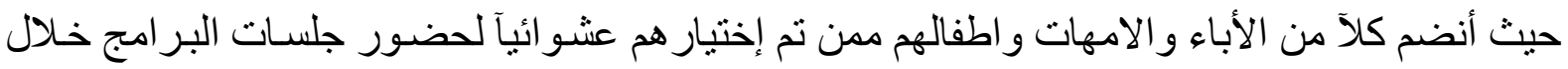
مرحلة الرضاعة وفي مرحلة الطفولة الوسطى.

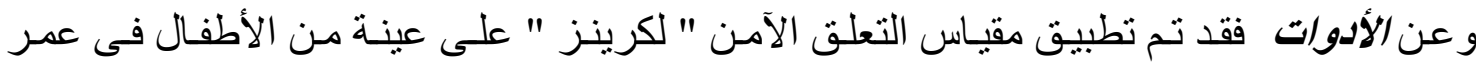

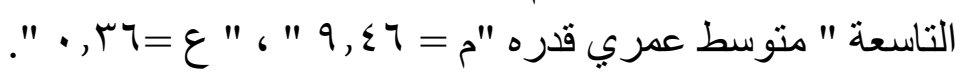

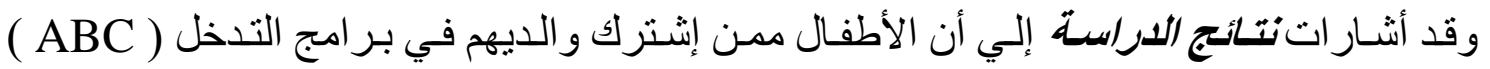

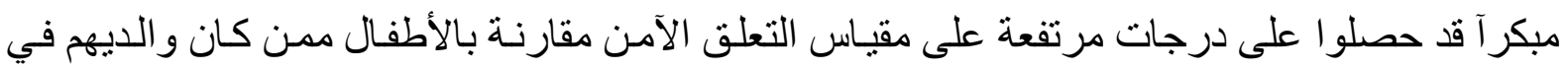
المجمو عة الضابطة بالبرنامج.

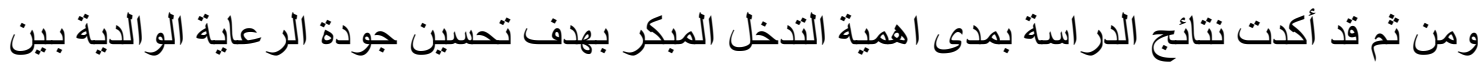

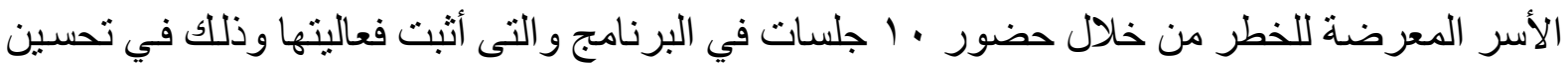

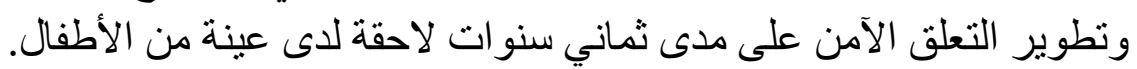

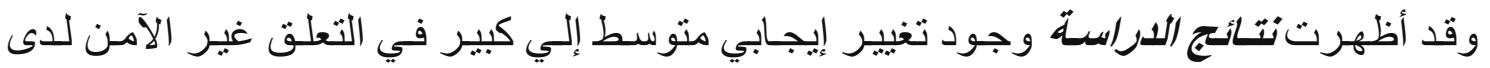

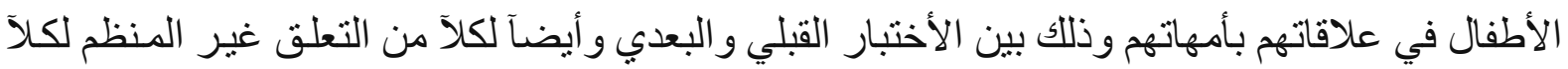

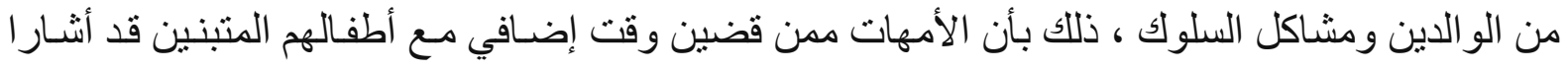

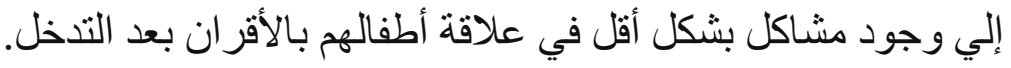

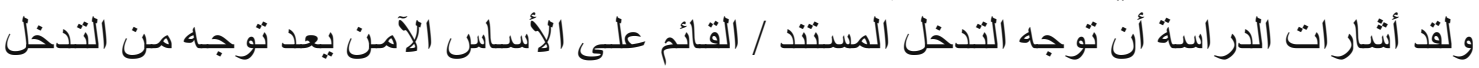
الواعد في تحسين العلاقات بين الوالدين و الطفل في الأسر بالتبني وتقليل مشاكل التعلق و السلوك.

\section{تعقيب عام على الار اسات السابقة:}

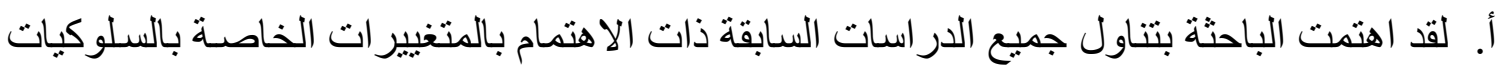

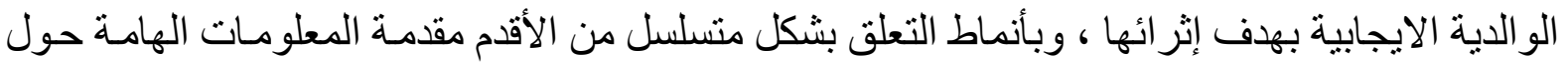

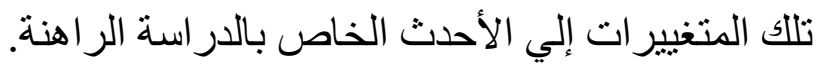

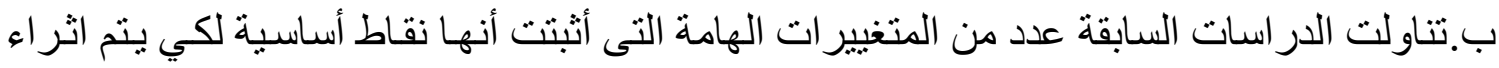

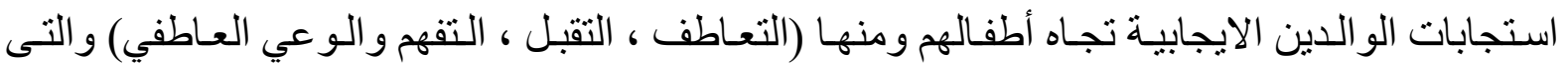

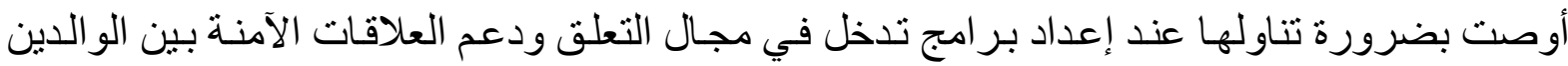
و الطفل.

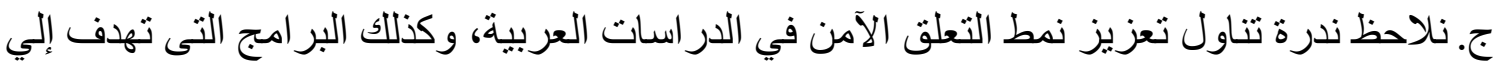

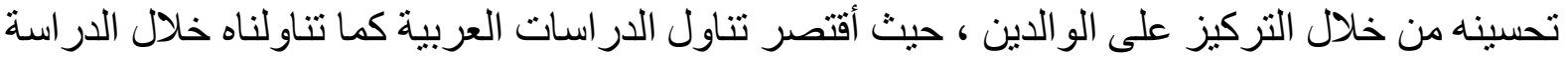
الر اهنة بمجال التعلق بدر اسات وصفية تهتم بدر اسة أنماط التعلق في علاقته بالمتغيير الت الثنات الثخصية. 


\section{فروض البحث}

ـ ـ توجد فروق بين منوسطى درجات القباس القبلي والبعدي على مقياس التقيم الأسري للدى عينـة

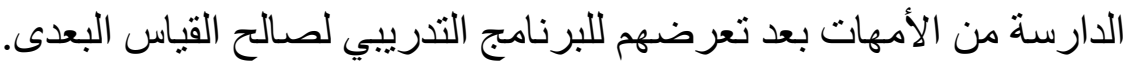

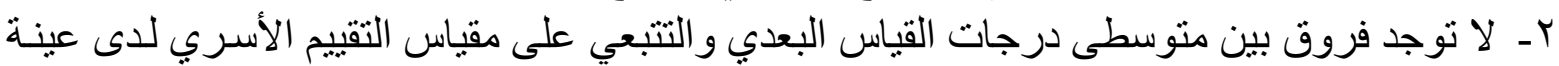

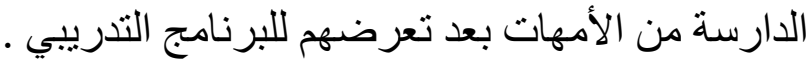

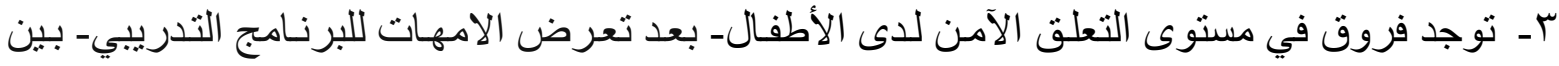

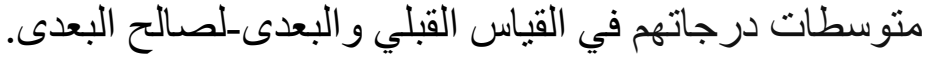
ـ ـ لا توجد فروق في مستوى التعلق الآمن لدى الأطفال في متوسطات درجاتهم بين القياسبين - البعدي و التتبعي.

\section{منهج البحث}

أستخدمت الباحثة المنهج التجريبي يإسـتخدام تصـيم المجموعـة التجريبيـة الو احدة مـن الأمهات

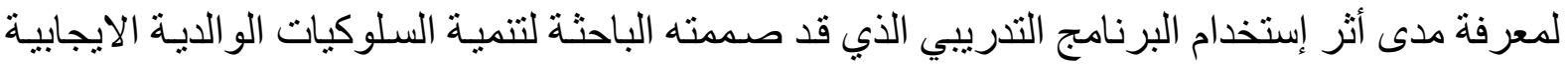
عند الأمهات ، على تحسين مستوى التعلق الآمن لدى الأبناء في مرحلة الطفولة الوسطى، وذلك بتطبيق التهيق

\section{عينة البحث

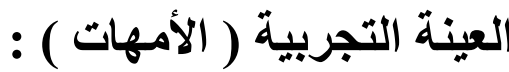

وقد كان في اختيار العينة التجربية عدد من الخطوات التهات التى تم إتباعها : أـ قد تم توجيه دعوة إلي الو الدين للأطفال ذوو الدرجات المنتوسطة و المنخفضة لنمط التعلق الآمن ، الحضور البرنامج. بـ أقتصر الحضور على الأمهات فقط ، لرفض الأباء المشاركة في إعتبار هم أن التربيـة هـى شـأن الأم فقط. ج- قد لاحظت الباحثة بعد تطبيق مقياس التقييم الأسري على الأمهات ( العينـة التجريبيـة ) و الذي الذي فيه يقيس عددآ من المهار ات الأسرية أن الأمهات أكثر قربـآ للأطفال و أكثر مسئولية في تولى شـئون الأن الأسرة من الأباء.

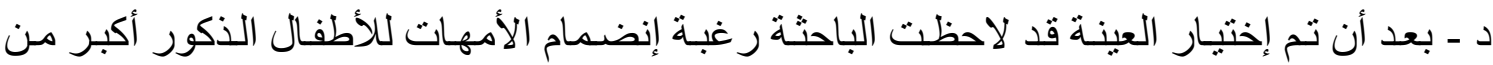
الإناث ، وذللك لظهور المشاكل السلوكية على الأولاد الأكور عن الإناث.

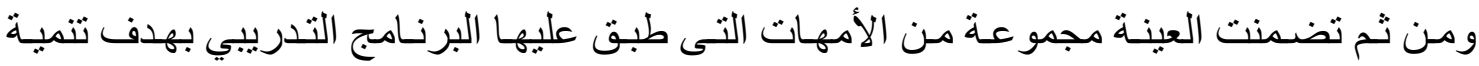
السلوكيات الو الدية الايجابية ،لمعرفة مدى التغيير في مستوى (نمط التعلق الآمن) لدى أبنائهم من الذكور والأناث، كمتغير تابع ،وفيما يلي جدو لا يصف عينة الدر اسة من الأمهات و الأبناء: جدول (1) وصف عينة الدر اسة من الأمهات و الأبناء

\begin{tabular}{|c|c|c|c|c|c|c|c|c|c|}
\hline نسبة الأمهات & كدة الزواج & كدة الزواج & التمليميتوى & الانحراف & متوسط العمر & العمر & العدد & \multicolumn{2}{|c|}{ العينة } \\
\hline$\%$ \%. & ro & 1. & عال & $\varepsilon, Y \wedge \theta$ & ro & \&Q_rq & Ir & \multicolumn{2}{|c|}{ الأمهات } \\
\hline - & - & - & - & $r, r \wedge V$ & $\Lambda, Y r$ & Ir-t & $\wedge$ & ذكور & \multirow{2}{*}{ الأبناء } \\
\hline - & - & - & - & $1, V R r$ & $1,0$. & Ir_t & $\varepsilon$ & إناث & \\
\hline
\end{tabular}




\section{أدوات البحث}

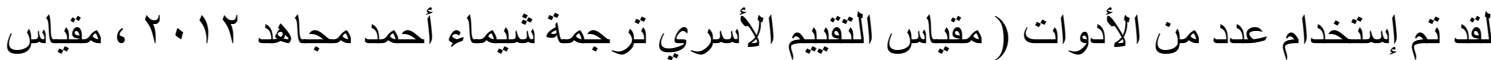

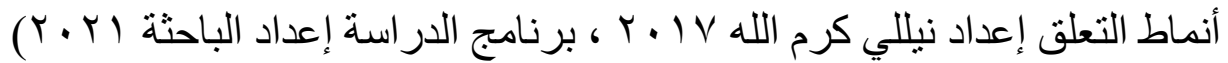

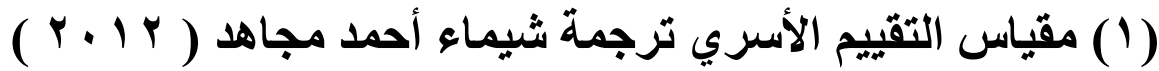

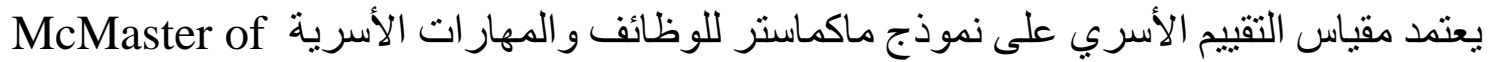

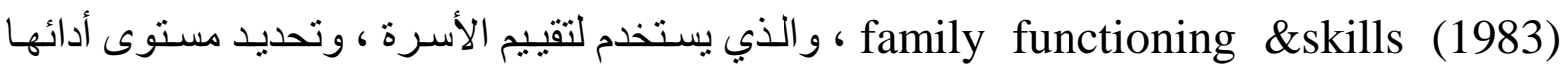

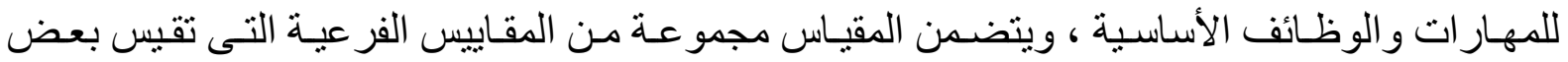

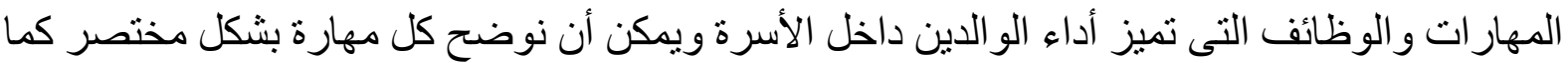

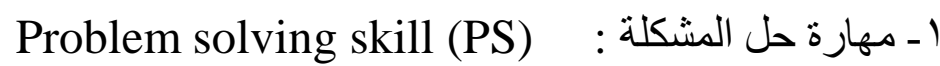

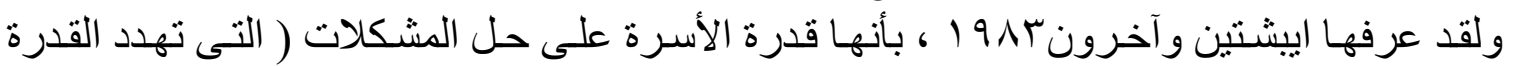

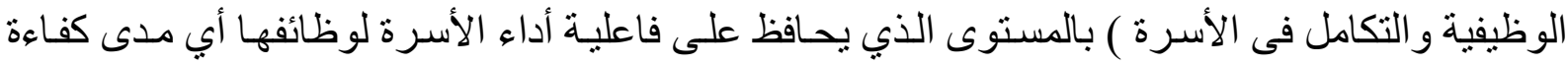

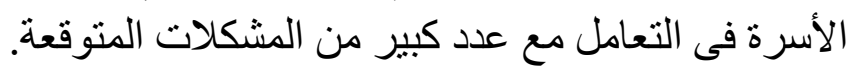

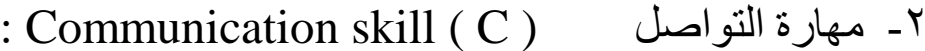

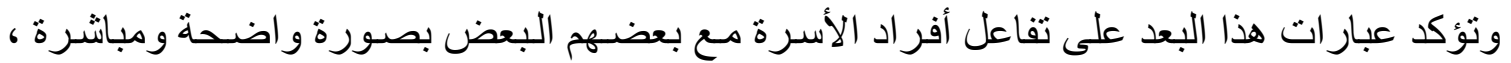

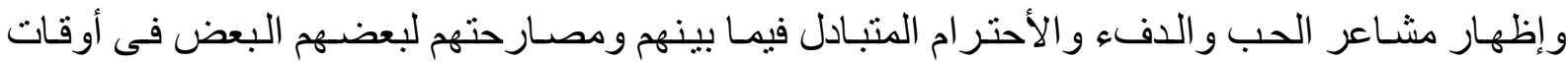
الغضب ، و الأعتر اف بالخطأ فى حق الأخر.

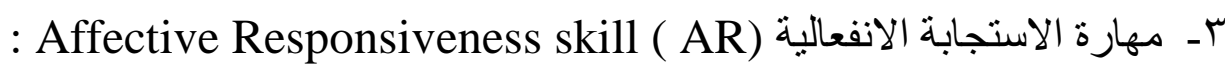

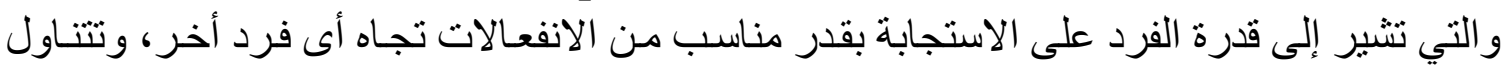

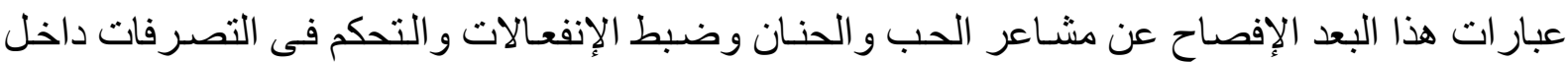

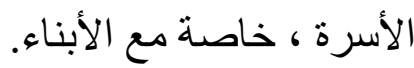

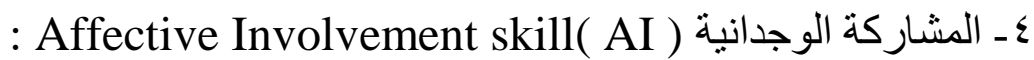

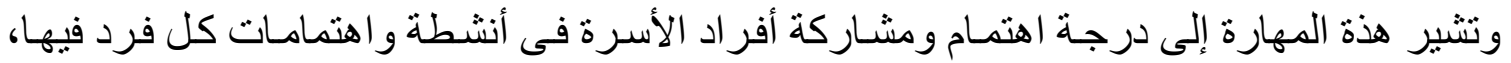

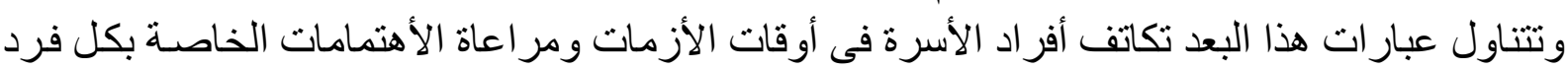

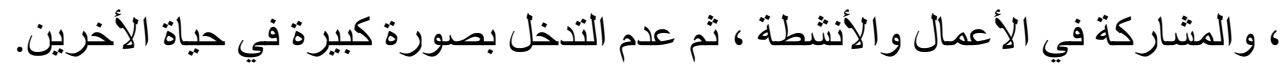

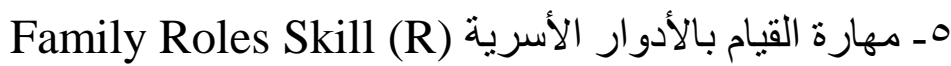

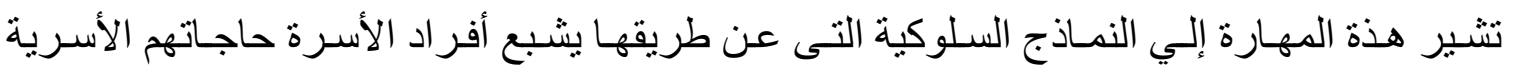

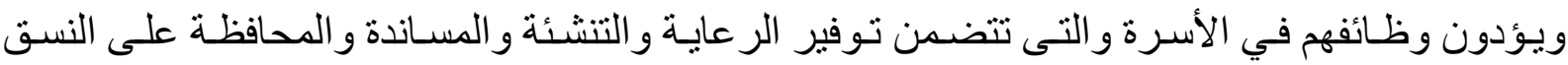

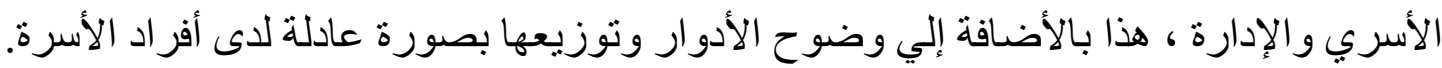

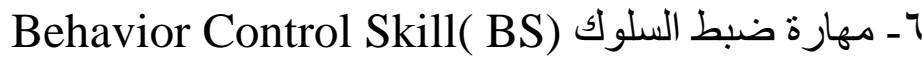

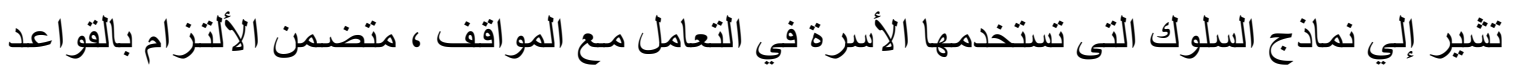

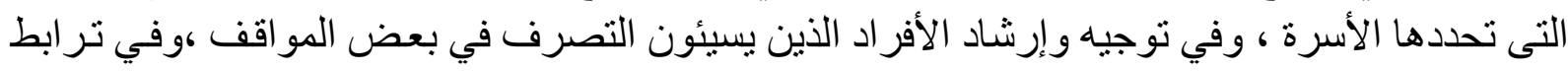

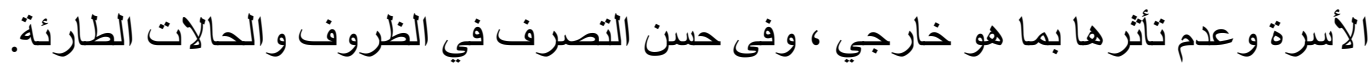




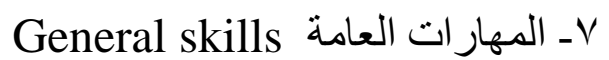

و الذي يشير إلي المهار ات العامة التى تستخدمها الأسرة في التعامل مع المو اقف الحياتية اليومية.

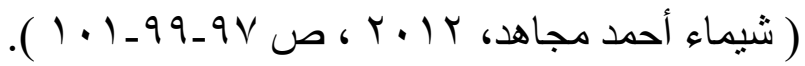

\section{مكونات المقاييس الفرعية وتصحيحها :}

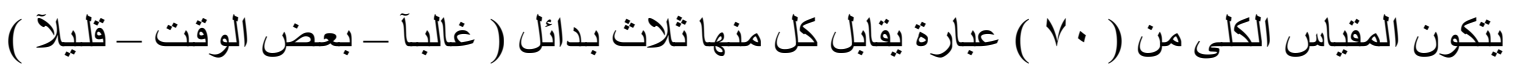

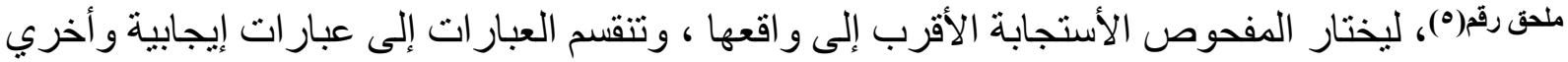

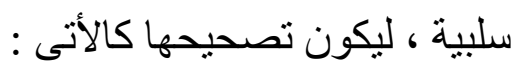

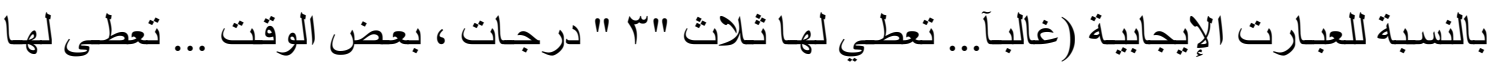

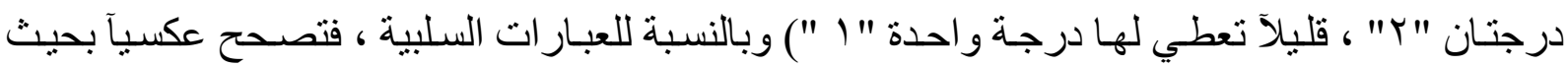

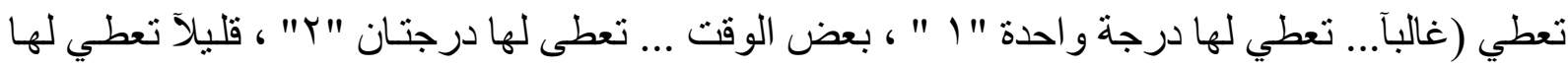

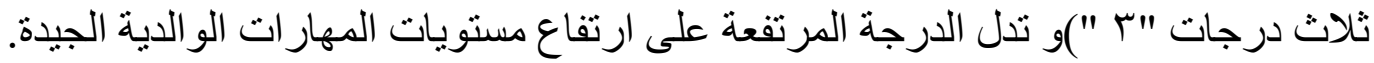

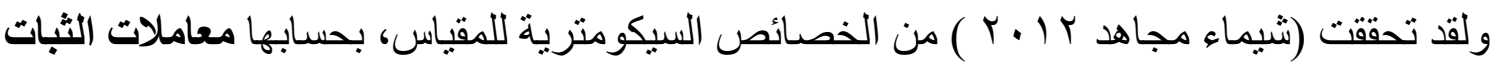

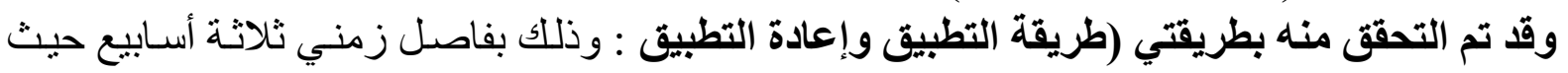

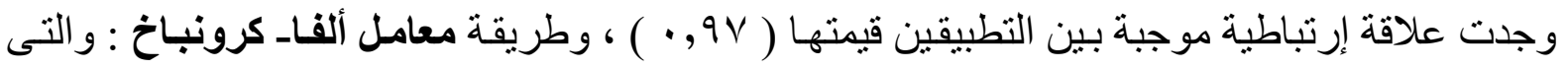

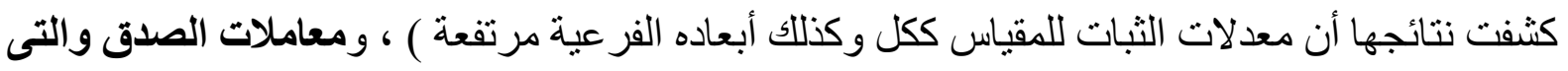

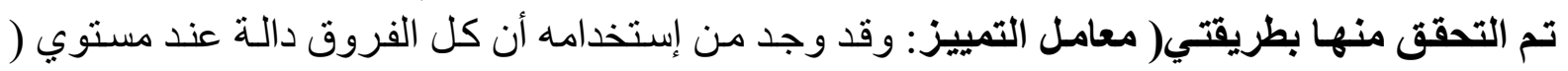

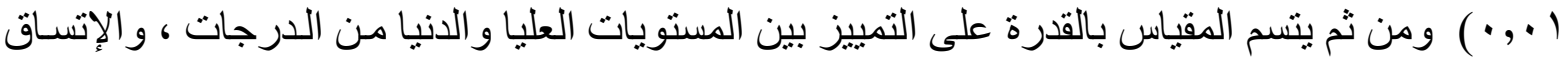

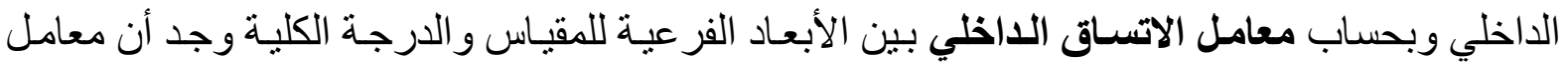

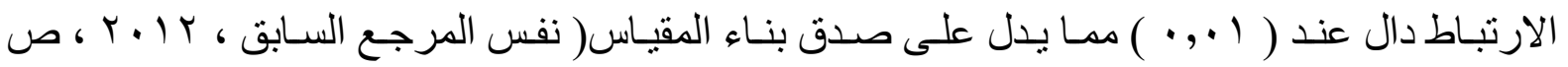

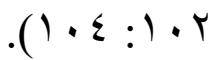

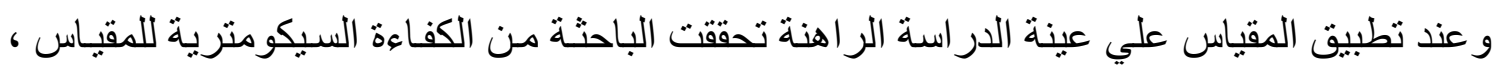

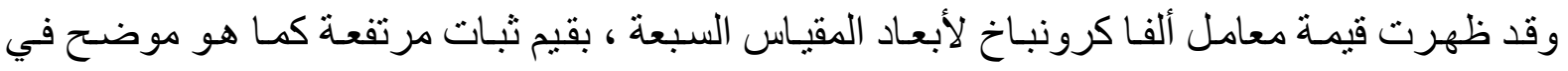

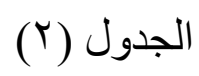

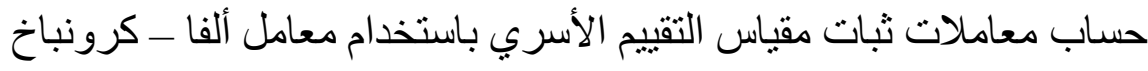

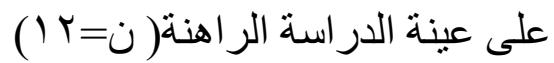

\begin{tabular}{|c|c|c|}
\hline معامل الفا كرونباخ & المهارة & p \\
\hline , ^ $\leqslant \vee$ & حل المشكلة & 1 \\
\hline , A ₹ & التواصل & $r$ \\
\hline,$V \circ r$ & الاستجابة الانفعالية & $r$ \\
\hline ,VIr & المشاركة الوجدانية & $\varepsilon$ \\
\hline , V79 & الأدوار الأسرية & 0 \\
\hline , ^५० & ضبط السلوك & 7 \\
\hline ,qrq & التواصل & $\mathrm{v}$ \\
\hline ,97V & الارجة الكلية & $\Lambda$ \\
\hline
\end{tabular}




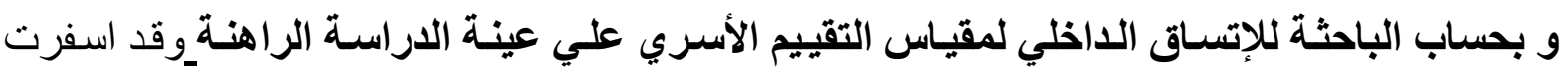

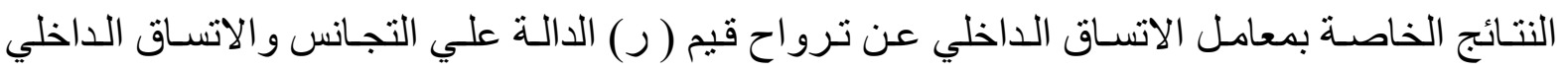

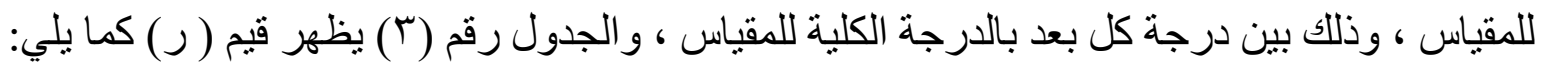

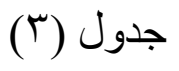

حساب معاملات الاتساق الداخلي بين الابعاد الفر عية للمقياس و الدرجة الكلية على عينة الدر اسة

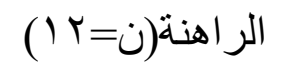

\begin{tabular}{|c|c|c|}
\hline الأتساق الاخلي & المهارة & م \\
\hline $\bar{Q}, 9 \cdot \wedge * *$ & حل المشكلة & $\overline{1}$ \\
\hline ,qrV** & التو اصل & $r$ \\
\hline , Аรษ** & الاستجابة الانفعالية & $r$ \\
\hline , $1 \wedge * *$ & المشاركة الوجدانية & $\varepsilon$ \\
\hline,$\vee \wedge \diamond * *$ & الأدوار الأسرية & 0 \\
\hline 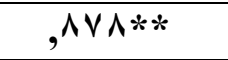 & ضبط السلوك & 7 \\
\hline,$\wedge 9 . * *$ & التواصل & $\mathrm{V}$ \\
\hline 1 & الارجة الكلية & $\wedge$ \\
\hline
\end{tabular}

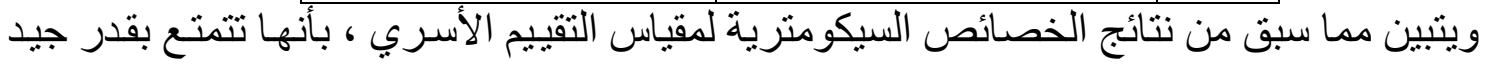

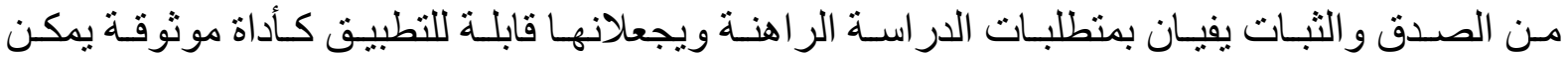
استخدامها لقياس السلوكيات الو الدية الايجابية لاتى الأمهات.

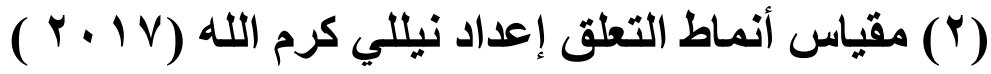

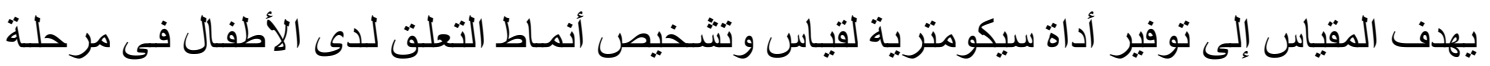

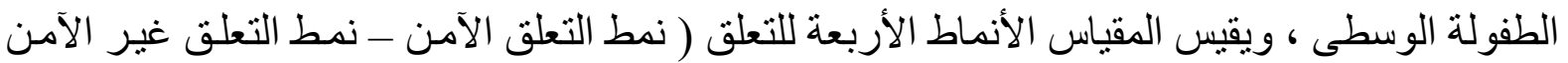

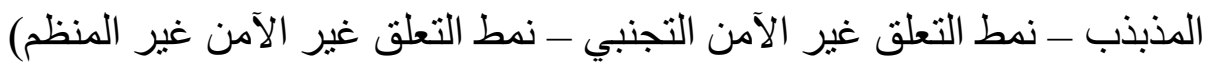

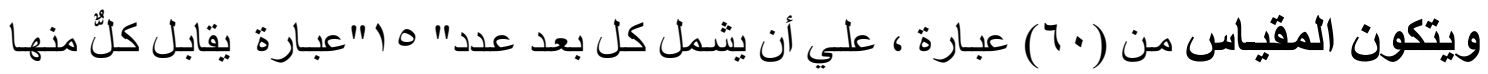

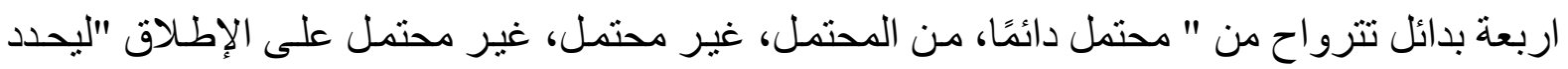

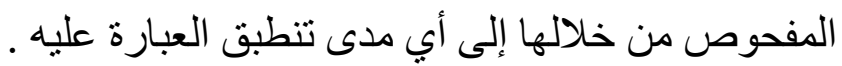

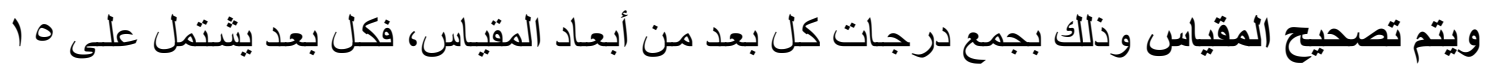

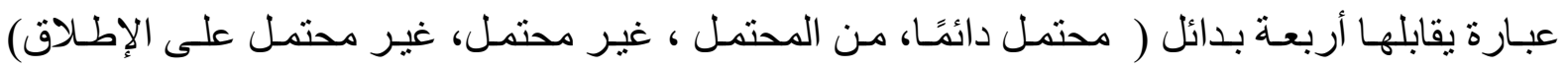

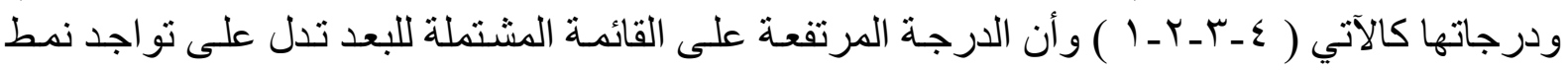

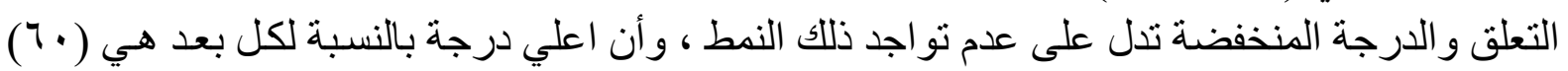

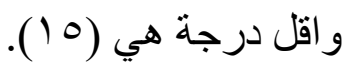

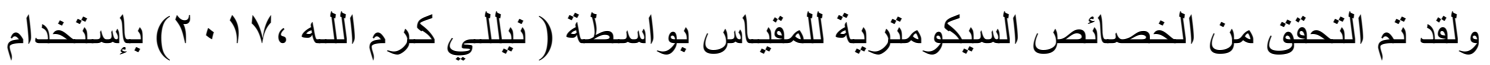

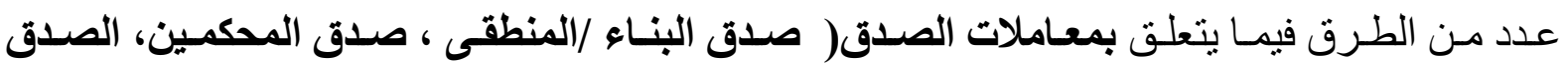

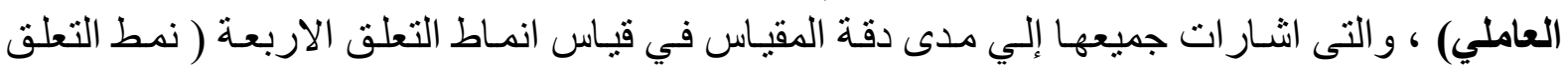

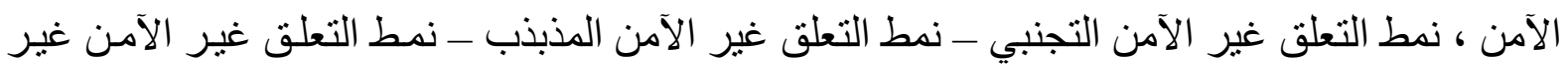

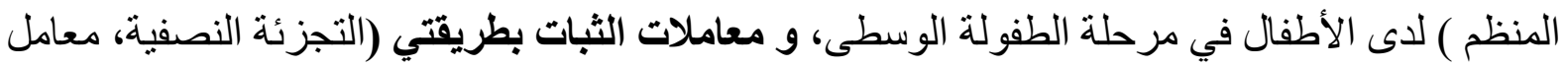

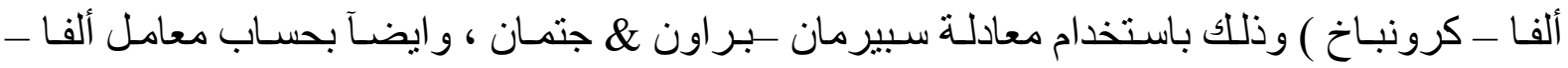




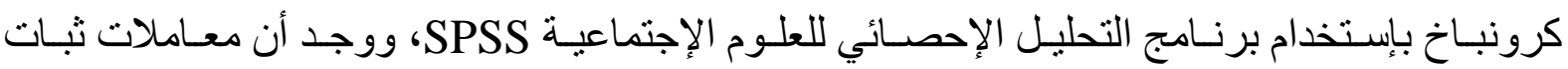

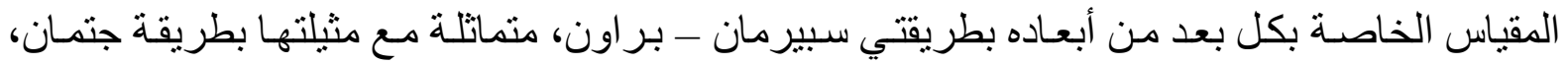

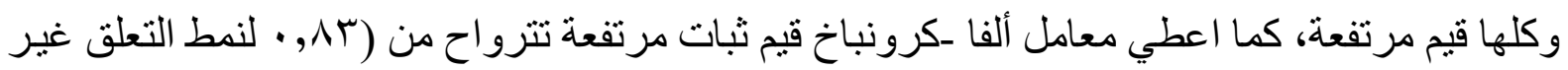

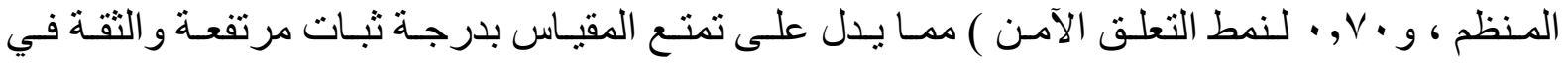

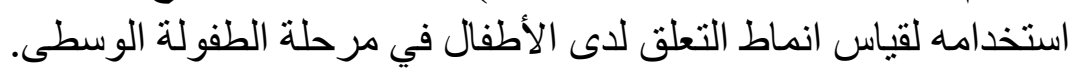

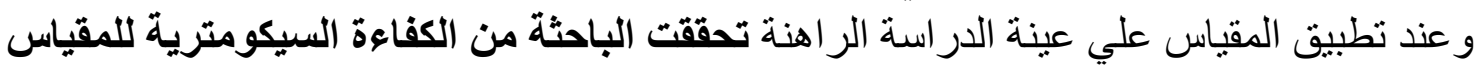

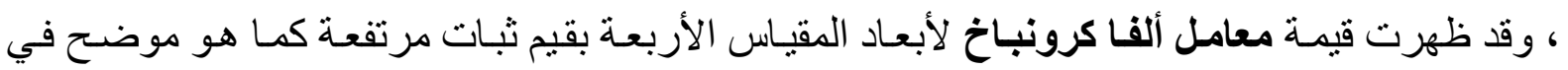

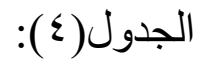

$$
\text { الجدول (乏) ( }
$$

قيم ثبات مقياس أنماط النعلق لعينة الدراسة الر اهنة

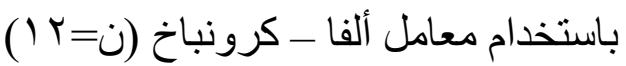

\begin{tabular}{|c|c|c|}
\hline معامل ألفا - كرونباخ & الأبعاد - اد & 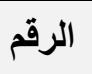 \\
\hline, 71 & نمط التطلق الآمن & 1 \\
\hline,$\pi$ & نمط التطق غير الآمن التجنبي & r \\
\hline, $\mathrm{V} \varepsilon$ & نمط التطق غير الآمن المذبذب & $r$ \\
\hline, $\mathrm{V} \varepsilon$ & نمط التعلق غير الآمن غير المنظم & $\varepsilon$ \\
\hline
\end{tabular}

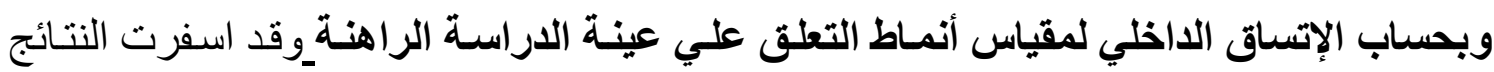

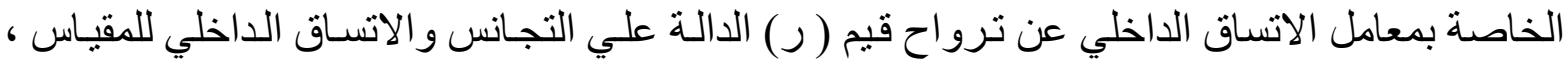

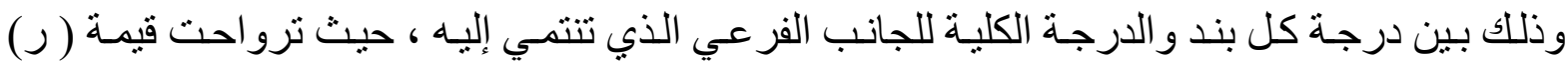

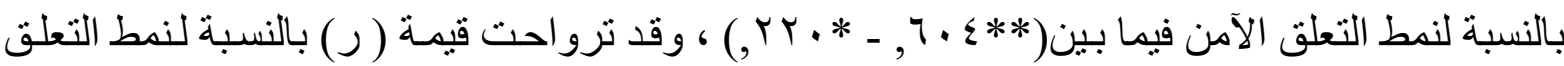

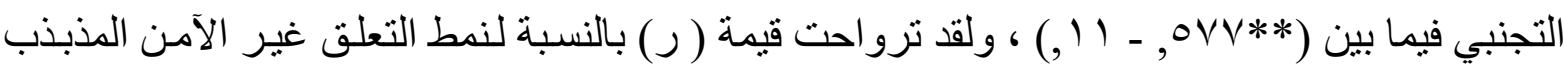

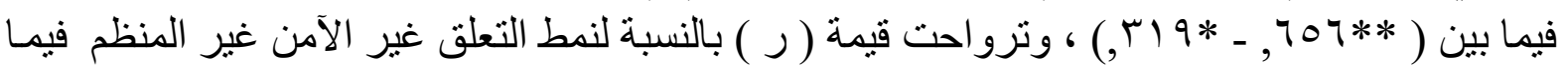

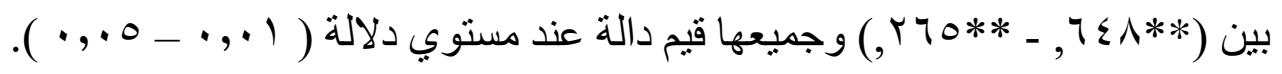

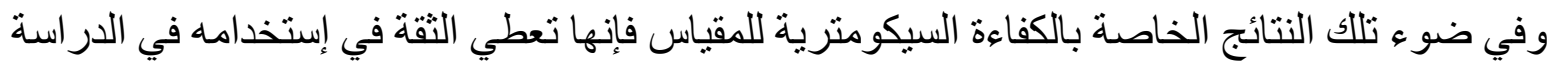

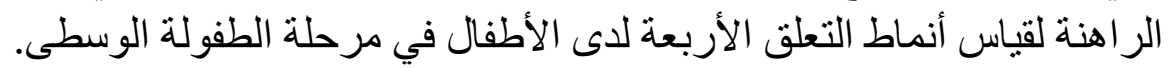

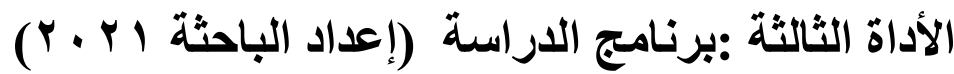

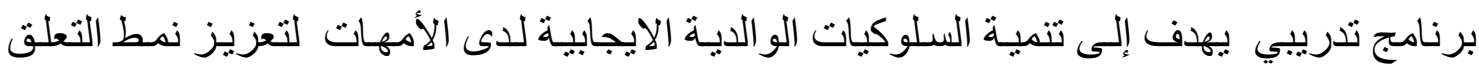

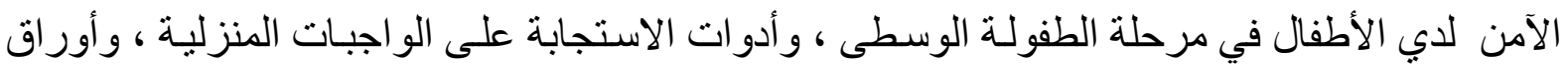

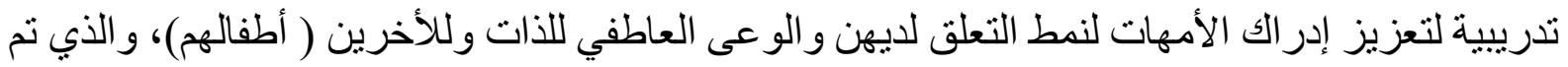

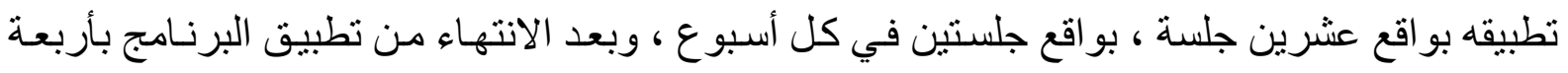

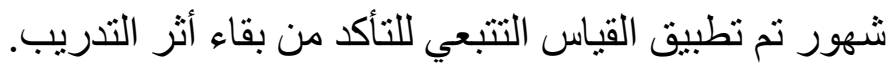

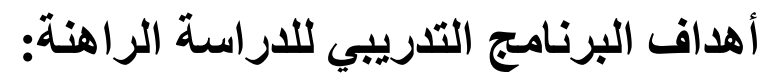

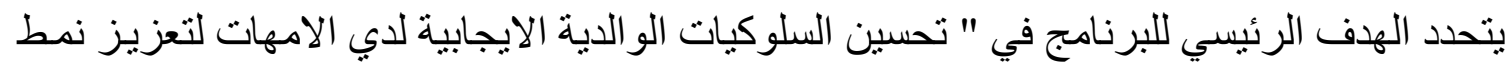
التعلق الآمن لاى الأبناء " الرئيدي 


\section{وتوضح الباحثة توزيع الجلسات في ضوء الوحدات التدريبية الرئيسية للبرنامج فيما يلي :}

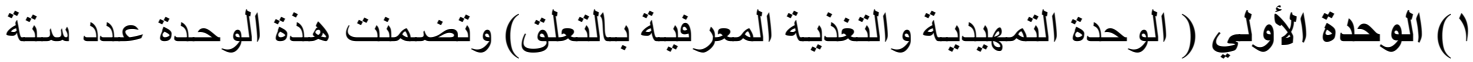

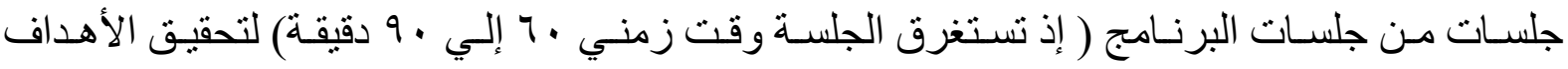

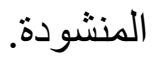

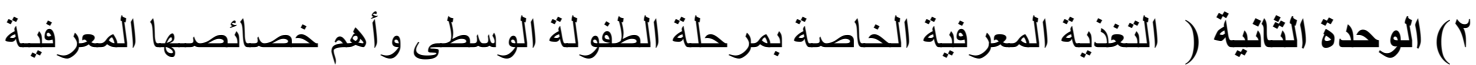

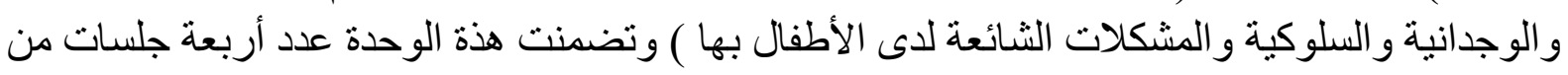
جلسات البرنامج لتحقيق الأهداف المنشودة.

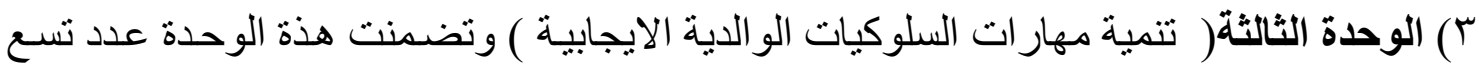
جلسات من جلسات البرنامج لتحقيق الأهداف المنشودة.

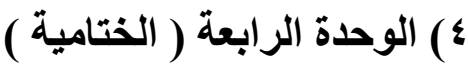

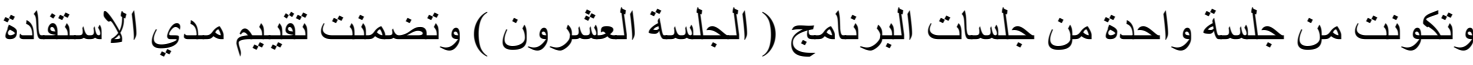

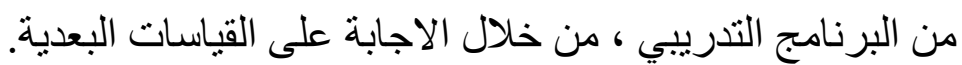

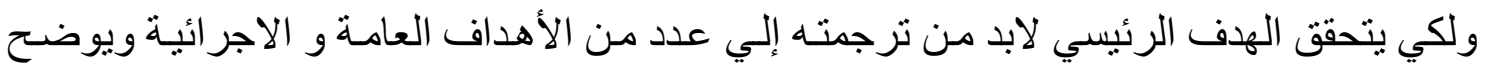

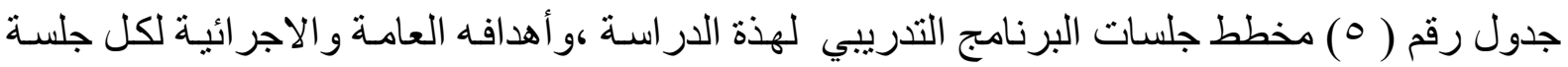
و الفنيات و الأدو ات المستخدمة لتحقيق الأهداف المنشودة للبرنامج كما يلي:

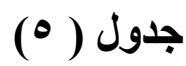

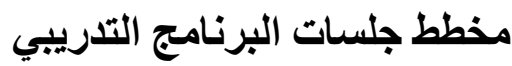

\begin{tabular}{|c|c|c|c|c|c|}
\hline التدريبية المستخدمات والألعابة & المستخدمة القيات & الأهداف الإجرائية & الهدف العام & الموضوع & الجلسة \\
\hline لعبة كسر الجليا & 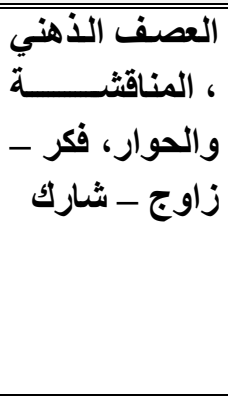 & 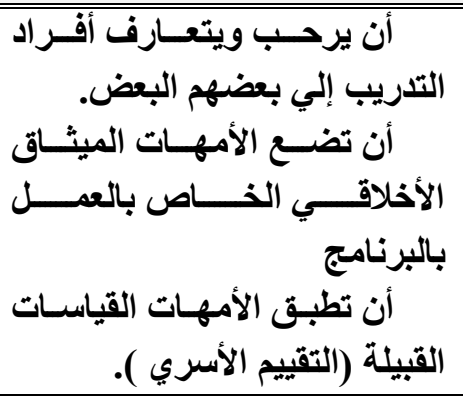 & 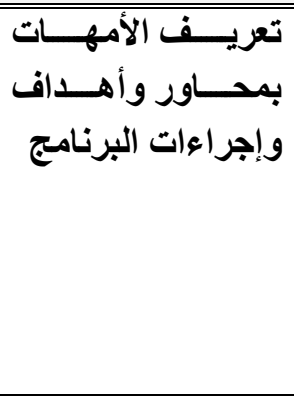 & 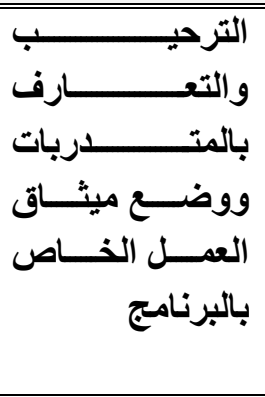 & 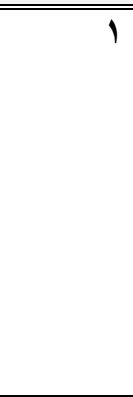 \\
\hline 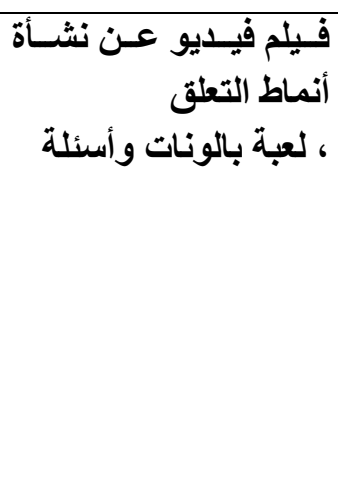 & 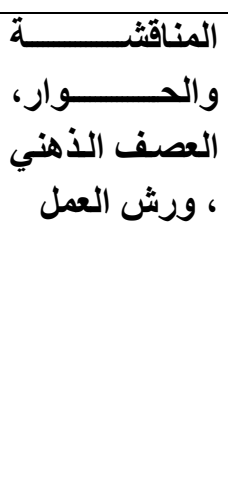 & 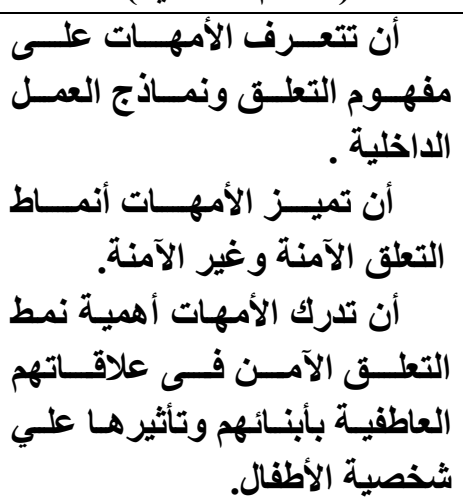 & 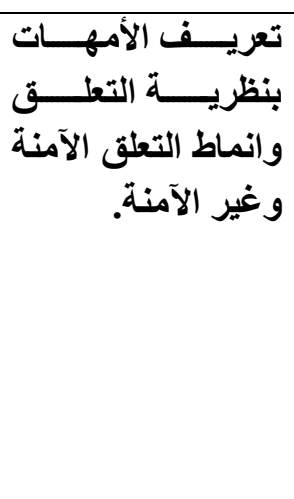 & 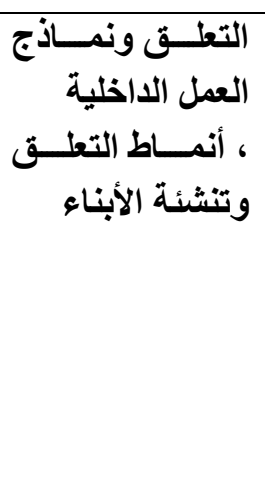 & $\varepsilon-r-r$ \\
\hline
\end{tabular}




\section{تابع جدول (0)}

مخطط جلسات البرنامج التدريبي (ه)

\begin{tabular}{|c|c|c|c|c|c|}
\hline الأدوات والألعاب التدريبية & المستخدمة الفنيات & الأهداف الإجرائية & الهدف العام & الموضوع & الجلسة \\
\hline 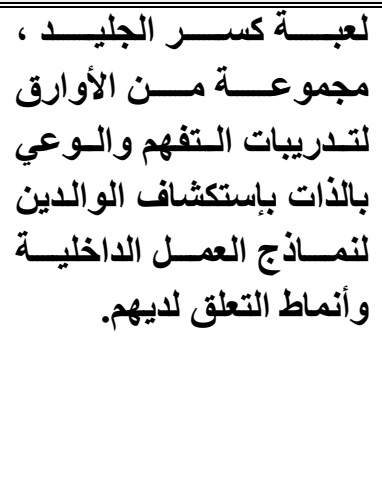 & 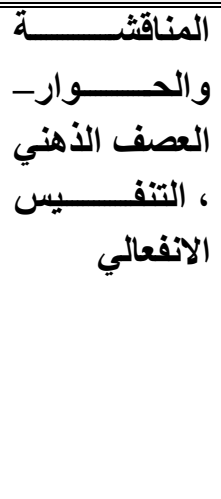 & 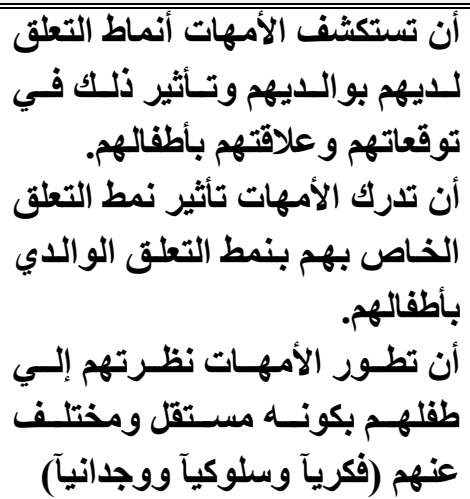 & 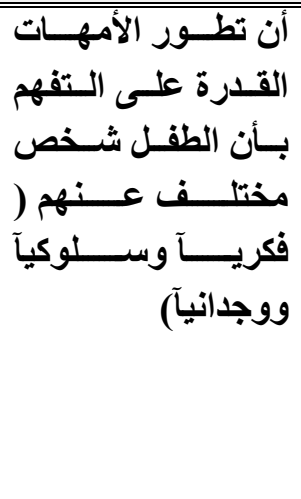 & 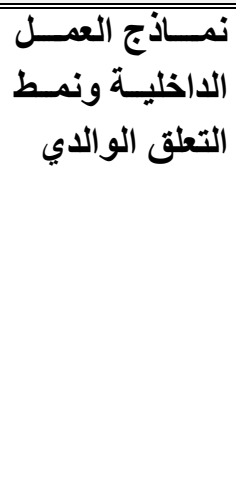 & 7.0 \\
\hline 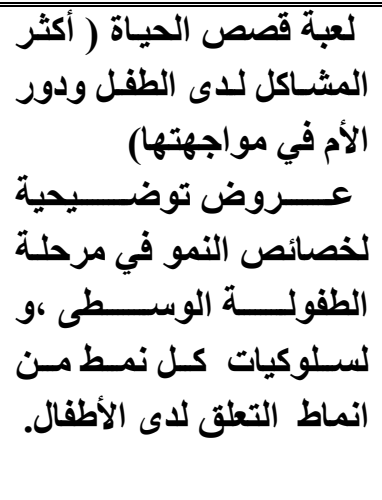 & 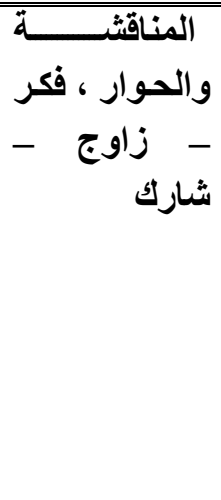 & 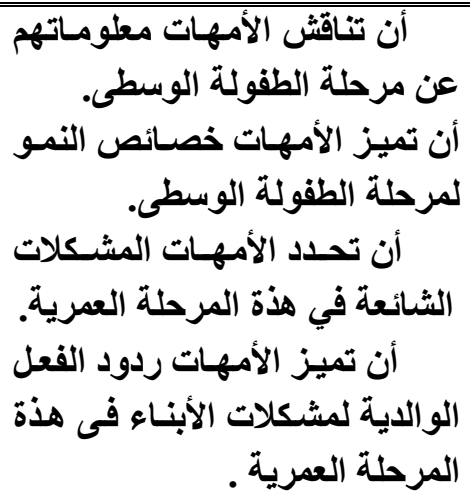 & 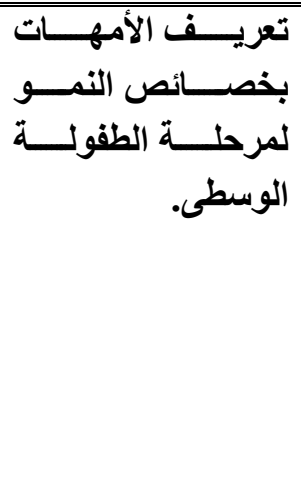 & 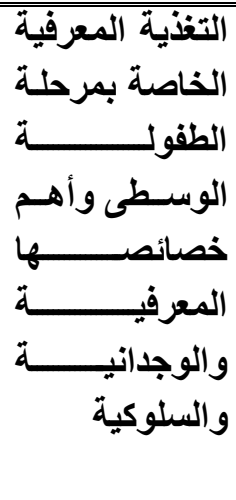 & $\begin{array}{r}-a_{-} \Lambda_{-} V \\
1 .\end{array}$ \\
\hline عـرض توضسيحي لنمـوذج & 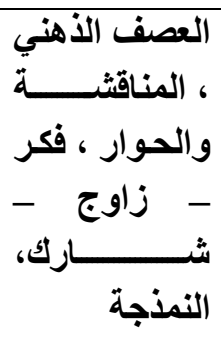 & 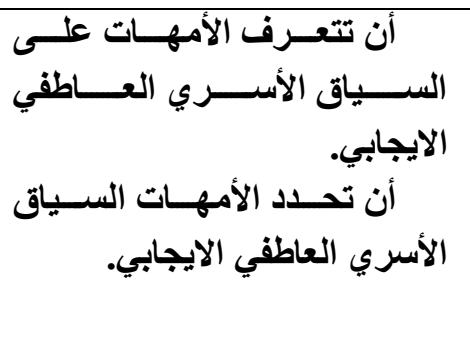 & 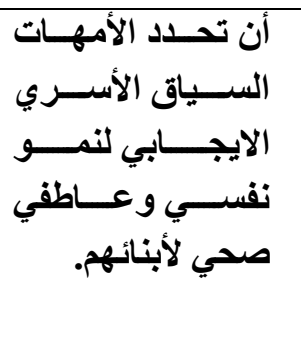 & 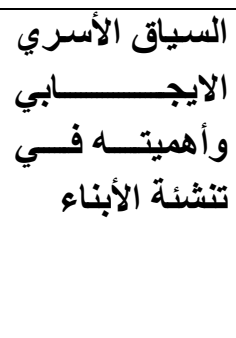 & $|r-1|$ \\
\hline التدريبية مجموعـة مـــن الأوارق & 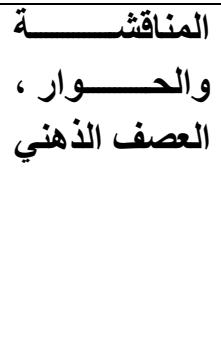 & 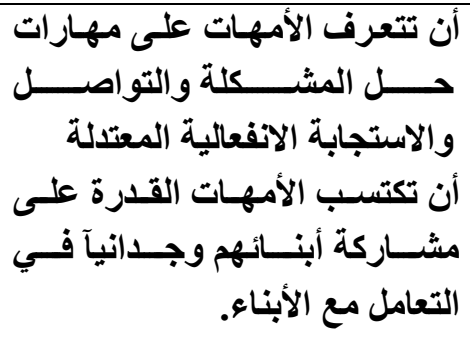 & 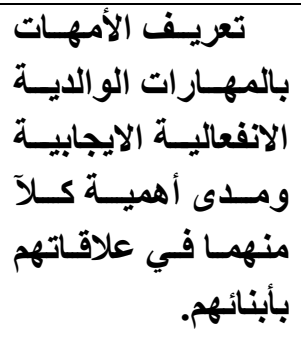 & 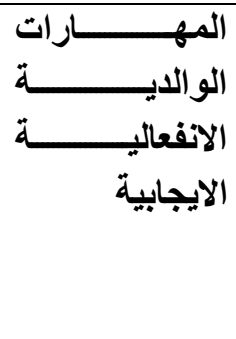 & $1 \leq-14$ \\
\hline ألألعاب مـرح، مجموعة من التدريبية & 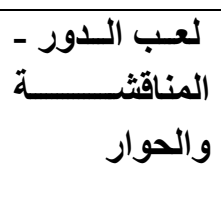 & 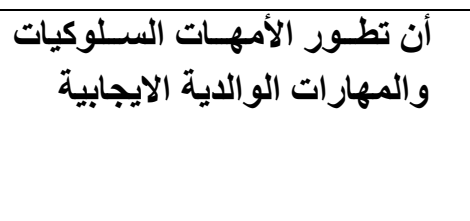 & 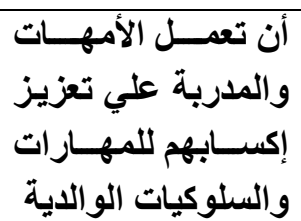 & 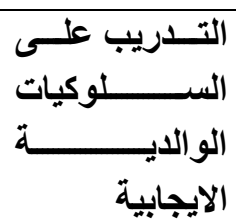 & 10 \\
\hline
\end{tabular}




\section{تابع جدول (0)}

مخطط جلسات البرنامج التدريبي (ه

\begin{tabular}{|c|c|c|c|c|c|}
\hline الأدوات والألعاب التدريبية & المستخدمة & الأهداف الإجرائية & الـهدف العام & الموضوع & الجلسة \\
\hline ضيحي & 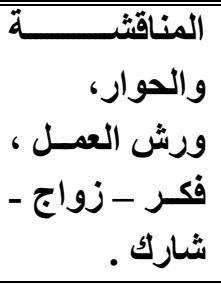 & 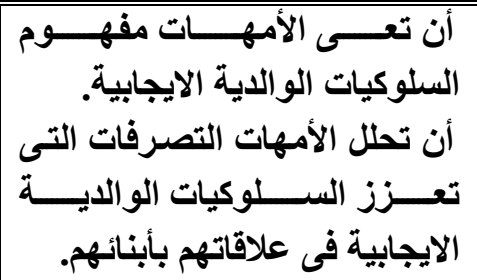 & 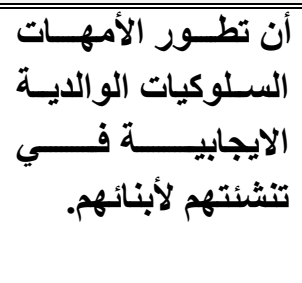 & 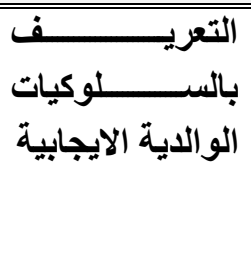 & 17 \\
\hline 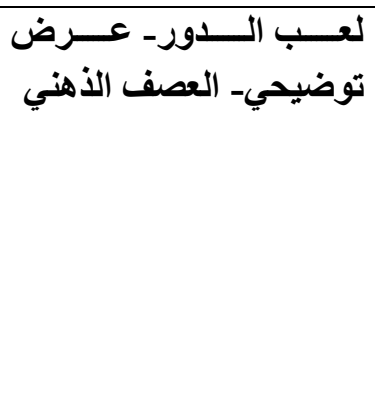 & 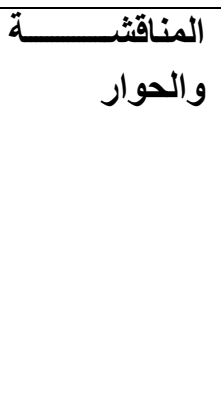 & 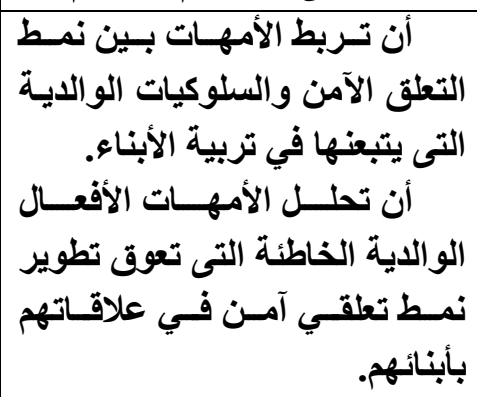 & 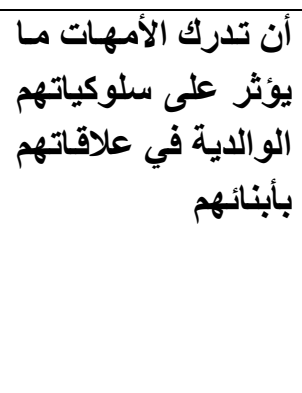 & الطوير السلوكيات الايجة الايجية & IV \\
\hline التدريبية محموعـة مـــن الأوراق & 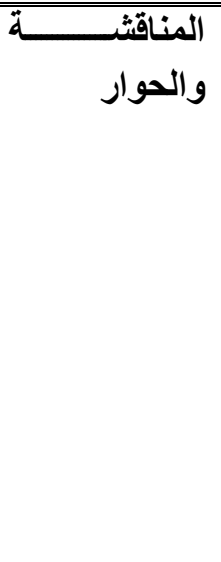 & 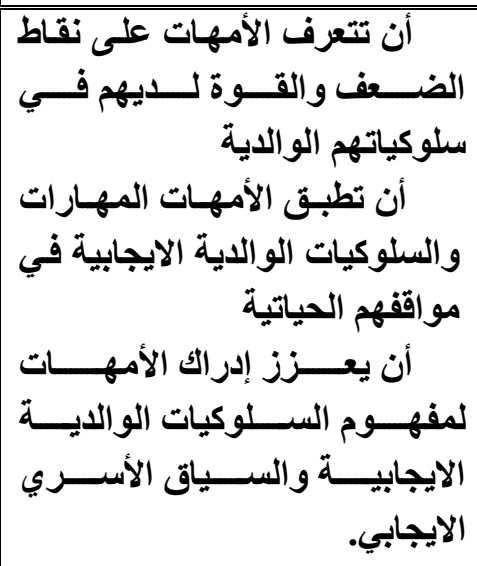 & 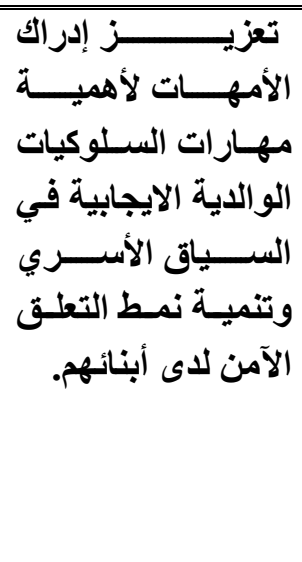 & 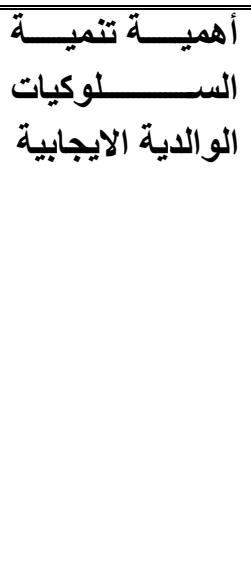 & 19.11 \\
\hline \multicolumn{4}{|c|}{ وللأطفال يتم تطبيق مقياس أنقيق أدوات الداراسة والتقى تتضمن ( مقياس تقييم الأسري ) للأمهات. } & الحتاميه & r. \\
\hline
\end{tabular}

\section{الأساليب الاحصائية}

قد استخدمت الباحثة عددآ من الأساليب الإحصائية التي تتناسب مع طبيعة العينة وفروض الدار اسـة

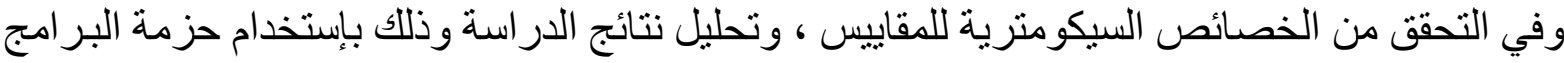
الإحصائية للعلوم الإجتماعية (SPSS) ،ويمكن أن نشير إلي تللك الأساليب على نحو أكثر تفصيلياً كما

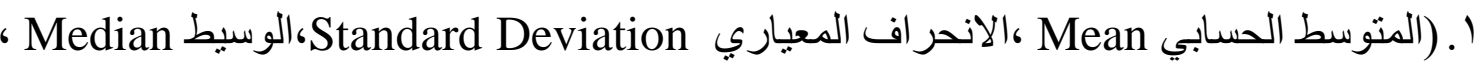

معامل الإلتواء Skewness factor ) للتحقق من الوصف الإحصائي لمتغيير ات الدراسة.

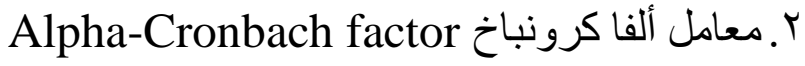
؟. معامل الإرتباط لبيرسون pearson correlation factor لحساب الإتساق الداخلى.

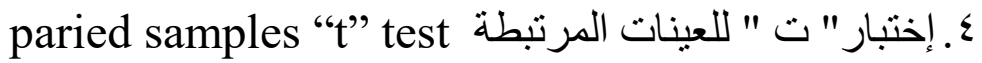




\section{نتائج الاراسة ومناقشاتها}

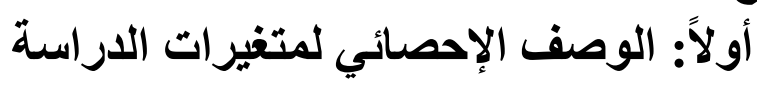

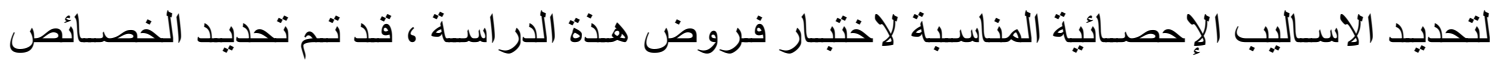

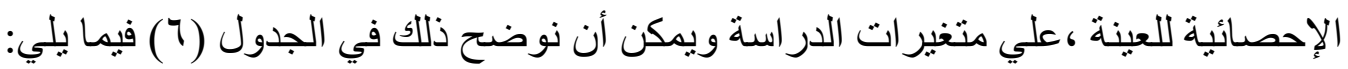

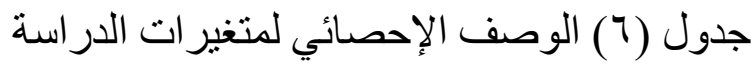

\begin{tabular}{|c|c|c|c|c|c|c|c|}
\hline الألتواء & الإنعرافياري & درجة & درجة & الوسيط & المتوسط & المقياس & م \\
\hline \multicolumn{7}{|c|}{ القياس القبلي لعينة الأمهات ( ن = Y I) } & أولآ \\
\hline \multicolumn{8}{|c|}{ مقياس التقييم الأسري } \\
\hline $1,10 V_{-}$ & r,TVq & 1. & $r r$ & 19 & $1 \Lambda, 7 V$ & حل المشكلة & 1 \\
\hline$\left\{\mid V_{-}\right.$ & $1, r \vee q$ & Yr & $r \wedge$ & $r q, \ldots$ & $r \Delta, \leqslant Y$ & التواصل & $r$ \\
\hline, 291 & $1, r r V$ & 19 & YY & $19,0$. & $r \cdot, I V$ & |لاستجابة الانفعالية & $r$ \\
\hline ,VYT & $r, 99 q$ & 10 & ro & $1 \wedge, \ldots$ & $1 \wedge, 01$ & المشاركة الوجدانية & $\varepsilon$ \\
\hline, 94 & $\varepsilon, \cdot \varepsilon \wedge$ & 19 & rV & $r r, \ldots$ & $r_{1, r_{0}}$ & الأدوار الأسرية & 0 \\
\hline, $1 \cdot 1$ & $1, \leqslant 9 \vee$ & $r \cdot$ & ro & YY,O. & YY,TV & ضبط السلوك & 7 \\
\hline 199 & $r, V V \leq$ & rq & $r \mu$ & $r \cdot, 0$ & $r q, r r$ & المهارات العامةة & $\mathrm{V}$ \\
\hline $1,1 \cdot \varepsilon$ & $\Lambda, V \leq r$ & $1 \leqslant 9$ & IVY & $10 r, \ldots$ & $107, \mu r$ & الارجة الكلية & $\wedge$ \\
\hline \multicolumn{7}{|c|}{ القياس البعدى لعينة الأمهات ( ن= Y I ) } & ثانياً \\
\hline \multicolumn{8}{|c|}{ مقياس التقييم الأسري } \\
\hline, $11 r$ & $\varepsilon, I T V$ & IV & $r v$ & $r_{1}, \cdots$ & $r_{1}, v_{0}$ & حل المشكلة & 1 \\
\hline , $19 Y_{-}$ & r,orq & $r r$ & rq & $r q, \ldots$ & $r q, \cdot 1$ & التواصل & r \\
\hline, Yq० & $r, \varepsilon Y q$ & 11 & ro & $r 1, \ldots$ & $r 1,1$ & | الاستجابة الانفعالية & $r$ \\
\hline, $1 \cdot \varepsilon$ & $r, .00$ & 19 & $r \varepsilon$ & $19, \ldots$ & $19,7 V$ & | المشاركة الوجدانية & $\varepsilon$ \\
\hline , IY & $\varepsilon, V \Psi \wedge$ & $r \cdot$ & $r$ & Yo, O. & $r q, \cdot \Lambda$ & |الأدوار الأسرية & $\theta$ \\
\hline,$\leqslant \vee \leqslant$ & $0, \cdot 1 \mathrm{~V}$ & 19 & $r r$ & $r \varepsilon, \ldots$ & $r \leqslant, 9 Y$ & ضبط السلوك & 7 \\
\hline,$r \cdot r$ & 4,797 & rV & $r q$ & $r q, \ldots$ & $r \cdot, v \theta$ & | المهارات العامـة & $\mathrm{v}$ \\
\hline , 974 & 19,894 & $1 \leqslant 9$ & $r \cdot r$ & $17 \varepsilon, \ldots$ & $I V \cdot r r$ & | الارجة الكلية & $\Lambda$ \\
\hline \multicolumn{7}{|c|}{ القياس التتبعي لعينة الامهات ( ن= • 1 ) } & ثَالثاً \\
\hline \multicolumn{8}{|c|}{ مقياس التقييم الاسري } \\
\hline,$q \leq r_{-}$ & r, Trq & 19 & ro & $r r, \ldots$ & Y1,0. & حل المشكلة & 1 \\
\hline,$\cdots$ & 1,100 & Yo & rq & $r v, \ldots$ & $r v, \ldots$ & التواصل & $r$ \\
\hline,$\cdots v_{-}$ & Y,779 & rr & $r$ r. & Y४,०. & $r q, r \cdot$ & الاستجابة الانفعالية & $r$ \\
\hline IrV & $1,7 \leq V$ & 19 & $Y \leq$ & YI,0. & $Y_{1}, \varepsilon \cdot$ & |المشاركة الوجدانية & $\varepsilon$ \\
\hline
\end{tabular}

تابع جدول (†) الوصف الإحصائي لمتغيرات الدراسة 
فاعلية برنامج تدريبي لتنمية السلوكيات الوالدية الايجابية وأثره في تعزيز نمط التعلق الآمن لدي الأبناء

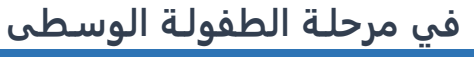

\begin{tabular}{|c|c|c|c|c|c|c|c|}
\hline الألتواء معامل & الإنحراف & درجة & العلى & الوسيط & المتوسط & المقياس & 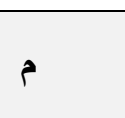 \\
\hline , एq & $1, V q r$ & 11 & rT & $19,0$. & $r \cdot, 1$. & الأدوار الأسرية & 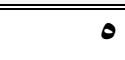 \\
\hline , AIV & 1,090 & rr & rV & $r \leqslant, \ldots$ & $r r, q$. & ضبط السلوك & 7 \\
\hline , ^ミ1_ & $r, I \vee \wedge$ & Yq & $r \varepsilon$ & $r r, \ldots$ & $r_{1,1 .}$ & المهارات العامةة & 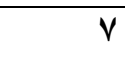 \\
\hline , rYA_ & $9,0 \wedge 1$ & 101 & $1 \wedge r$ & $I V Y, 0$. & IVI, r. & الارجة الكلية & $\Lambda$ \\
\hline \multicolumn{7}{|c|}{ القياس القبلي لعينة الأطفال (ن= r I I) } & رابعاً \\
\hline \multicolumn{8}{|c|}{ مقياس أنماط التعلق } \\
\hline $1,1 \cdot-$ & $\theta, \wedge \wedge \theta$ & $r r$ & Or & $\varepsilon V, \ldots$ & $\{0,9 r$ & نمط التعلق الآمن & 1 \\
\hline , OYI- & $r, \wedge q 0$ & $r V$ & $r q$ & $r \leqslant, 0$. & $r r, \varepsilon r$ & التمط التعلق غير الآمن & $r$ \\
\hline , $71 \cdot-$ & $0, r \leqslant \Lambda$ & rr & $r v$ & $r, \ldots$ & $r \cdot, 0 \Lambda$ & المذبذ التعلق غير الآمن & $r$ \\
\hline,$\cdot \wedge{ }_{-}$ & $\Lambda, \otimes \vee \varepsilon$ & 10 & $\varepsilon r$ & $r \wedge, 0$. & $r \wedge, r r$ & غير المنظم التعلى غير الآمن & $\varepsilon$ \\
\hline \multicolumn{7}{|c|}{ القياس البعدي لعينة الأطفال ( ن= Y I ) } & خامساً \\
\hline \multicolumn{8}{|c|}{ مقياس أنماط التعلق } \\
\hline, 901 & $\varepsilon, M 17$ & $\leqslant 7$ & 89 & $\varepsilon \wedge, \ldots$ & $0 \cdot, \cdot 1$ & نمط التعلق الآمن & 1 \\
\hline (Y & $v, V 0$. & 10 & $\varepsilon \varepsilon$ & $r \wedge, 0$. & $r q, r r$ & التمط التعلق غير الآمن & r \\
\hline,$V \vee \varepsilon_{-}$ & $7,1 \leqslant r$ & 10 & $\mu \wedge$ & $r q, \ldots$ & rq,0. & المذط التعلق غير الآمن & $r$ \\
\hline,$r \leqslant \varepsilon$ & 1,707 & 10 & $\varepsilon \varepsilon$ & $r \wedge, 0$. & $r \wedge, V_{0}$ & غير المنظم غير التعلى غير & $\varepsilon$ \\
\hline \multicolumn{7}{|c|}{ القياس التتبعي لعينة الاطفال ( ن=• (1) } & سادساً \\
\hline \multicolumn{8}{|c|}{ مقياس انماط التعلق } \\
\hline,$\cdot V \cdot-$ & $r, 10$. & $\leqslant \leqslant$ & 0. & $\leqslant V, 0$. & $\leqslant V, Y$ & نمط التعلق الآمن & 1 \\
\hline, $0 \leq$ & $\varepsilon,\{9 Y$ & $r r$ & $r \wedge$ & $r \cdot, \cdots$ & $r_{1, r .}$ & التمط التعلق غير الآمن & $r$ \\
\hline,$\wedge \leqslant 1-$ & $r, Y, r$ & rr & rY & $r q, \ldots$ & $r \wedge, 1$. & المذبذب التعلق غير الآمن & $r$ \\
\hline $1,1 \cdot 1$ & $7, v \leq 9$ & r. & $\leqslant \varepsilon$ & $Y \wedge, 0$. & $r q, \ldots$ & غير المنظم التعلق غير الآمن & $\varepsilon$ \\
\hline
\end{tabular}

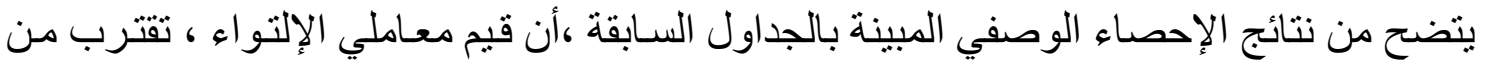

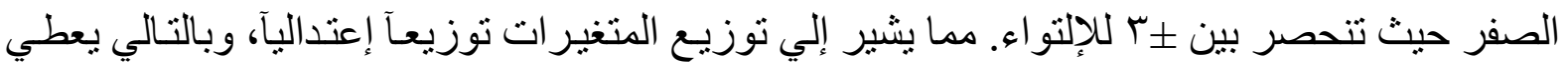
الثقة في إستخدام الإحصاء البار اميتري. 
"توجد فروق بين متوسطى درجات القياس القبلي و البعدي على مقياس التقييم الأسري للى عينة الدارسـة

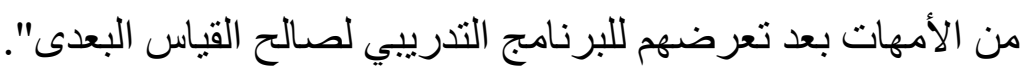

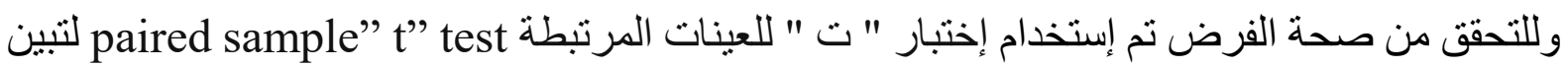

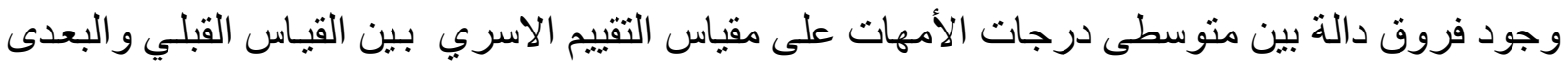
ويوضح الجدول رقم ( V ) نتائج الأختبار و الدلالة الإحصائية كما يلي:

$$
\text { جدول (V) ع (V) }
$$

نتائج إختبار" ت " لدرجات الأمهات على مقياس التقييم الأسري بين القياسيين القبلي و البعدي

$$
\text { ( إن (1) }
$$

\begin{tabular}{|c|c|c|c|c|c|c|c|}
\hline الاحصائية & "تيمة" & الإنحراف اللفرق & متوسط الفرق & المتوسط & \multicolumn{2}{|c|}{ المقاييس } & r \\
\hline \multirow{2}{*}{, 10} & \multirow{2}{*}{$\Upsilon, \wedge \wedge \varepsilon$} & \multirow{2}{*}{$r, V \cdot \varepsilon$} & \multirow{2}{*}{$r, \cdot \wedge r$} & $11,7 V$ & قياس قبلي & \multirow{2}{*}{ حل المشكلة } & \multirow[t]{2}{*}{1} \\
\hline & & & & Y I, Vo & قياس بعدى & & \\
\hline \multirow{2}{*}{, $\{7$} & \multirow{2}{*}{, vqr } & \multirow{2}{*}{$r, \cdot r_{0}$} & \multirow{2}{*}{ ( } & $r Q, \varepsilon Y$ & قياس قبلي & \multirow{2}{*}{ التواصل } & \multirow[t]{2}{*}{$r$} \\
\hline & & & & $r q, \cdot \Lambda$ & قياس بعدي & & \\
\hline \multirow{2}{*}{, 171} & \multirow{2}{*}{$1, \leqslant \vee 7$} & \multirow{2}{*}{$r, 101$} & \multirow{2}{*}{, ११V } & $r \cdot, I V$ & قياس قبلي & \multirow{2}{*}{ الاستجابة الانفعالية } & \multirow[t]{2}{*}{$r$} \\
\hline & & & & $Y 1, \cdot \Lambda$ & قياس بعدي & & \\
\hline \multirow{2}{*}{,$\cdot \leq V$} & \multirow{2}{*}{$r, r r \Lambda$} & \multirow{2}{*}{$1,7 \vee 7$} & \multirow{2}{*}{$1, \cdot \Lambda r$} & $\mid \wedge, 01$ & قياس قبلي & \multirow{2}{*}{ المشاركة الوجدانية } & \multirow[t]{2}{*}{$\varepsilon$} \\
\hline & & & & $19,7 V$ & قياس بعدي & & \\
\hline \multirow{2}{*}{,$\cdot r q$} & \multirow{2}{*}{$r, 0 . q$} & \multirow{2}{*}{$Y, T \vee Y$} & \multirow{2}{*}{$\varepsilon, \wedge \mu r$} & YI, Yo & قياس قبلي & \multirow{2}{*}{ الادوار الأسرية } & \multirow[t]{2}{*}{0} \\
\hline & & & & $Y q, \cdot 1$ & قياس بعدي & & \\
\hline \multirow{2}{*}{,$\wedge \wedge$} & \multirow{2}{*}{$1, \wedge \vee \leq$} & \multirow{2}{*}{$\varepsilon, 109$} & \multirow{2}{*}{ Y, YO. } & $Y Y, T V$ & قياس قبلي & \multirow{2}{*}{ ضبط السلوك } & \multirow[t]{2}{*}{9} \\
\hline & & & & $r \varepsilon, 9 r$ & قياس بعدي & & \\
\hline & 1.1 .9 & $r y, r$ & $1 \leqslant 1 y$ & $r q, r r$ & قياس قبلي & الهـ & V \\
\hline $9^{\circ}$ & $1, x \cdot 4$ & $1,1,1$ & 1,218 & $r \cdot, v_{0}$ & قياس بعدي & أحهو) & \\
\hline & س & $1 r \mu \Lambda \Lambda$ & 1 & $107, .1$ & قياس قبلي & الارجة الكلية & $\Lambda$ \\
\hline & 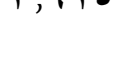 & אוגוריו & 16,0 & $I V \cdot, r T$ & قياس بعدي & للتقييم الاسري & \\
\hline
\end{tabular}

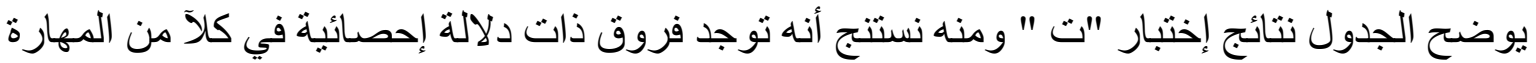

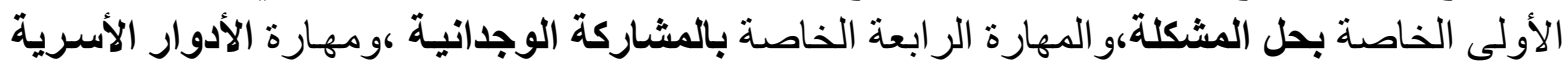

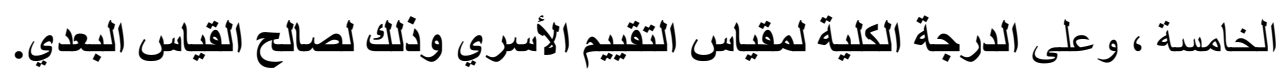

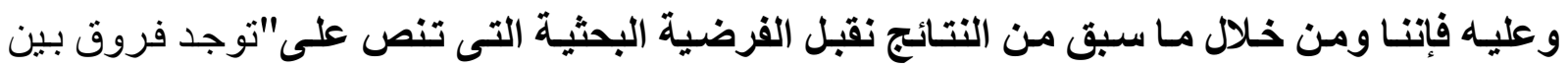

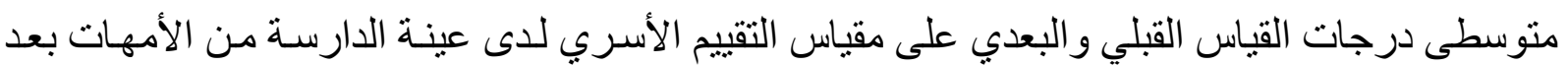
تعرضهم للبرنامج التنريبي لصالح القياس الفياس البعدى".

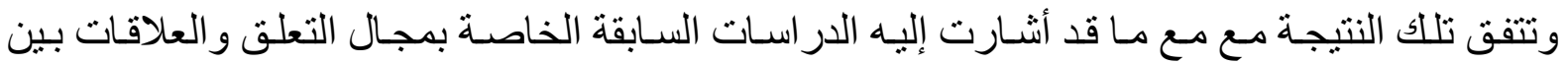

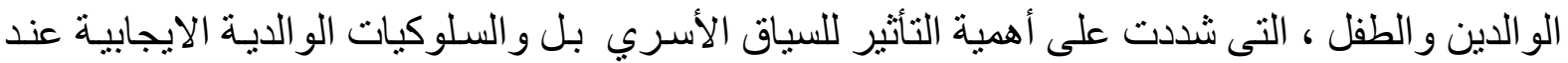
العمل على تعزيز علاقات التعلق بين الأطفال وو الديهم.

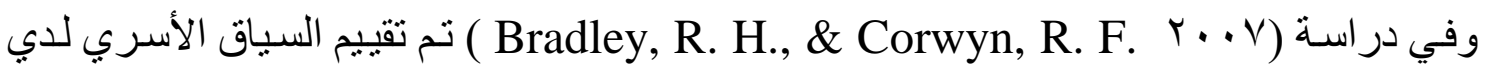

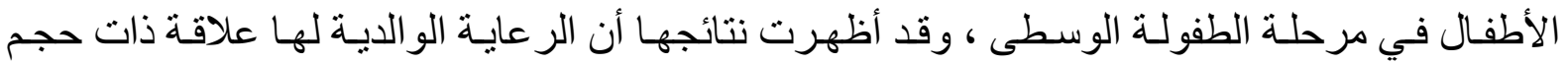




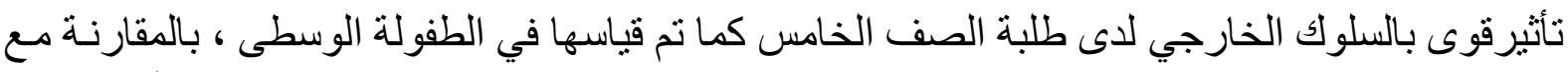

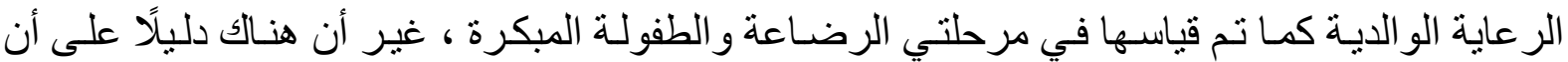

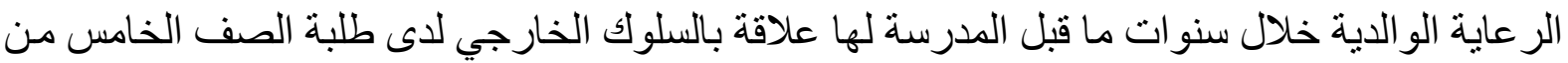
خلال الرعاية الو الدية اللاحقة وضبط الذات الذات.

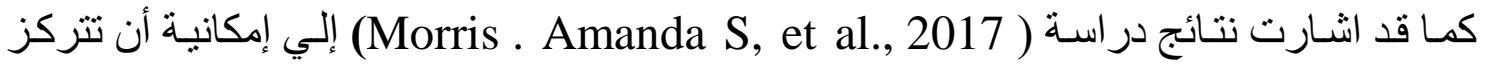

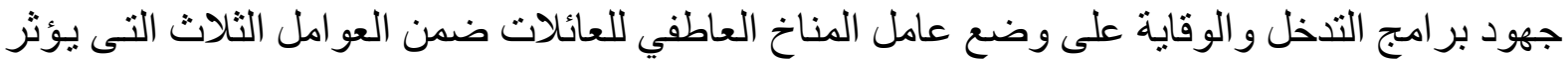

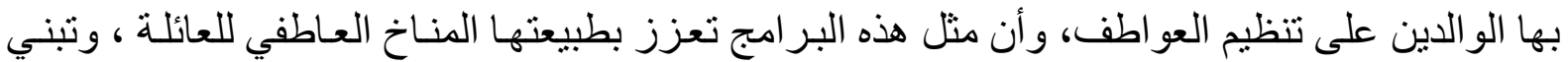

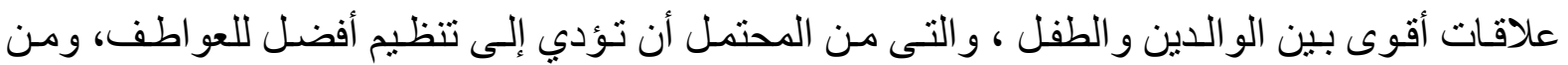

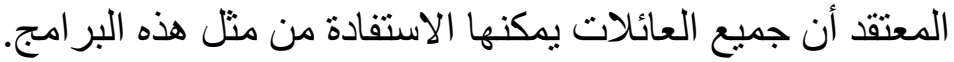

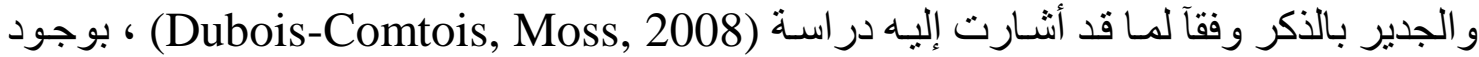

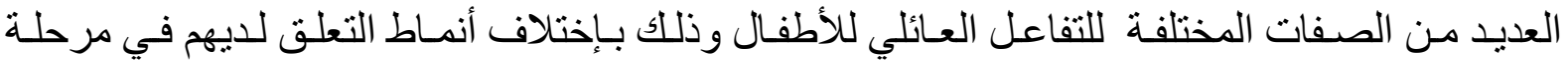

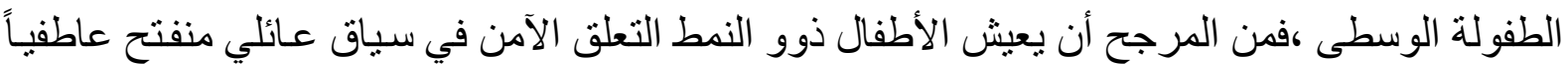

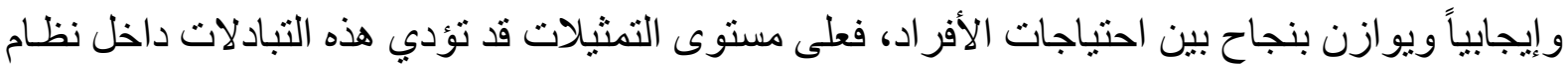

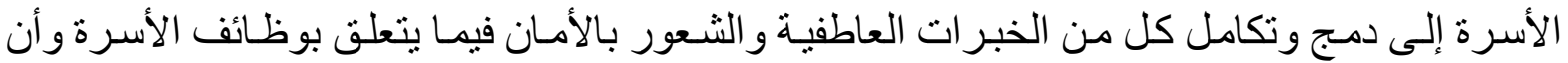

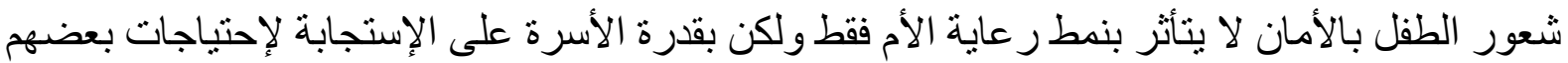

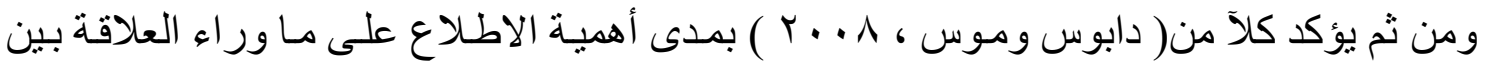

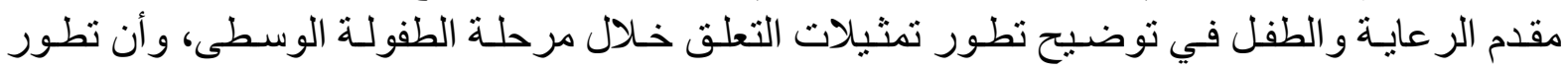

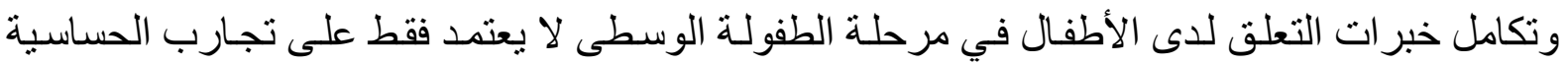

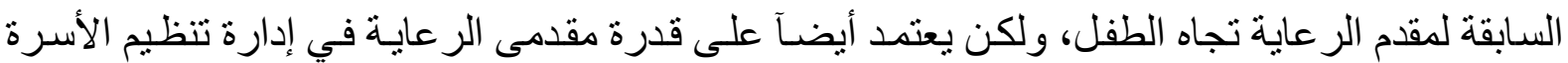

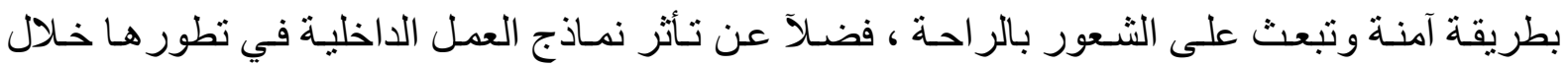

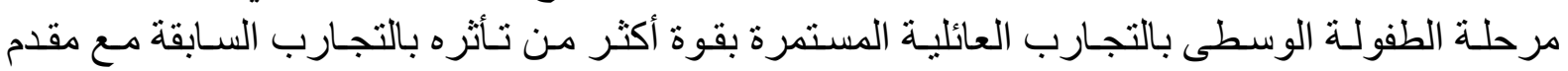

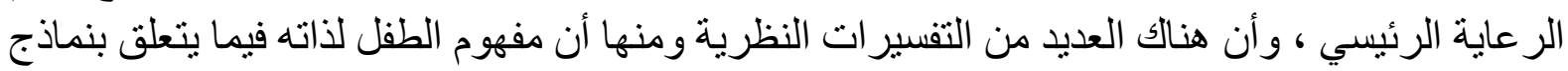
التعلق لديه يتضمن بشكل كامل التفاعلات العائلية.

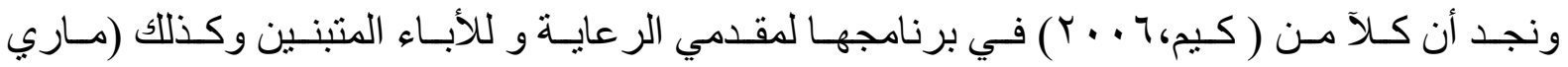

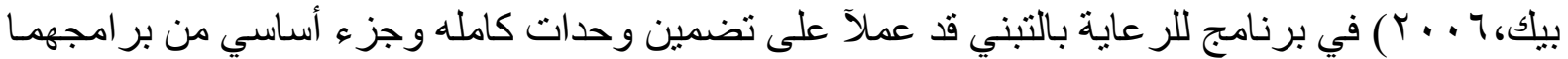

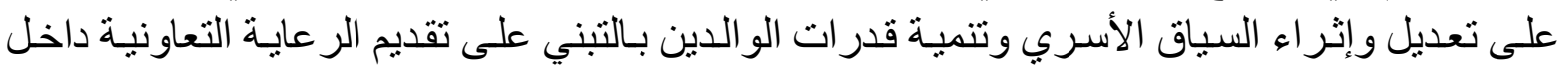
الأسرة من أجل تعزيز علاقات التعل التعلق الآمنة مع أطفالهم.

\section{ثالثاً: إختبار صحة الفرض الثاني ومناقشة نتائجه والذي ينص على الثَ}

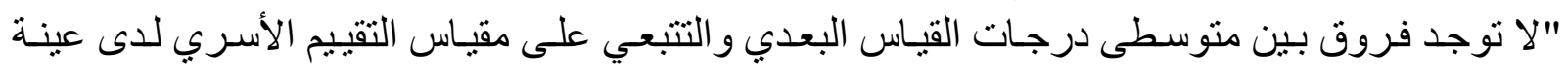

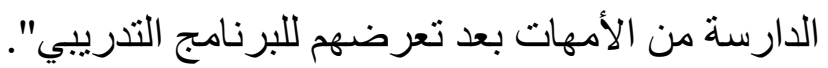

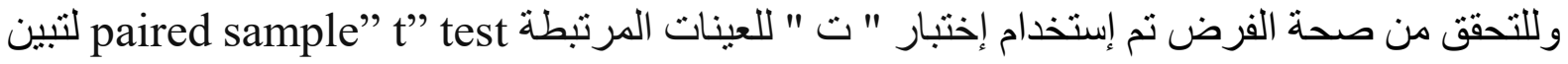

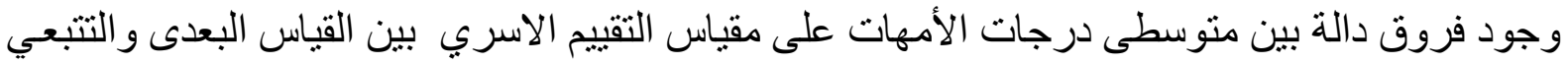

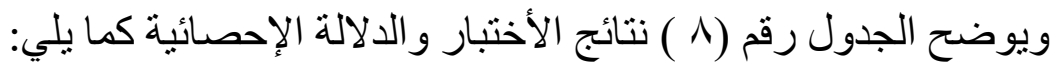

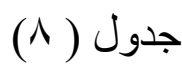

نتائج إختبار" ت " لدرجات الأمهات على مقياس التقييم الأسري بين القياسيين البعدي و التتبعي 


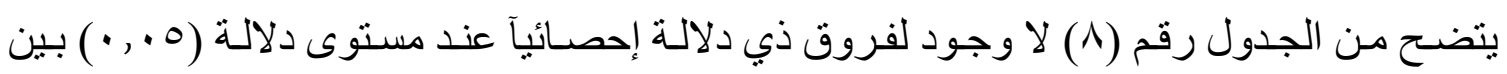

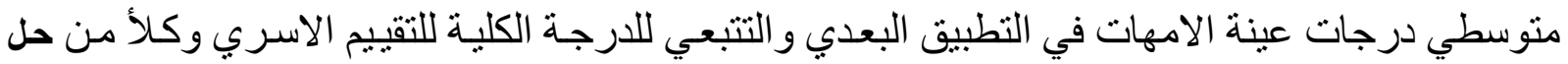

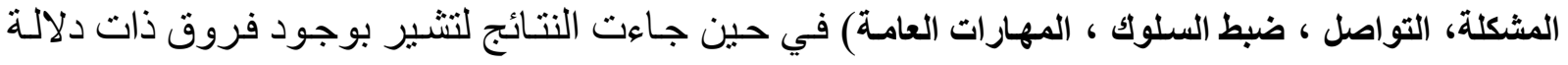

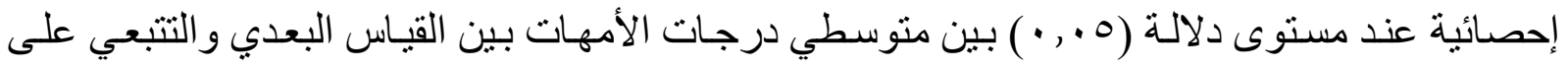

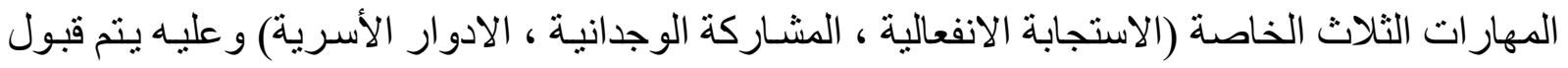

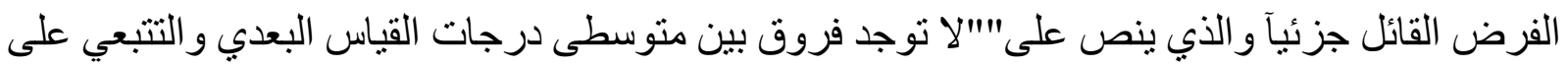

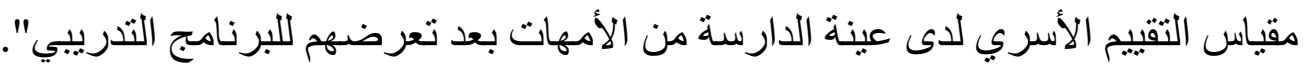

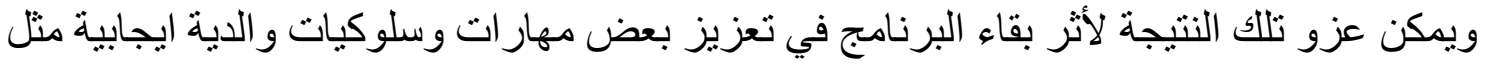

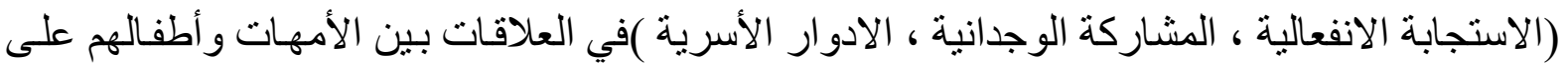

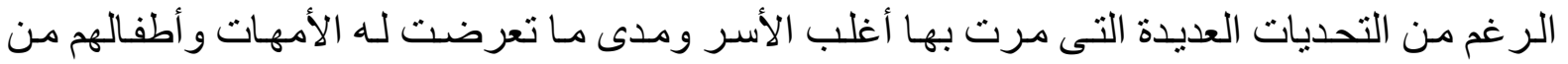

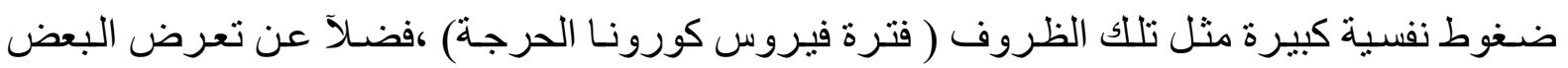

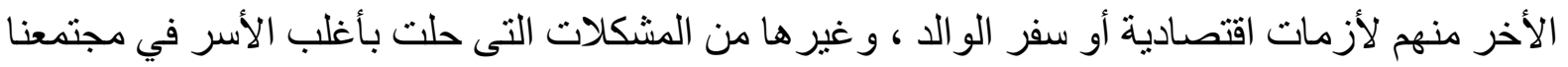

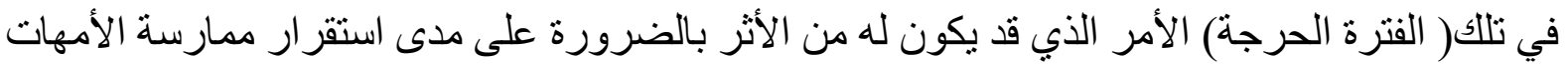
لمثل تلك السلوكيات الايجابية في تفاعلتهم داخل الأسرة.

\section{رابعآ: إختبار صحة الفرض الثالث ومناقشة نتائجه والذي ينص على}


"توجد فروق في مسنتوى التعلق الآمـن لدى الأطفال- بعد تعرض الأمهات للإبرنـامج التـدريبي- بين

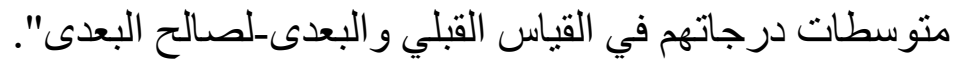

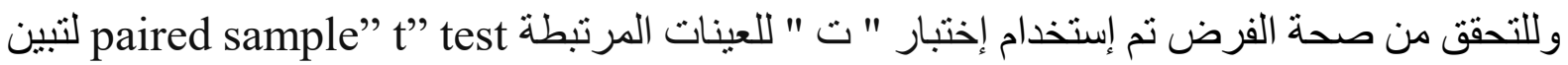

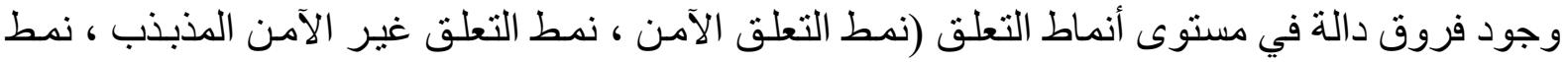

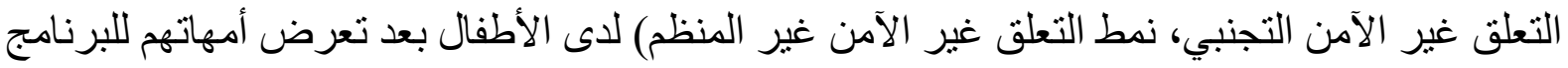

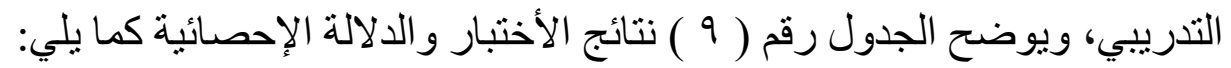

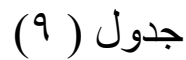

نتائج إختبار " ت " لعينة الأطفال في أنماط التعلق بين القياسيين القبلي و البعدي( ن= Y I )

\begin{tabular}{|c|c|c|c|c|}
\hline الاحصائية & "تيمة & الإلعرياري & متوسط الفرق & أنماط التعلق \\
\hline,$\cdot 1 \leqslant$ & $r, q 10$ & $\varepsilon, 901$ & $\varepsilon, 17 V$ & نمط التعلق الآمن \\
\hline, $7+1$ & orq,- & $7,97$. & $1, \cdot \wedge r_{-}$ & نمط التعلق غير الآمن المذبذب \\
\hline, 97 & 1,119 & $\vee, \vee \vee 0$ & $\varepsilon, \wedge \mu_{-}$ & نمط التعلق غير الآمن التجنبي \\
\hline , & ivo, & $\Lambda, r \times q$ & \&IV & نمط التعلق غير الآمن غير المنظم \\
\hline
\end{tabular}

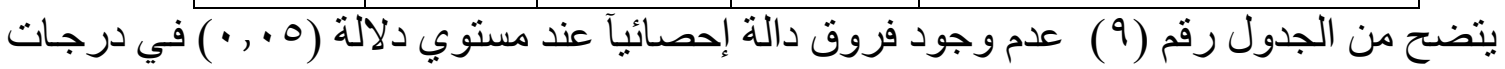

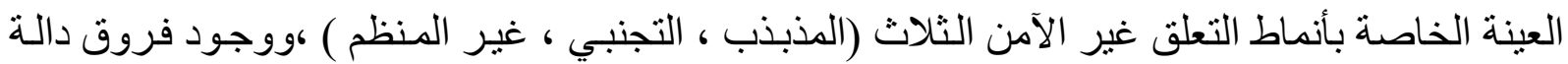

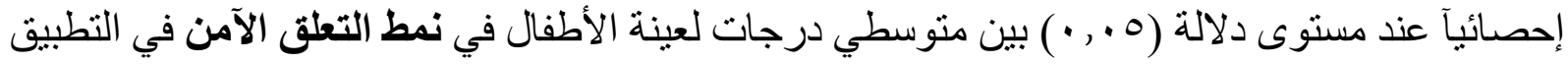

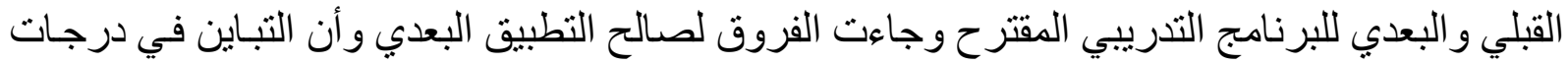

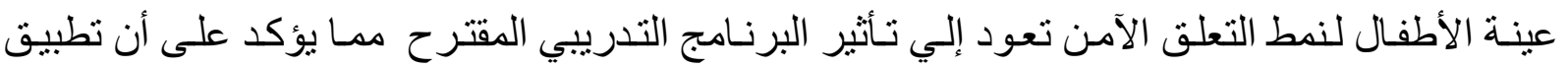

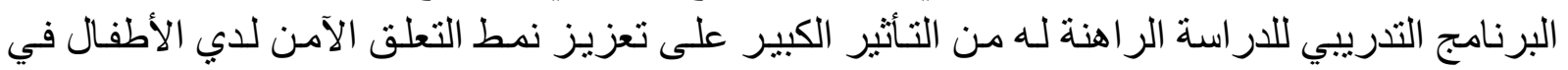

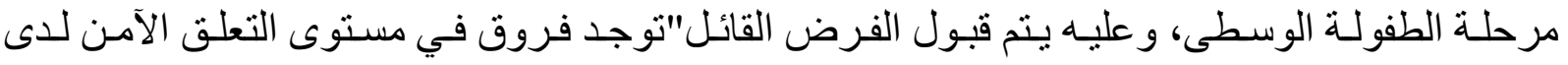

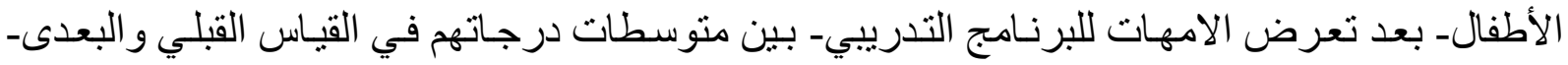

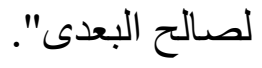

وتعزو تللك النتيجة إلي إهتمام الباحثة في تصميمها للبرنامج المقترح للار اسة الرهنة على التى إستخدام

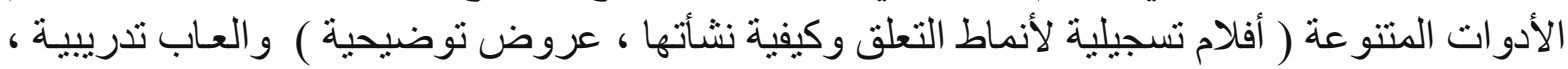

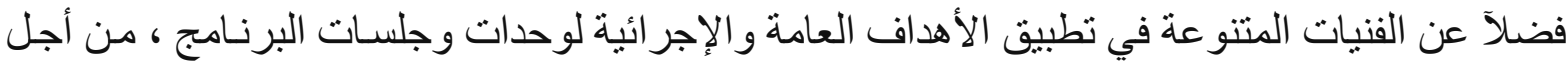

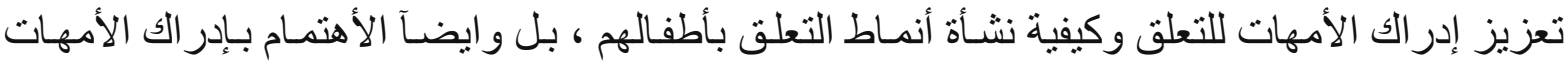

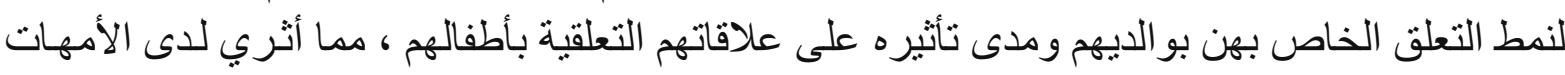

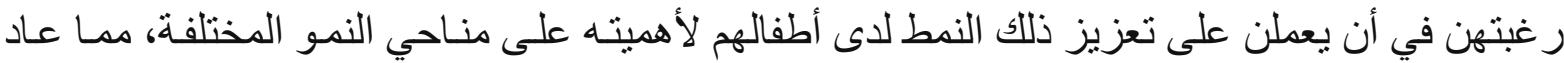

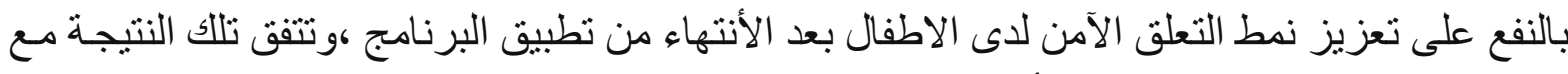

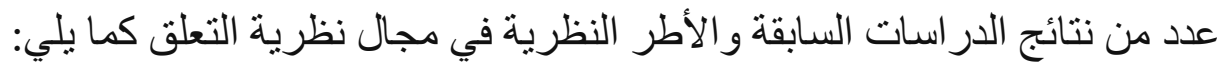

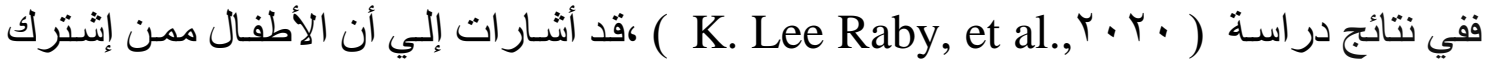

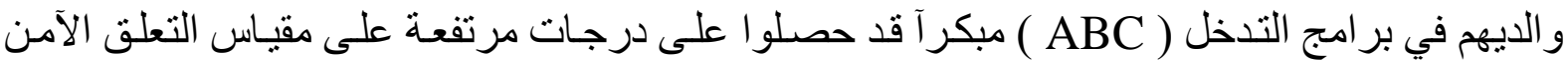

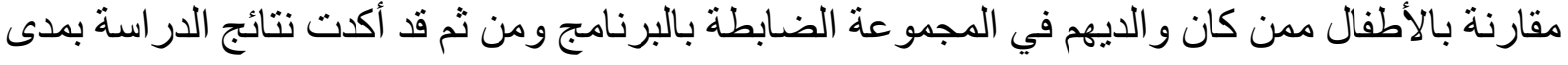

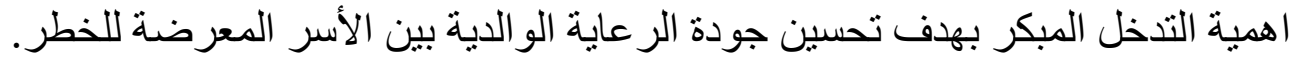




\section{خامسآ: إختبار صحة الفرض الرابع ومناقشة نتائجه}

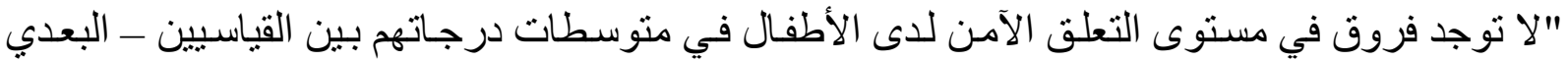

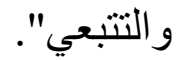

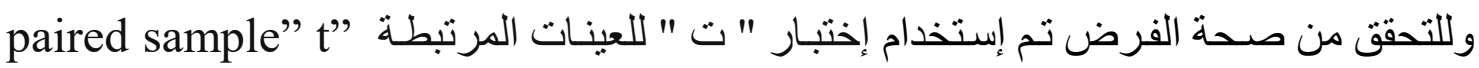

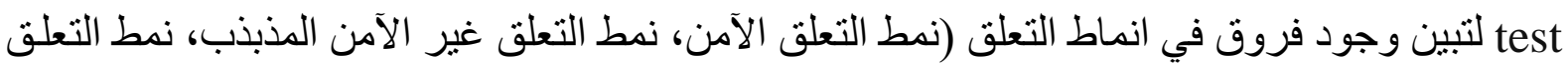

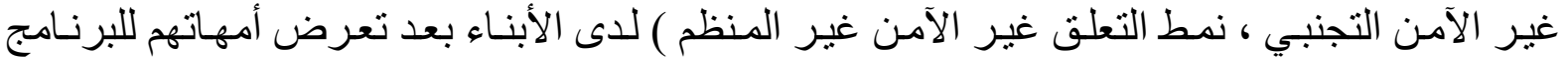

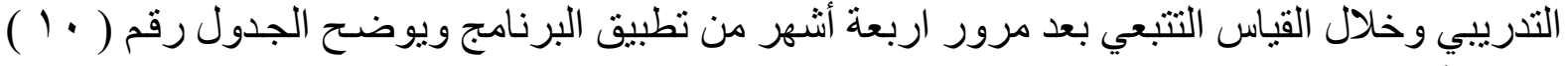

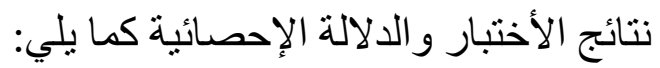

$$
\text { جدول (1) (1) }
$$

نتائج إختبار" ت " لعينة الأطفال في أنماط التعلق بين القياسيين البعدي و التتبعي (ن= Y I )

\begin{tabular}{|c|c|c|c|c|}
\hline الاحصائية & قيمة "ت" & المعياري للفرق الإنحراف & متوسط & أنماط التعلق \\
\hline$\overline{7.7 .}$ & $r, 1 \leqslant 0$ & $\overline{E, \varepsilon Y Y}$ & $\Gamma, \ldots$ & نمط التعلق الآمن \\
\hline $1 \cdot \varepsilon$ & $1, \Lambda \cdot V_{-}$ & $0, r \leqslant q$ & $r, \ldots$ & نمط التعلق غير الآمن المذبذب \\
\hline 94. & $\cdot, \cdot 9 \cdot-$ & $V, \cdot r q$ & r.., & نمط التعلق غير الآمن التجنبي \\
\hline , $\leqslant$. & VMY,- & $\vee, \vee Y q$ & $1, \wedge \ldots$ & نمــط التعلـق غيـر الآمـن غيـر \\
\hline
\end{tabular}

يتضح من الجدول رقم (• ( ) عدم وجود فروق ذبي دلالة إحصائياً عند مستوى دلالة (0 • , • ) بين

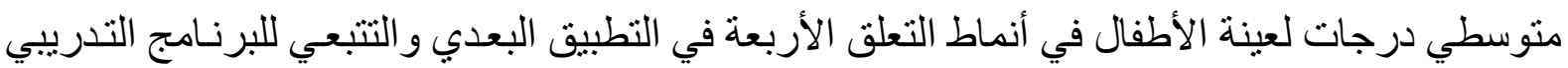

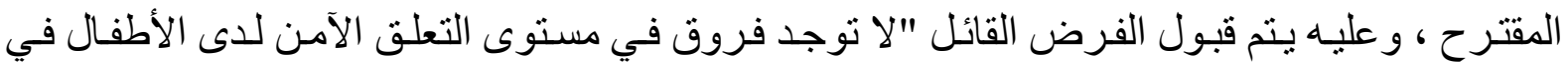
القياسين - البعدي و التتبعي". ويمكن عزو تللك النتيجة لأثر بقاء البرنامج في تعزيز التعلق الآمن في العلاقات بين الأمهات

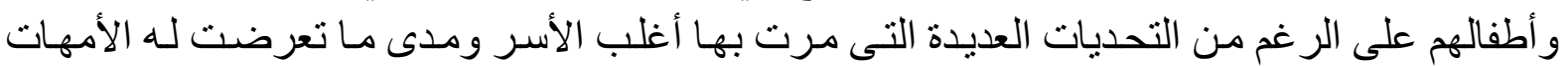

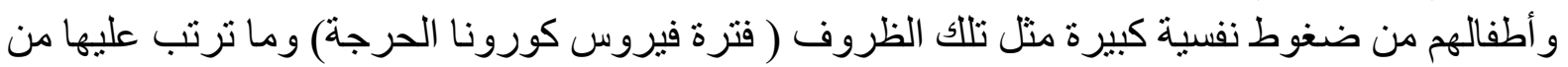

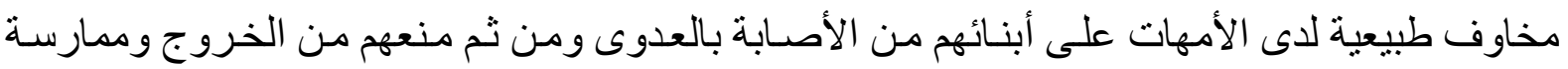

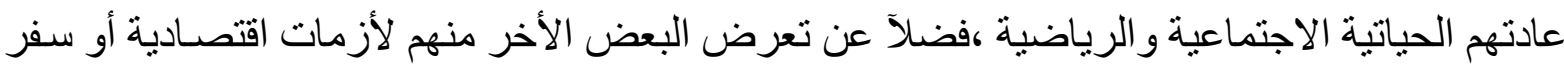

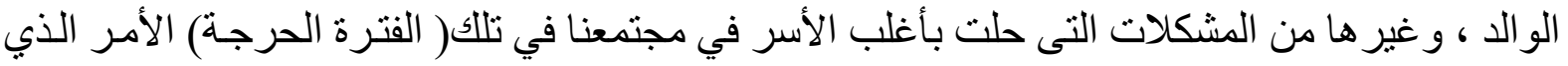
قد يكون له من الأثر بالضرورة على مدى استثر ار مستوى التعلق الآمن.

\section{وعليه يمكن تلخيص نتائج الاراسة في نقاط كما يلي:}

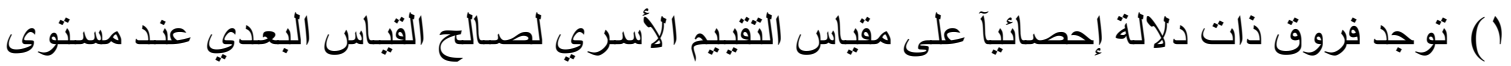

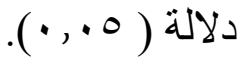

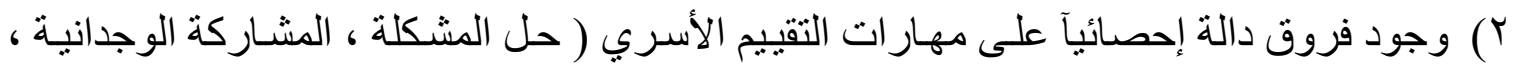

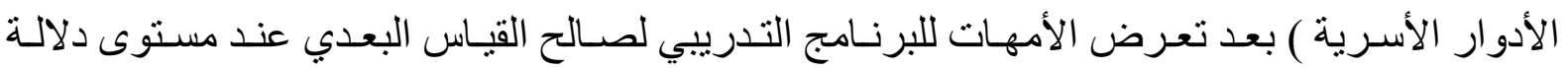


ץ) لا نوجد فروق دالة إحصائياً بين القياس القبلي و البعدي في مهار ات التيات التقيم الأسري (التواصل

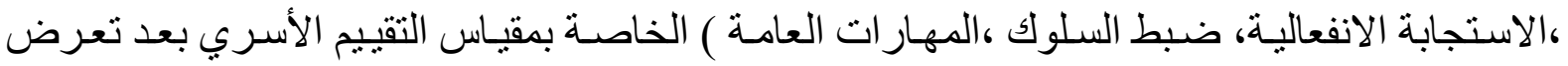
الأمهات للبرنامج التدريبي.

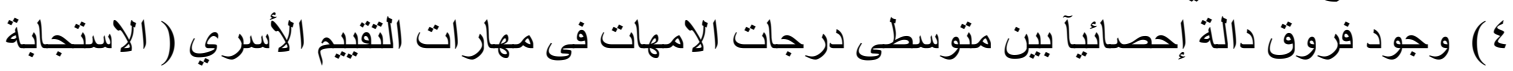

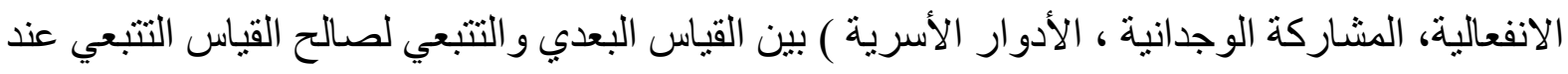

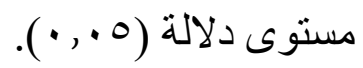

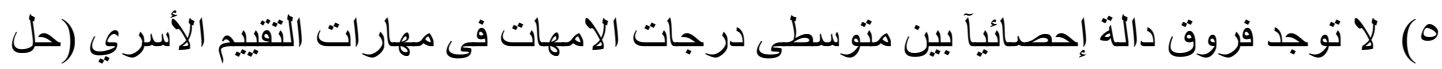

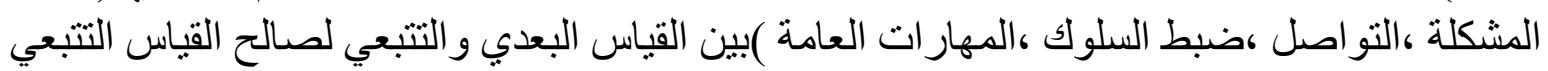

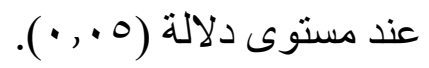

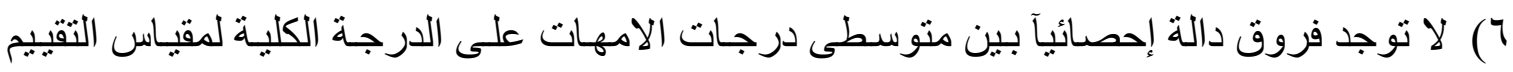

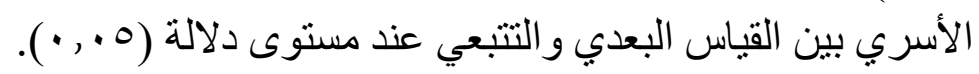

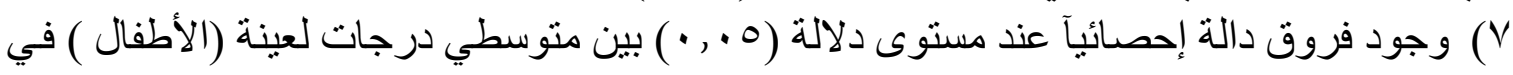

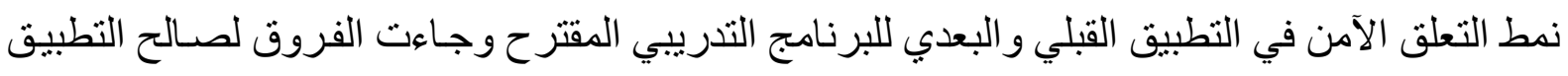

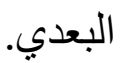

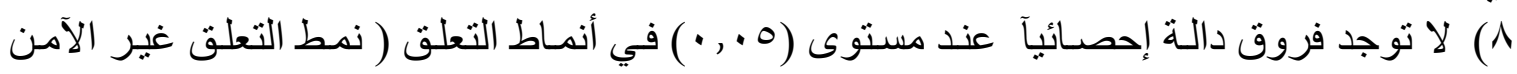

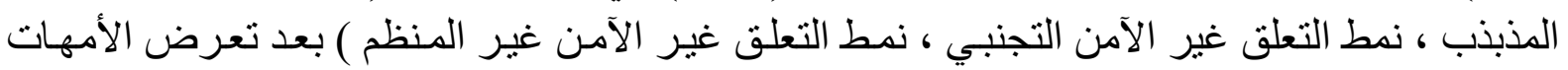
للبرنامج التدريبي.

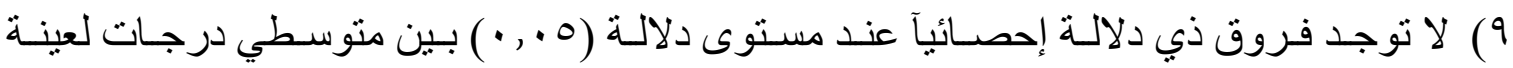

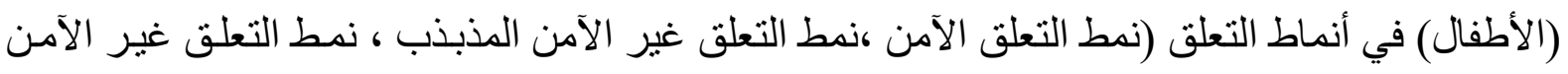

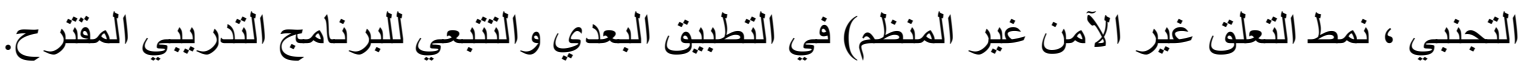

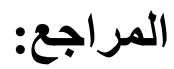

\section{المراجع العربية}

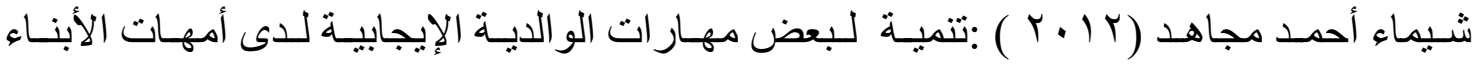

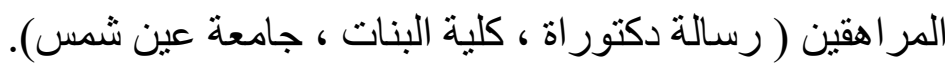

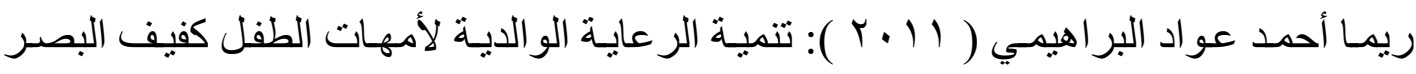

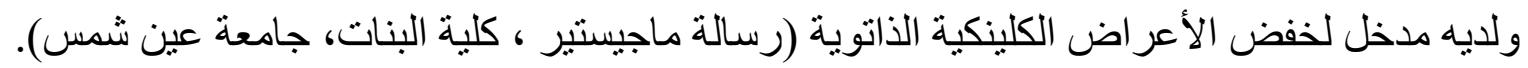

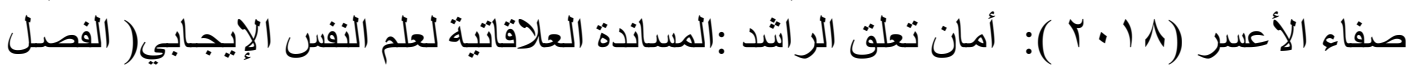

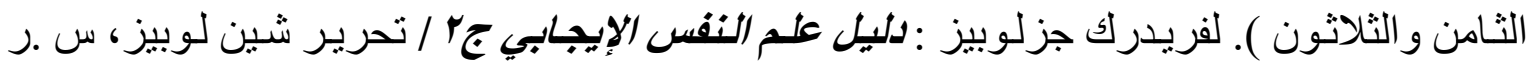

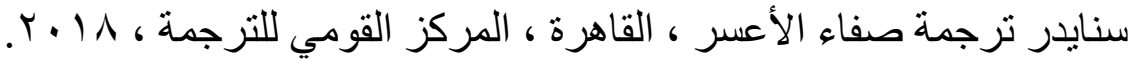

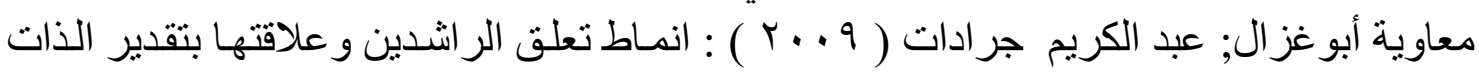

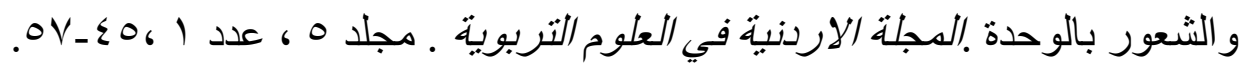

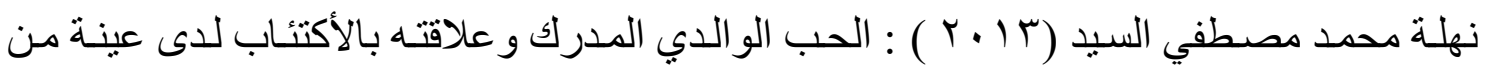

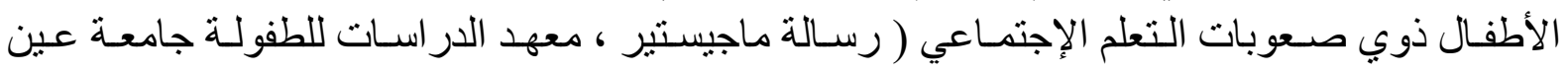

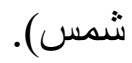




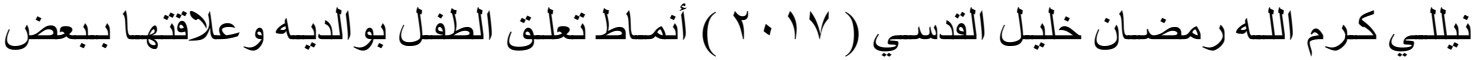

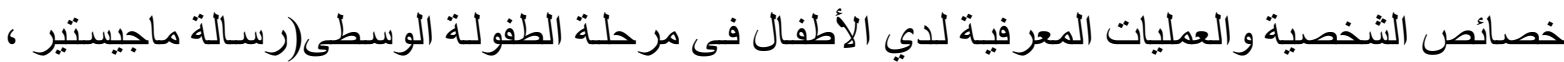
كلية البنات ،جامعة عين شمس).

\section{References:}

American Psychological Association (2020) Dictionary of psychology (Th Ed.), Washington, DC 20002-4242

Bretherton, Inge (1992).The origins of attachment theory John Bowlby and Mary Ainsworth. Developmental Psychology,28(5),759-775.

doi.org/10.1037/0012-1649.28.5.759

Bradley, Robert H; Crowyn, Robert F(2007) Externalizing Problems in Fifth rade: Relations With Productive Activity, Maternal Sensitivity, and Harsh Parenting From Infancy Through Middle Childhood .Developmental Psychology, VoL 43, Issue 6.pp1390-1401. https://doi.org/10.1037/0012-1649.43.6.1390

Blaustein, Margret E ., Kinniburgh ,Kristine M (2007) Intervening beyond the child the intertwining nature of attachment and truma. Section 3 " providing the family as secure base for therapy with children and adolescents. http://www.traumacenter.org

Cherry, k. A (2006)What is attachment theory? Retrieve from: http://Psychology.about.com

Colonnes .i,c;wissink,i.b;Noom,M.J\&J.J.Assecher (2013)Basic Trust An Attachment-Oriented Intervention Based on Mind-Mindedness in Adoptive Families. RESEARCH ON SOCIAL WORK PRACTICE,23(2):179188.DOI: $10.1177 / 1049731512469301$

Dubois-Comtois. Karine, Moss. Ellen (2008) beyond the dyad: do family interactions influence children's attachment representations in middlechildhood. Attachment \& Human Development, VoL10, Issue 4 Pages 415-431.

https://doi.org/10.1080/14616730802461441

Giannotta, Fabrizia; Ortega, Enrique \& Statin, Hakan (2013): An attachment parenting intervention to prevent adolescent's problem behaviors: Apilot study in Italy. Child and Youth Care Forum 42(1).DOI: 10.1007/s10566-012-9189-3.

Kim, Angel; Rubin, Kenneth; Burgess, Kim; Oh, Wonjung;Rose-Krasnor, Linda; Booth-Laforce, Cathryn (2006)Attachment,self-worth,and peer-group functioning inmiddle childhood . Attachment \& Human Development ;VoL8' Issue:4 pp309 - 325.DOI: 10.1080/14616730601048209. 
K. Lee Raby,Theodore E. A. Waters, Alexandra R. Tabachnick, Lindsay Zajac and Mary Dozier ( 2021) Increasing secure base script knowledge among parents with Attachment and Biobehavioral Catch-up, Development and Psychopathology, 33(2)p.g554-564.doi:10.1017/S0954579420001765

Moss, Ellen ., François,Jean Bureau., Julie Béliveau, Marie .,Zdebik ,Magdalena and Lépine .Suzanne. (2009) Links between children's attachment behavior at early school- age, their attachment -related representation, and behavior problem in middle childhood, International journalof behavioral development.voL33,.No (2),pp. 155-166.doi/abs/10.1177/0165025408098012.

Morris, Philip. E ( 2011) Enhancing Parent-child attachments in middle childhood: A clinical Application dissertation .(PH.D), AZUSA PACIFIC UNIVERSITY, Avalible from Proquest Dissertations \&Theses( PQDT)(UMI NO.3480014).

Morris. Amanda S , Criss. Michael M , Silk. Jennifer S \& Houltberg. Benjamin J (2017) The Impact of Parenting on Emotion Regulation During Childhood and Adolescence,CHILD DEVELOPMENT PERSPECTIVES, Volume 11, Number 4, Pages 233-238. DOI: 10.1111/cdep.12238.

Neil,Juliet Hall ( 2007 )Attachment: Supporting young children's emotional wellbeing. http://www.e-being.co.uk-

Rice, Kenneth G., Mirzadeh,Saied Ali (2000) perfectionism, attachment, and adjustment. Journal of Counseling Psychology, VoL 47,.No (2) pp. 238-250. . https://doi.org/10.1037/0022-0167.47.2.238.

Richaud de Minzi, M.C.(2006) Loneliness and Depression in Middle and Late Childhood: The Relationship to Attachment and Parental Styles, The Journal of Genetic PsychologyResearch and Theory on Human Development, Vol167,-

Issue2,pp189210.www.tandfonline.com/doi/citedby/10.3200/GNTP.167.2.189210

Wagner,Patricia Ellen.(1992)Development of ameasure of Attachment for children ages 8 to 12 . Ph.D.George Mason University; ProQuest Dissertations \& Theses

Williams, Kylie; Kennedy, J.H ( 2012) Bullying behaviors and attachment styles , North American Journal of Psychology 14(2):321-338.

https://www.researchgate.net/publication/279589538 


\title{
The Effectiveness of a Training Program, which Develops Positive Parental Behaviors and its Impact on Enhancing Secure Attachment Pattern among Children in Middle Childhood Stage
}

\author{
Nelly Karam Allah Ramadan Khalil El Kodsi \\ (PHD)Degree -Department of Psychology
}

Faculty of Women for Arts, Science \& Education

Ain Shams University - Egypt

Nellykaram50@yahoo.com

Asmaa Abdel Moneim Ibrahim

Professor of psychology

Faculty of Women for Arts, Science \& Education

Ain Shams University - Egypt
Shahinaz Ismail Abdul Hady

Lecturer in psychology

Faculty of Women for Arts, Science \& Education

Ain Shams University - Egypt

\section{Abstract}

The present study aims to examine the impact of a training program, which develops positive parental behaviors among mothers on enhancing secure attachment pattern for children in middle childhood stage The experimental sample consists of mothers $(\mathrm{n}=12)$ aged between 29 and 45 years with an average age $(\mathrm{m}=35.00)$ and a standard deviation $(\mathrm{st}=4.285)$ and the number of the children of mothers participating in the program $(n=12)$ to discover the extent of change at the level of secure attachment as a dependent variable ; the number of males $(n=8)$ and the number of females $(n=4)$ whose ages range between 6 and 12 years, with an average age $(\mathrm{m}=9.25)$ and a standard deviation $(\mathrm{st}=2.301)$. The study includes number of tools patterns of attachment scale prepared by Nelly Karam Allah (2017); as for the tools applied on the sample of mothers, they include the family assessment scale, translated and prepared by Shimaa Ahmed Megahd (2012), and the attachment program for developing positive parental behaviors, prepared by researcher (2021). The results of the study have revealed the presence of statistically significant differences in the skills of the family assessment scale (problem solving, sympathy, family roles, the total score on the family assessment scale) between the average scores of mothers in the pre-measurement and the postmeasurement after the mothers' exposure to the training program, in favor of the post-measurement at the level (0.05). There are also differences in the mothers' average scores between the post-measurement and the follow-up measurement in relation to the family assessment skills) emotional 
response ,sympathy, family roles, (in favor of the follow-up measurement.The results have also revealed the presence of statistically significant differences in the secure attachment pattern among children in the middle childhood stage after their mothers 'exposure to the training program, in favor of the postmeasurement at the level (0.05), but there are no significant differences in the secure attachment pattern among the children between the post-measurement and the follow-up measurement at the signal level (0.05).

Keywords: positive parental behaviors, secure attachment pattern, the training program. 